\title{
ACUTE AND CHRONIC REJECTION: COMPARTMENTALIZATION AND KINETICS OF COUNTERBALANCING SIGNALS IN CARDIAC TRANSPLANTS
}

ANUPURNA MAHARAJ KRISHEN KAUL

\author{
Bachelor of Pharmacy \\ Pune University
}

May 2000

\author{
Submitted in partial fulfillment of requirements for the degree \\ DOCTOR OF PHILOSOPHY IN REGULATORY BIOLOGY \\ Specilization in CELLULAR AND MOLECULAR MEDICINE \\ at the \\ CLEVELAND STATE UNIVERSITY
}

November, 2014 
(C) Copyright by Anupurna Kaul 2014 
We hereby approve this dissertation of

Anupurna Maharaj Krishen Kaul

Candidate for the Doctor of Philosophy in Regulatory Biology Degree.

This dissertation has been approved

for the Department of

Biological, Geological, and Environmental Sciences and

CLEVELAND STATE UNIVERSITY

College of Graduate Studies by

Dr. William M. Baldwin III, Dissertation Chairperson

Department of Immunology, Cleveland Clinic

Department \& Date

Dr. Christine Moravec, Dissertation Committee Member

_- Department of Cardiovascular Medicine, Cleveland Clinic

Department \& Date 
Dr. Booki Min, Dissertation Committee Member

_Department of Immunology, Cleveland Clinic

Department \& Date

Dr. Barsanjit Mazumder, Dissertation Committee Member

BGES Deptt, Cleveland State University

Department \& Date

Dr. Girish Shukla, Internal Examiner

_BGES Deptt., Cleveland State University

Department \& Date

Dr. Carol de la Motte, External Examiner

_Department of Pathobiology, Cleveland Clinic

Department \& Date

Student's Date of Defense: November 20 ${ }^{\text {th }}, 2014$ 


\section{DEDICATION}

To my mother, Nancy Kaul, for her unconditional love and friendship. Her work ethic has been my guide and continues to inspire me 


\section{ACKNOWLEDGMENTS}

First and foremost, I would like to thank my advisor, my Guru, Dr. William M. Baldwin, for his patience and mentorship. Thank you Dr. Baldwin, for your continuous support and guidance. You always believed in my research abilities and communicated about areas I should improve on. This research would not be possible without your constant support and encouragement. You are not only a great mentor but also a great person. I also want to thank Jane for her usual visits with goodies and potted flower bulbs for all of us that helped in bonding us as a family in the lab.

I would like to thank all my thesis committee members, Dr. Christine Moravec, Dr. Barsanjit Mazumder and Dr. Booki Min for their valuable comments and suggestions during my committee meetings. I specially want to thank Dr. Moravec for her support during my tough times when I was looking for a permanent lab to pursue research.

I would like to thank my thesis examination committee members, Dr. Girish Shukla and Dr. Carol de la Motte for accepting to be on my dissertation committee. Thank you Dr. Shukla for the opportunity to teach your Cell Biology class. Thank you Dr. De la Motte for collaborating on the hyaluronan project and your valuable suggestions. I would also like to thank Dr. Jeffrey Dean, for his guidance when I joined the program.

I would like to thank our collaborators, Dr. Robert Fairchild and Dr. Anna Valujskikh for their suggestions on my project during joint lab meetings. It was a great learning experience working with them. Critical reviews and discussions during joint lab 
meetings were useful to keep this research going on its course and helped in improving this work. My thanks to all the lab members in Dr. Fairchild and Dr. Valujskikh's research group for their prompt help whenever I needed.

I would like to thank all my lab mates and colleagues, Nina Dvorina, Dr. Hsiao Hsuan Kuo and Sridevi Goparaju for your friendship, support and moments of great joy and laughter. Thank you Nina for your funny jokes and always willing to give rides back home from lab.

My special thanks to my family: My parents Nancy Kaul and Maharaj Krishen Kaul for having confidence in me even when I failed at times, for their unconditional love, constant support and encouragement. I will be forever grateful to you for inspiring me to pursue my dreams. I would like to thank my in-laws, Sudesha Kaul and Bansilal Kaul for their parental love, support and words of encouragement. Thank you so much, mummy papa, for going out of the way to keep me focused and supporting me in achieving this goal. I would like to thank my grandparents Somnath Kaul, Somrani Kaul, Jagarnath Razdan and Arandati Razdan for their love and blessings. I would also like to thank my sister Meenakshi Raina for giving me motherly love and affection. I thank you sister for always supporting me and taking care of me which helped me to move forward. I would also like to thank my sisters, Bharti Bhat and Anshu Koul for their love and support. I would also like to thank my brother-in-law Ajay Raina for all his help and support. Thank you jijaji for always believing in me. I would also like to thank my brothers-in-law Chander Shekher Bhat and Ajay Koul for their support.

Finally, I would like to thank the person who has been my inspiration, my strength, my love, my husband, Dr. Pankaj Kaul. You believed in me and that gave me 
confidence to achieve what I wanted to achieve. Thank you for sharing all my tough times and supporting me. Thank you for listening to all my problems and helping me find solution to those problems. I wanted to let you know that all of this has become possible because of you.

Above all, I am grateful to God that we were blessed with twins, Vivaan and Eliana, bringing lots of joy and happiness in our life. Majority of my success in experiments happened during the months I was carrying you guys. Your smiling faces have given me great relief while writing this manuscript. I love you both and thank you for your contribution to complete this work. 


\title{
ACUTE AND CHRONIC REJECTION: COMPARTMENTALIZATION AND \\ KINETICS OF COUNTERBALANCING SIGNALS IN CARDIAC TRANSPLANTS
}

ANUPURNA MAHARAJ KRISHEN KAUL

\begin{abstract}
Heart disease is the major cause of mortality in the United States and other parts of the world. Heart transplantation is the treatment of choice for patients with end stage heart failure. However, transplanted organs fail due to either acute or chronic rejection. This acute and chronic rejection impacts distinct compartments of cardiac allografts. Acute rejection is characterized by infiltration of mononuclear cells whereas chronic rejection is characterized by progressive narrowing of coronary arteries. In a minor histoincompatibility mismatch mouse model we found hearts transplanted from male to female C57BL/6 mice undergo an acute rejection with diffuse interstitial infiltrates at 2 weeks that resolve by 6 weeks when about half of the large arteries develop CAV. These processes are dependent on $\mathrm{T}$ cells because no infiltrate developed in $\mathrm{T}$ cell deficient mice. Markers of M1 macrophages were upregulated in the interstitium acutely and then decreased as markers of M2 macrophages increased chronically. Interstitial and arterial infiltrates were microdissected and expression of an array of 86 genes was screened by real time PCR. Programmed cell death protein 1 (PD1), a negative costimulator, and its ligand PDL1 were highly upregulated in the interstitium during the resolution of acute rejection. Flow cytometry analysis of graft infiltrating cells confirmed an enrichment of macrophages expressing PDL1. Treatment with a blocking antibody to PDL1 in the acute phase increased interstitial $\mathrm{T}$ cell infiltrates. In the arterial compartment, Toll Like
\end{abstract}


Receptor 4 (TLR4) was upregulated at 6 weeks. Hyaluronan, an endogenous ligand of TLR4, was increased in arteries with neointimal expansion. Injection of hyaluronan fragments increased intragraft production of chemokines. Our data indicate that negative co-stimulatory pathways are critical for the resolution of acute interstitial infiltrates. In the arterial compartment recognition of endogenous ligands including hyaluronan by innate TLR4 may support the progression of cardiac allograft vasculopathy (CAV). Importantly, our model localizes many of the molecular markers that have been associated with acute and chronic rejection in clinical studies of cardiac transplants. 


\section{TABLE OF CONTENTS}

\section{Page}

ABSTRACT ix $-x$

LIST OF FIGURES xiv - xxiii

LIST OF TABLES xxiv

\section{CHAPTERS}

I. INTRODUCTION ..................................................

1.1 Introduction to transplant...............................................1

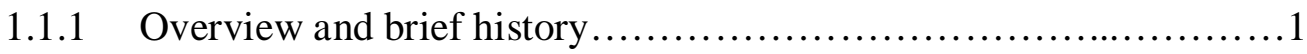

1.2 Heart Transplant.......................................................

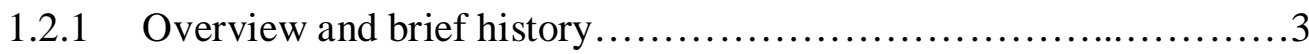

1.2.2 Statistics/ Survival of heart transplant patients...................4

1.3 Overview of cardiac allograft rejection............................... 5

1.3.1 Types of allograft rejection.................................... 5

1.3.2 Incidence and pathology of acute cardiac allograft rejection.........6

1.3.3 Incidence and pathology of chronic cardiac allograft rejection.......11

1.3.4 Small animal models of cardiac allografts........................14

1.4 Mechanisms controlling cardiac allograft rejection.......................16

1.4.1 Role of co-stimulatory molecules............................16

1.4.2 Role of PD-1 and its ligand PD-L1 in transplantation.....................19

1.4.3 Cytokine and chemokine expression in cardiac allograft rejection...20

1.4.4 Role of chemokines in acute and chronic cardiac allograft

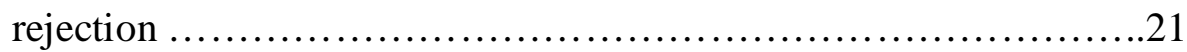


1.4.5 Role of IL1R1 and IL1R2 and their association with cardiac allograft rejection. .23

1.4.6 Pattern recognition molecules and their endogenous ligands (Toll like

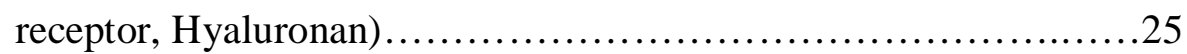

1.4.7 Hyaluronan..................................................26

1.4.8 Hyaluronan Role in transplantation..............................28

1.5 Compartmentalization of Acute and Chronic Rejection....................30

\section{ACUTE AND CHRONIC REJECTION: COMPARTMENTALIZATION AND KINETICS OF COUNTER BALANCING SIGNALS IN CARDIAC} TRANSPLANTS .31

2.1 Abstract........................................................... 31

2.2 Introduction...................................................

2.3 Materials and Methods............................................ 35

2.3.1 Mice........................................................35

2.3.2 Heterotopic heart transplantation.............................36

2.3.3 CD4 T cell isolation, sorting and transfer.......................36

2.3.4 Treatment with blocking antibody or hyaluronan fragments..........37

2.3.5 Histology and immunohistochemistry ..........................38

2.3.6 Laser capture microdissection and real time RT PCR..............39

2.3.7 Isolation of graft infiltrating cells for flow cytometry..............42

2.3.8 Quantitation of chemokines, hyaluronan and IL-1 receptors in allografts. 
2.3.9 Analysis of gene expression by quantitative RT-PCR............43

2.3.10 Statistical Analysis............................................43

2.4 Results.....................................................44

2.4.1 Hearts transplanted from male to female B6 undergo acute rejection that transitions into chronic rejection..................................44

2.4.2 CD4 T-cells orchestrate acute and chronic rejection.............47

2.4.3 Mediators expressed more highly in the interstitial than in the arterial compartments during acute and chronic rejection......................51

2.4.4 Expression of IL-1R2 and PDL1 by cells in the circulation and infiltrating graft...............................................56

2.4.5 Blocking PDL1 early prevents resolution of acute interstitial

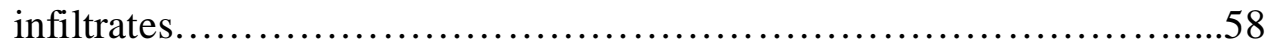

2.4.6 Effect of blocking PDL1 early on mediators in the interstitial and arterial compartments............................................63

2.4.7 TLR4 and hyaluronan are upregulated in the arterial compartment during chronic rejection.......................................65

2.4.8 Low mol. weight hyaluronan increases MIG and MCP-1 production in cardiac allografts............................................69

2.5 Discussion..................................................... 71

III CONCLUSION AND FUTURE WORK.............................76

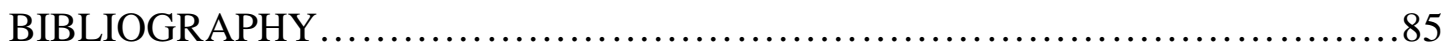

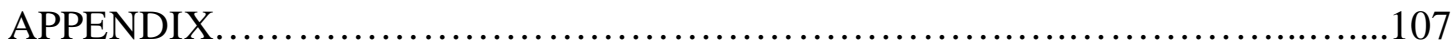




\section{LIST OF FIGURES}

Figure 1 (A-F). $\quad$ Grades of cellular Rejection: Hematoxylin-eosin stain on frozen section of (A) showing Grade 0R with intact myocardim with no infiltrates, (B) showing Grade 0R with no infiltrates in interstitium or perivascular space, (C-F) showing Grade 1R with mild interstitial infiltrates in between myocytes (Tan et al

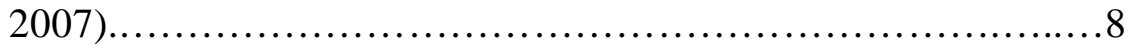

Figure 1 (G-L). Grades of cellular Rejection: Hematoxylin-eosin stain on frozen section of $(\mathrm{G}-\mathrm{H})$ showing Grade 1R with focal diffused interstitial infiltrates of mononuclear cells, (I-J) showing Grade 1R with focal myocyte damage, (K-L) showing grade $2 \mathrm{R}$ with mltifocal myocyte damage and intense interstitial infiltrates (Tan et al 2007).........9

Figure 1 (M-R). Grades of cellular Rejection: Hematoxylin-eosin stain on frozen section of (M-N) showing Grade 2R with moderate rejection and widening of the interstitium, (O-Q) showing Grade 3R with diffuse inflammation. Myocardial pieces are diffusely infiltrated by dense mononuclear inflammatory infiltrates, (R) showing Grade 3R with edema and hemorrhage with mixed inflammatory infiltrates including neutrophil (Tan et al 2007).................10 
Figure 2. Schematic representation of a coronary artery, site of CAV (A) H\& E staining of human heart tissue showing pathology of cardiac allograft

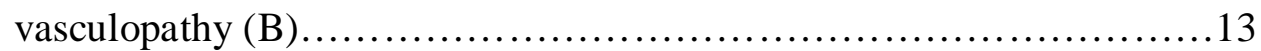

Figure 3. Schematic representation of vascular remodeling in graft vascular disease depicts mechanisms by which vascular remodeling can impact the vessel lumen. Intimal hyperplasia occurs through the recruitment of inflammatory cells and smooth muscle like cells and extension of extracellular matrix reduces luminal diameter. Adventitial fibrosis restricts positive remodeling of medial smooth muscle cells. Increased medial tone can also participate in intimal responses by increasing wall shear stresses (Mitchell et al 2009). .13

Figure 4. Schematic describing the heterotopic cardiac transplantation procedure. Cardiac allografts are primarily vascularized and beat but are not hemodynamically loaded; the host does not rely on the transplant to survive. The donor aorta is anastomosed to the host abdominal aorta, and the donor pulmonary vein is sewn to the host inferior vena cava. The aortic valve is initially competent and the coronary arteries and myocardium are perfused at aortic pressures; blood returns to the right atrium and into the host inferior vena cava (Mitchell et al 2009). .16 
Figure 5. Schematic representation of Co-stimulatory molecules in $\mathrm{T}$ cell activation. Activation of $\mathrm{T}$ cell requires two signals, first engagement of $\mathrm{T}$ cell receptor with MHC peptide complex and ligation of co-stimulatory molecules on $\mathrm{T}$ cells with their respective ligands on antigen presenting cells. T cells receiving both signal 1 and positive costimulation will proliferate and will produce cytokine. However, co-stimulatory molecules such as CTLA4 and PD1, can lead to negative T cell signaling resulting in reduced cell proliferation and cytokine production (Gao et al

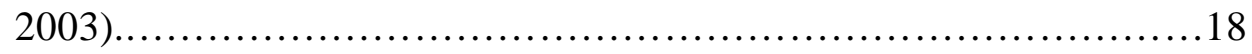

Figure 6. This plot depicts the expression of chemokines at various stages in immune responses to allografts. The early stages are dominated by neutrophils and monocytes, followed by NK cells, T lymphocytes, and macrophages, and eventually by smooth muscle-like cells and a number of chemokines are expressed such as MIG/CXCL9, CCL5 to form GAD lesion in later stage of transplant rejection (Shimizu et al 2003) .22

Figure 7. Schematic representation of TLRs and hyaluronan fragments in allograft rejection (Tesar et al 2006). 30 
Figure 8. Immunoperoxidase stains of acute and chronic infiltrates in cardiac allografts. At 2 weeks (top row), allografts contained a diffuse interstitial infiltration of CD3 $\mathrm{T}$ cells (A) and Galectin $-3^{+}$macrophages (B) with limited periadventitial involvement of larger arteries (right side of figures). The macrophages displayed cytoplasmic projections on high power (inset). At 6 weeks, the interstitial infiltrates diminished, and large arteries developed adventitial and intimal infiltrates composed of CD3 T cells (C) and larger numbers of macrophages (D). Original magnifications 200x

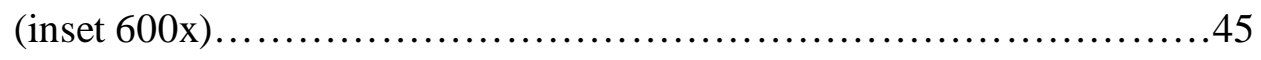

Figure 9. Immunoperoxidase stains of mononuclear infiltrates in cardiac isograft at 2 and 6 weeks in wild type recipients. At 2 weeks (top row), male cardiac isografts to wild type male recipients contained few CD3 T cells (A) and Galectin-3 positive macrophages (B) with no pathology. At 6 weeks (second row), the male cardiac isografts to wild type male recipients contained few CD3 T cells (C) and Galectin-3 positive macrophages (D) with no pathology. Original magnifications $200 x \ldots \ldots \ldots \ldots \ldots \ldots \ldots . \ldots 46$

Figure 10. Only limited numbers of macrophages in either the 2 week (A) or 6 week (B) infiltrates were positive for Ym-1 (Chitinase 3-like 3) a marker for M2 macrophages. These M2 macrophages were scattered as individual large ovoid cells (inset). Limited numbers of Foxp3 positive regulatory T cells 
were present both in interstitial and arterial compartments at 2 weeks (C)

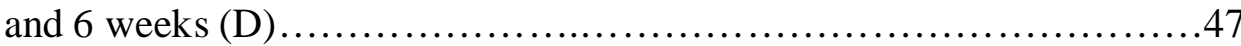

Figure 11. Immunoperoxidase stains of mononuclear infiltrates of CD3 (A) and Macrophages (B) in cardiac allograft at 2 weeks in Rag1-/- recipients with male wild type heart. Female wild type heart transplanted to female RAG ${ }^{-}$ /- recipients reconstituted with Marilyn CD4 T cells, contained few CD3 T cells (C) and Galectin-3 positive macrophages (D) at 2 weeks. At 6 weeks, no arteries developed vaculopathy and only few CD3 T cells (E) and few Galectin-3 positive macrophages (F). Original magnifications

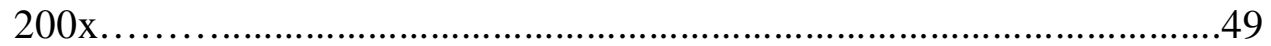

Figure 12. Male hearts transplanted to female $\mathrm{RAG}^{-/-}$recipients reconstituted with Marilyn CD4 T cells. At 2 weeks, allografts contained diffuse interstitial infiltrates of CD3 $\mathrm{T}$ cells (A) and Galectin- $3^{+}$macrophages (B) with limited periadventitial involvement of larger arteries. At 6 weeks, the interstitial infiltrates diminished, and large arteries developed adventitial and intimal infiltrates of CD3 $\mathrm{T}$ cells (C) and large numbers of macrophages (D). At 10 weeks, the arterial lesions contained decreased numbers of CD3 $\mathrm{T}$ cells (E), and increased macrophages (F). Original magnifications 200x (A-D) and 40x (E, F).......................50 
Figure 13. Male hearts transplanted to female $\mathrm{RAG}^{-/-}$recipients reconstituted with Marilyn CD4 T cells and sacrificed at 10 weeks. Large artery with limited numbers of T cells (A), large numbers of macrophages in the neointima as well as adventitia (B), and alpha-smooth muscle expressing cells in the neointima (C). Original magnifications 200x.....................51

Figure 14. Procurement of individual vascular compartments laser capture microdissection method allowed for the separate dissection of the mouse interstitium and coronary arteries.................................53

Figure 15. Quatitative PCR on 3 microdissected allografts at 2 and 6 weeks expressed as fold change relative to isografts from the same time points. Confirmation of key cytokines, receptors and ligands from the initial PCR array (A). Markers for M1 inflammatory macrophages are consistently higher in the interstium (left panel) at 2 weeks (filled bars) than at 6 weeks (open bars), whereas in the arterial compartment (right panel) these markers are low at 2 weeks and increase by 6 weeks (B). In contrast, the converse occurs for markers of M2 wond healing macrophages with the exception of IL-10 (C). Error bars represent standard errors of the mean of 3 allografts. Differences between 2 and 6 week values were significant at the $\mathrm{P}<0.05^{*} ;<0.01^{* *}$; or $<0.001^{* * *}$ level as indicated..............55 
Figure 16A. Confirmation of expression of chemokines by ELISA and flow cytometry. MIG, RANTES and MCP-1 were elevated at 2 weeks and then diminished by 6 weeks in the homogenates of myocardium from cardiac allografts

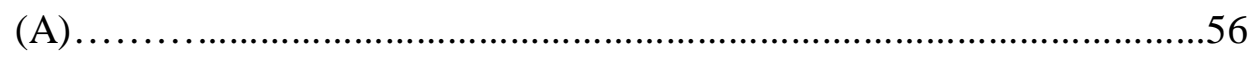

Figure 16 (B-G). Confirmation of expression of the decoy receptor for IL-1 and negative co-stimulatory ligand PDL1 by ELISA and flow cytometry. IL-1R2 was also elevated in the allograft compared to isograft homogenates at 2 weeks and to a lesser degree at 6 weeks by ELISA (B). Flow cytometry demonstrated that PDL1 was expressed by majority the F4/80 macrophages that were infiltrating the allografts at 2 weeks (C). This represented a major enrichment compared to the limited percentage of circulating monocytes that expressed PDL1 (D). Local expansion may contribute to the enrichment of PDL1 expressing macrophages in the graft because many of the macrophages labeled with the proliferation marker Ki67 at 2 weeks (E) and 6 weeks (F). Each symbol in the scattergams represents data from an individual animal. Levels of CD274 (PDL1) mRNA in interstitial compared to arterial tissue in allografts at 2 weeks

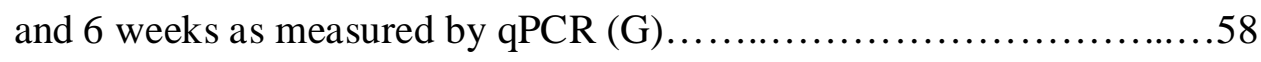

Figure 17. Immunohistology and cell counts from mice treated with blocking antibodies to PDL1. Administering blocking antibody to PDL1 on days 8, 10 and 12 increased interstitial infiltrates of $\mathrm{CD}^{+} \mathrm{T}$ cells (B) and PD1 ${ }^{+}$ 
(D) cells compared to controls (A and C, respectively) at 2 weeks. Blocking PDL1 did not increase arterial pathology at 2 weeks (right side of panels A-D). Cell counts per 5 high power fields verified about a 2fold increase in CD3 and PD1 expressing cells at 2 weeks (E) and 6 weeks (F), but there was an overall decrease in cells from 2 to 6 weeks. Each symbol in the scattergrams represents an individual animal. All differences between control and anti-PDL-1 treated mice were significant

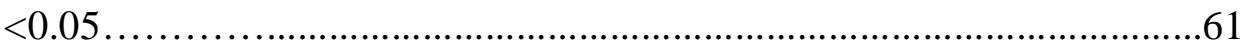

Figure 18. Immunohistology of acute interstitial infiltrates in allograft following treatment with blocking antibodies to PDL1. Double stain for CD3 (brown) and PD1 (blue) demonstrates the majority of cells express both CD3 and PD1 (original magnification 600x) .......................62

Figure 19. Treatment with blocking antibodies to PDL1 resulted in increased expression of MIG, RANTES and MCP-1 in allografts by ELISA that was greater at 2 weeks than 6 weeks (A). These samples were taken from the apex of the hearts which contains few large arteries. Microdissection of allografts at 2 weeks demonstrated levels of MIG, RANTES, MCP-1, IL-1R1, IL-1beta, IL-6 TNFa and Nos2 were greater in the interstitium than the arterial compartment (B, C). M2 macrophage markers were changed to a lesser extent (D). Bars represent average of 3-4 samples in each group. PCR results represent fold changes compared to allografts 
treated with control antibody. Differences between interstitial and arterial values were significant at the $\mathrm{P}<0.05^{*}$; $<0.01^{* *}$; or $<0.001^{* * *}$ level as indicated.....................................................64

Figure 20. TLR4 quantification by qPCR analysis on interstital and arterial tissue from allografts relative to isografts at 2 and 6 weeks.................66

Figure 21. Upregulation of hyaluronan in the arterial compartment at 6 weeks. ELISA measurements of hyaluronan in allografts and isografts (A). Differences at 6 weeks were significant $\mathrm{P}<0.01$. Hyaluronan surrounded infiltrating mononuclear cells in the neointimal lesions and adventitia of arteries as well as the interstitium of the graft (B). In isografts, hyaluronan formed a compact band in the adventitia of large and smaller arteries with limited amounts in the interstitum (C). Original magnifications

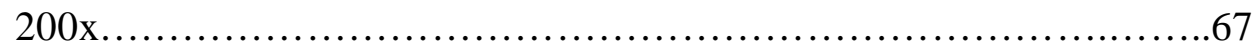

Figure 22. Immunofloresence showing HA expression in allograft artery (A) and non specific control (B) .68

Figure 23. CD44, which is the dominant receptor for hyaluronan, was expressed by the cells infiltrating the neointima and adventitia of the wild type artery (A) and SCID artery with passive transfer of transgenic CD4 T cells (B) at 6 weeks .69 
Figure 24. Both 4.7 or $35 \mathrm{kD}$ fragments of hyaluronan stimulated MIG and MCP-1 measure by ELISA on homgenates from the apex of cardiac allografts at 2 weeks (A). PCR on macrophages isolated from 3 heart allografts at 2 weeks demonstrated increased expression of MIG and MCP-1 as well as even greater increases in IL-6, IL-15, IL-18 TNF $\square$ and Nos2 (B,C). Markers for M2 macrophages were changed to a lesser extent (C). Each symbol in the ELISA scattergram represents results from an individual allograft. PCR results are expressed as fold increase in macrophages from mice treated with hyaluronan fragments compared to PBS $(n=3) \ldots \ldots \ldots . .70$

Figure 25. Schematic showing macrophages initiate and direct virtually all immune responses (Mills et $a l, 2014$ ). .79

Figure 26. Schematic representation of acute balance of immunity between compartments .82

Figure 27. Schematic representation of chronic balance of immunity between compartments. 


\section{LIST OF TABLES}

Table 1. Complete list of gene on microarray ...........................40

Table 2. PCR primer sequences.......................................41

Table 3. Genes upregulated in microdissected allografts expressed as fold change compared to isograft................................................54

Table 4. Cardiac allograft survival after treatment with blocking antibodies to

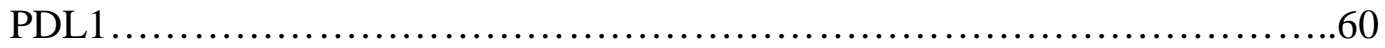




\section{CHAPTER I}

\section{INTRODUCTION}

\subsection{Introduction to transplant}

\subsubsection{Overview and brief history.}

The history of transplantation is long and complex. The idea of replacing diseased or damaged body parts has been around for millennia. Transplants of normal tissues and organs have been studied since the early 1900's. George Shone in 1912 demonstrated that skin grafted between genetically disparate animals (termed "homografts" in that era) were rejected. Moreover, he also demonstrated that subsequent grafts from the same donor were rejected more rapidly than the first. This so-called "second-set" reaction was the first evidence of the immune basis of rejection of normal tissues. In 1914, James B. Murphy demonstrated that resistance to tumor homografts was dependent on the lymphoid system. Also by the end of 1920s, scientists at the Rockefeller Institute established other principles of transplantation immunology including the central role of

the lymphocyte ${ }^{1}$. However, widespread appreciation of the immune basis of 
transplantation was established by the careful observations of Peter Medawar that were instigated by the need to perform skin grafts on injured pilots in World War $\mathrm{II}^{2}$. After the war Peter Medawar conducted extensive studies of skin homografts in rabbits, more firmly characterizing the timing, histological morphology, and immunological nature of rejection. It was Peter Medawar's experiments that demonstrated induction of chimerism can prevent graft rejection. In 1957, Morton Simonsen discovered GVHD (graft versus host disease) in chickens that he had injected as embryos with allogeneic lymphoid cells. He also demonstrated that to cause GVHD, lymphocytes must be mobile which suggested cellular immunity is important ${ }^{3}$. Better evidence of cellular immunity was provided by Avrion Mitchison. Mitchison introduced the method of passive transfer of cells and serum to study transplantation immunity using tumors ${ }^{4}$. In 1959, James Gowans gave proof of lymphocyte mobility by showing lymphocytes recirculate from blood to lymph and back again. Billingham, Brent and Medawar ${ }^{5,6}$ applied passive transfer methods to study skin grafts in mice. These passive transfer studies demonstrated that cells from the lymph nodes of a transplant recipient could transfer a second-set response to a previously “naïve” animal.

During this same period there were sporadic reports of organ transplants. With the exception of a few autografts of kidneys in dogs, all of these transplants resulted in failure. The first successful kidney transplant in humans was performed between genetically identical twin brothers by Murray and colleagues in $1954^{7,8}$. Kidney transplants between genetically disparate individuals had poor survival until effective immunosuppressive drugs were discovered. Joan Main and Richmond Prehn showed that weakening the immune system of adult mice by radiation allows them to induce 
chimerism by inoculating bone marrow cells. Skin grafts were then accepted if they came from the bone marrow donor strain ${ }^{9}$. It was not until 1963 when Starzl reported the combination of prednisone with azathioprine that clinically acceptable success was attained ${ }^{10}$.

With the subsequent introduction of better immunosuppressive drugs, particularly cyclosporine in 1980, transplants of liver, hearts and other organs began to have successful outcomes ${ }^{11}$.

In the developed countries the transplantation of human tissue and organ has become common. The commonly transplanted vascularized solid organs are: kidney, liver, heart and lung. The less frequently transplanted solid organs are pancreas and intestine. More recently composite tissue transplants have been performed. These include arms or hands as well as the highly publicized face transplants. Among nonvascularized solid organ transplant are heart valve and cornea. Pancreatic islets are injected but not surgically grafted. Bone marrow and pluripotent stem cell transplants are also transplanted as cell infusions, but because of their immune competence, have the additional risk of causing graft versus host disease. The success of a transplant differs with the tissue or organ transplanted ${ }^{12}$.

\subsection{Heart Transplant:}

\subsubsection{Overvie w and brief history:}

Heart transplant is the current therapy for end stage heart failure. The technique for heart transplantation was developed at Stanford University by Norman Shumway. The 
first human heart transplant was performed by Christiaan Barnard in South Africa in December 1967. This was followed by a rush of transplants around the world. However, the limitation of this procedure was survival rates which were measured in days or weeks. This low survival rate was because of rejection and opportunistic infections. The surgical technique has changed little. In 1970s the use of endomyocardial biopsy helped clinicians to confirm diagnosis of acute allograft rejection. In 1980, cyclosporine was introduced,

which resulted in improved survivals ${ }^{13-14}$. Advances in immnosuppressive drugs have resulted in continued improvements in graft survival.

\subsubsection{Statistics/ Survival of heart transplant patients.}

There are currently over 2900 people with end stage heart disease waiting for a heart transplant in the United States. The median graft survival is approximately 10 years. According to the 2013 Registry for the international society for heart and lung transplantation (ISHLT) “Acute rejection accounts for no more than $11 \%$ of deaths”, because of advances in immunosuppressive drugs which have curtailed the acute rejection to a great extent ${ }^{15}$. However, chronic rejection, which occurs months to years after transplantation, still remains a major challenge for the heart transplant patients.

The most common indications for cardiac transplantation in the adult are coronary heart disease and nonischemic cardiomyopathies. In children cardiomyopathy and congenital heart disease are the two most common indications for transplantation ${ }^{16}$. 


\subsection{Overvie w of cardiac allograft re jection.}

Solid organ transplant rejection occurs because of the recipient's immune response to donor tissue ${ }^{17}$. At present, success of heart transplantation has mostly been achieved through better understanding of the immunology of transplant rejection and the application of various strategies for recognizing, treating, and preventing allograft rejection $^{18}$.

Cardiac allograft rejection can be classified into three categories: hyperacute, acute and chronic rejection ${ }^{19-20}$.

\subsubsection{Types of allograft rejection}

Hype racute rejection is characterized by thrombotic occlusion of the graft vasculature that occurs within few minutes after the transplant. This hyperacute rejection results from pre-formed donor specific antibodies (DSA) to $\mathrm{ABO}$ blood group antigens or the so called major histocompatibility antigens (named HLA in humans for Human Leukocyte Antigens) ${ }^{21}$. The pathogenesis of hyperacute rejection involves antibody-mediated activation of the complement cascade which produces severe damage to the endothelial cells, as well as platelet activation followed by coagulation of blood and thrombosis ${ }^{16}$. Antibodies to HLA are formed generally through pregnancy, blood transfusions or previous transplantation ${ }^{22}$. Cross-matching involves placing recipient serum potentially containing donor-specific HLA antibodies onto donor lymphocytes containing HLA antigens. Antibody reactivity can be assessed either by cytotoxic reaction or with 
fluorescently labeled reagents ${ }^{23}$. With the help of blood typing for ABO compatibility and cross-matching for antibodies to HLA prior to transplant, hyperacute rejection has virtually been eliminated.

Acute Rejection occurs most frequently weeks to months after transplantation and it can involve both cell and antibody mediated rejection. Acute rejection is characterized by an intense infiltration of $\mathrm{T}$ cells and macrophages in the myocardium or antibodies binding to microvasculature, that if untreated results in graft loss within days to weeks ${ }^{24}$.

Chronic Rejection occurs months to years after transplant and is characterized by the progressive narrowing of the coronary artery ${ }^{25-26}$. This narrowing of the coronary artery is called cardiac allograft vasculopathy (CAV) ${ }^{24,}{ }^{26}$. Chronic rejection results from cell mediated or antibody mediated rejection.

\subsubsection{Incidence and Pathology of acute cardiac allograft re jection.}

The use of immunosuppressive drugs has curtailed acute rejection to a great extent. However, still $20 \%$ to $50 \%$ of patients may experience acute cardiac allograft rejection at least once within one year post transplant ${ }^{27}$.

Currently endomyocardial biopsies (EMB) are used as a diagnostic tool for acute cardiac

allograft rejection ${ }^{28}$. Biopsy of myocardium can detect lymphocytic infiltration or complement deposition and macrophage infiltration which are characteristic of acute cellular or antibody mediated rejection, respectively. A detailed grading system 
(International Society of Heart and Lung Transplantation or ISHLT guidelines) is used to assess the severity of cellular and antibody mediated rejection and guide treatment ${ }^{29}$. Based on the grading system that was originally adopted by the ISHLT in 1990, the revised 2004 working formulation for the standardization of nomenclature in the diagnosis of heart rejection classified acute cardiac allograft rejection into three grades (0R to 3R, with 3R being the most severe) (Figure 1A-1R). Briefly, the revised categories of cellular rejection are as follows: Grade 0R represents no rejection. Grade 1R represents mild rejection, and shows presence of immune cell infiltrates in the interstitial and/or perivascular space, with up to 1 focus of myocyte damage. Grade 2R, or moderate rejection, is characterized by the presence of two or more foci of cellular infiltrate with associated myocyte damage. In grade $3 \mathrm{R}$ represents severe rejection which is characterized by diffuse cellular infiltrate along with multifocal myocyte damage including hemorrhage, edema or vasculitis ${ }^{29}$.

In severe cases like grade $3 \mathrm{R}$ there is also participation of granulocytes in the rejection process ${ }^{16}$. In acute cardiac allograft rejection both donor and recipient-derived antigen presenting cells are involved and they can trigger direct and indirect alloresponse, respectively. In direct allorecognition, the intact foreign donor MHC antigens and peptides presented on the surface of donor APCs are recognized by recipient T cells. The donor organ-derived APCs can migrate from the allograft to the recipient's lymphoid tissues, where they activate, through the direct pathway, CD4+ and CD8+ T cells ${ }^{30-31}$. On the other hand, in indirect allorecognition, the recipient APCs first take up and process the donor MHC antigens, before presenting the donor-derived allopeptides to recipient $\mathrm{T}$ cells. While both direct and indirect pathways are activated as part of the 
alloimmune response post-transplant, it is thought that the direct pathway is primarily responsible for initiating the acute cellular rejection process, whereas the indirect pathway has been linked more so to the development of CAV and chronic rejection ${ }^{30-31}$.
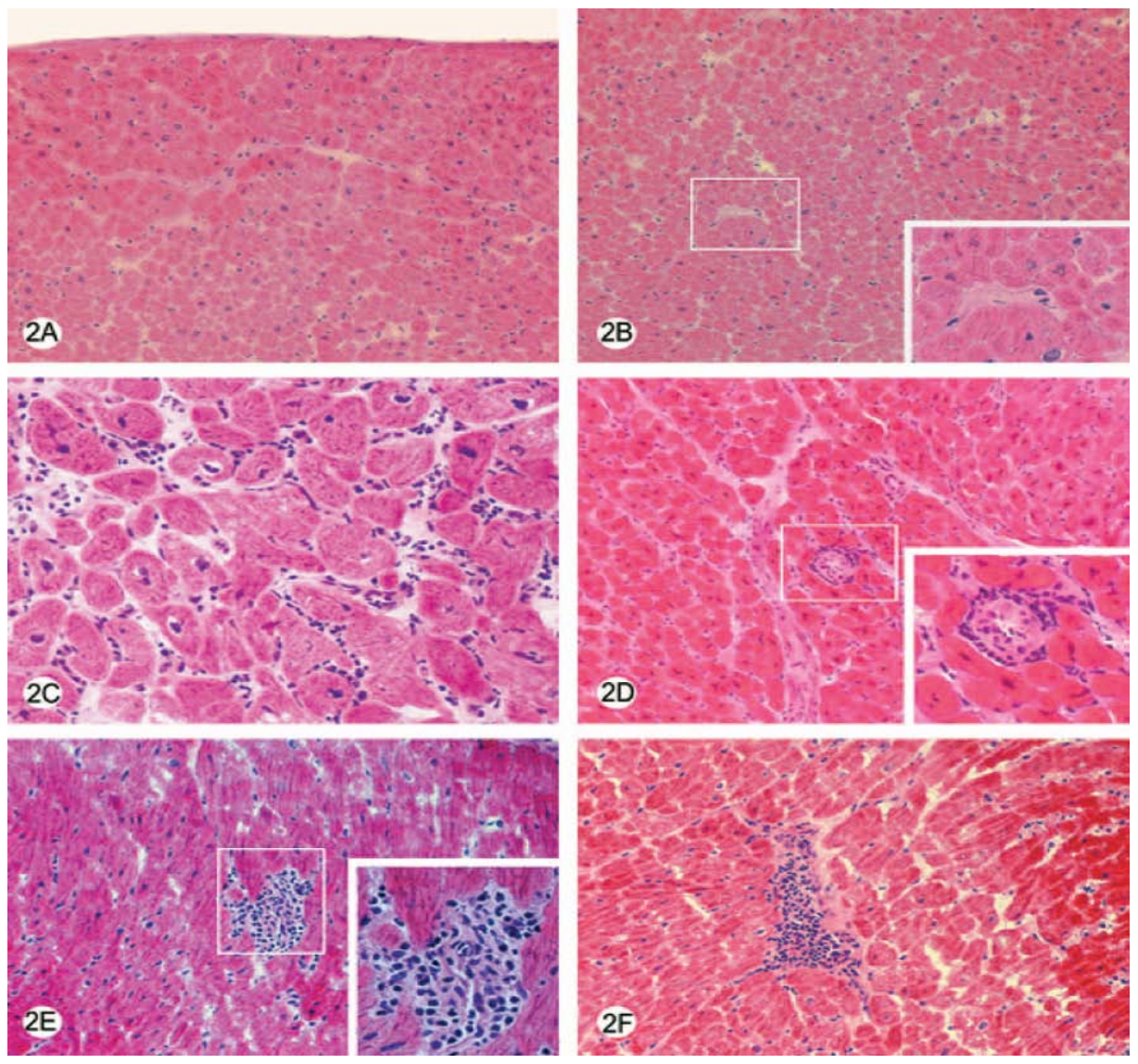

Figure 1 (A-F). Grades of cellular Rejection: Hematoxylin-eosin stain on frozen section of (A) showing Grade $0 \mathrm{R}$ with intact myocardim with no infiltrates, (B) showing Grade 0R with no infiltrates in interstitium or perivascular space, (C-F) showing Grade $1 \mathrm{R}$ with mild interstitial infiltrates in between myocytes (Tan et al 2007). 

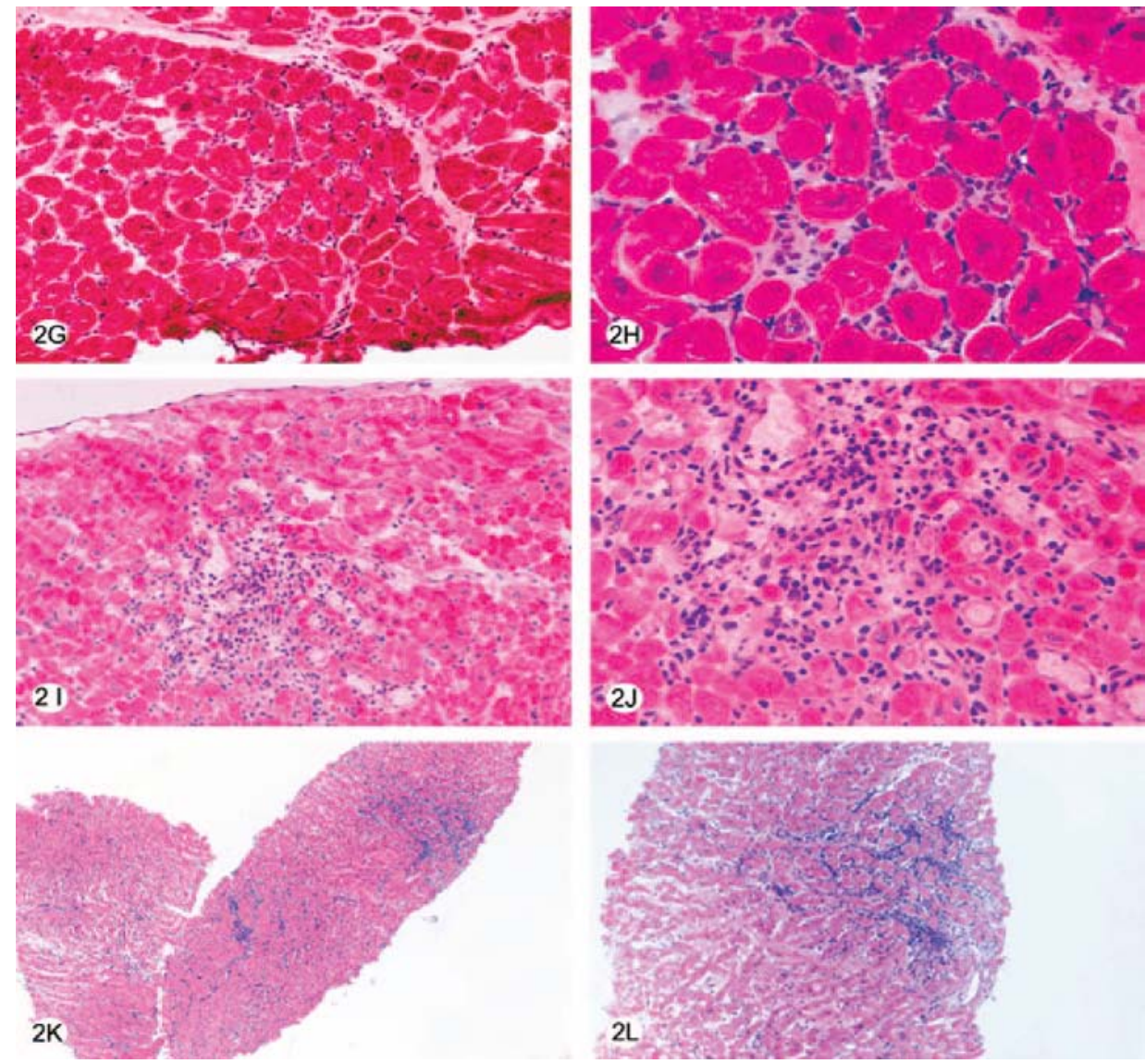

Figure 1 (G-L). Grades of cellular Rejection: Hematoxylin-eosin stain on frozen section of $(\mathrm{G}-\mathrm{H})$ showing Grade $1 \mathrm{R}$ with focal diffused interstitial infiltrates of mononuclear cells, (I-J) showing Grade 1R with focal myocyte damage, (K-L) showing grade $2 \mathrm{R}$ with mltifocal myocyte damage and intense interstitial infiltrates (Tan et al 2007). 

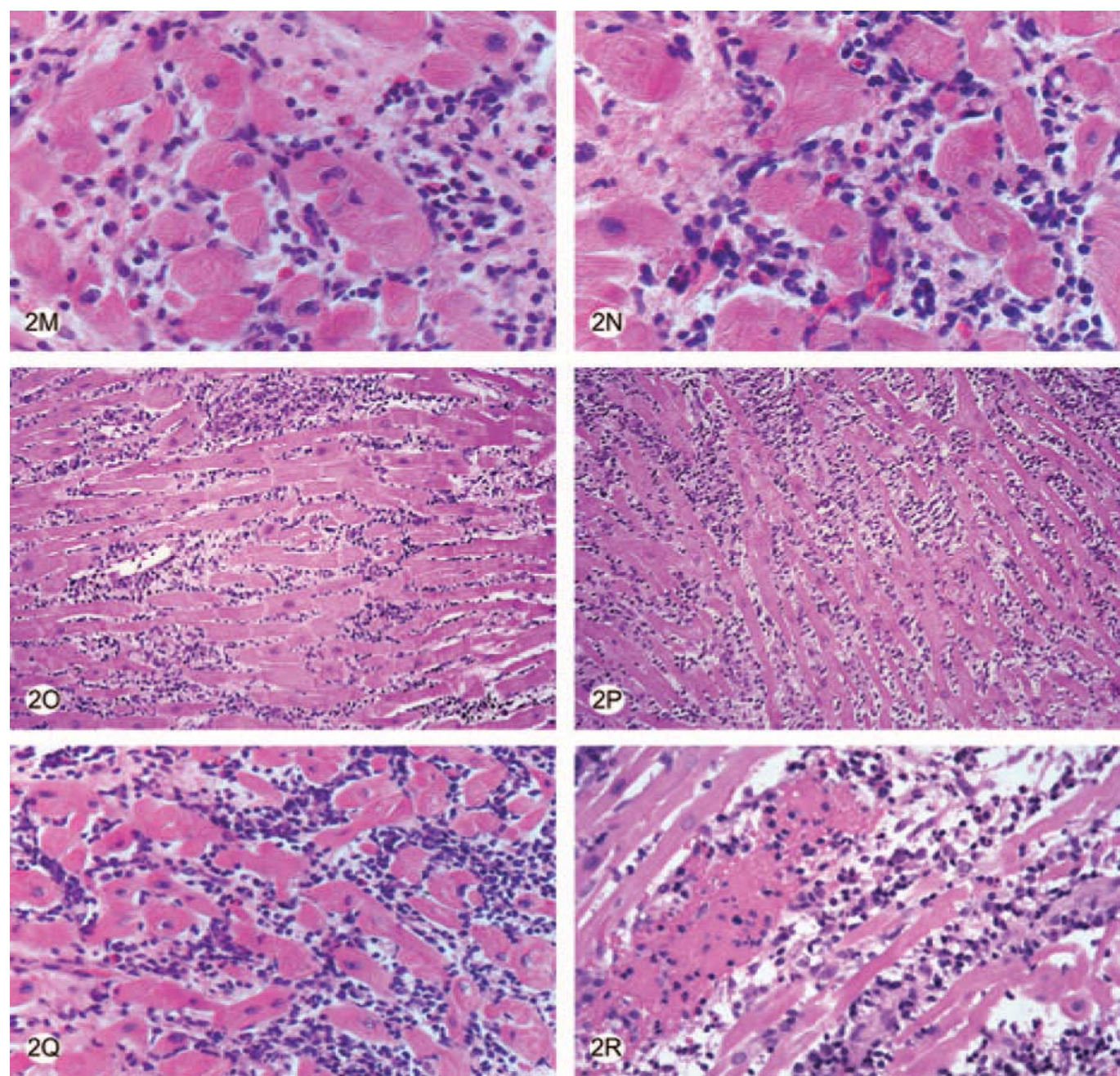

Figure 1 (M-R). Grades of cellular Rejection: Hematoxylin-eosin stain on frozen section of (M-N) showing Grade $2 \mathrm{R}$ with moderate rejection and widening of the interstitium, (O-Q) showing Grade 3R with diffuse inflammation. Myocardial pieces are diffusely infiltrated by dense mononuclear inflammatory infiltrates, (R) showing Grade 3R with edema and hemorrhage with mixed inflammatory infiltrates including neutrophil (Tan et al 2007). 


\subsubsection{Incidence and Pathology of Chronic cardiac allograft rejection.}

Chronic rejection occurs months to years after transplantation and can also be the result of antibody- and cellular-mediated components. Immunosuppression has curtailed acute rejection, however chronic rejection still remains a challenge for heart transplant patients. Recent estimates indicate that allograft vasculopathy is experienced by $32 \%$ of patients within five years after transplantation, and by $53 \%$ of patients within ten years of transplantation ${ }^{32}$. The mortality rate among patients with transplant vasculopathy is high, and diagnosis of allograft vasculopathy is complicated. Chronic rejection is characterized by the progressive concentric narrowing of the coronary artery (Figure 2A-B) along the length of coronary vessels ${ }^{25}$. This narrowing of coronary artery is called CAV ${ }^{24,26}$. Early stages may cause eccentric and focal stenosis that are more obvious in arteries. This loss in lumen results from intimal expansion (Figure 3) which occurs due to infiltration of host $\mathrm{T}$ cells and macrophages and smooth muscle cell proliferation ${ }^{33-34}$. CAV is a major factor that limits long term survival after cardiac transplantation.

Examination of endomyocardial biopsies is the current standard for diagnosing rejection. However, it does not detect changes in the coronary arteries which are the site of chronic rejection. Therefore, cardiac allograft vasculopathy is detected clinically by radiological techniques. There are studies that use more sensitive method of diagnosis like intravascular ultrasound (IVUS). IVUS detected new arteriopathy in about half of cardiac transplants within one year after transplantation ${ }^{35}$. Within 10 years of transplant, approximately $90 \%$ of patients develop significant $\mathrm{CAV}^{35}$. 
Both immune and nonimmune factors contribute to CAV development and impact graft survival. Endothelial cells express major histocompatibility complex class I and class II antigens, and thus are primary targets of cell-mediated and humoral immune responses ${ }^{16,}{ }^{36-38}$. Activated $\mathrm{T}$ cells secrete cytokines like tumor necrosis factor, interleukins and interferon which promote proliferation of alloreactive $\mathrm{T}$ cells that in turn activate monocytes and macrophages, and stimulate expression of adhesion molecules by endothelial cells ${ }^{39}$. After macrophages are activated they are recruited to the intima where they release cytokines and growth factors, leading to smooth muscle cell proliferation and synthesis of extracellular matrix ${ }^{40}$. The humoral immune response contributes to CAV through antibody production against HLA and endothelial cell antigens. Endothelial cell dysfunction resulting from sustained inflammatory injury also predisposes to thrombosis, vasoconstriction, and vascular smooth muscle proliferation ${ }^{40}$. Nonimmune factors are thought to influence CAV mainly by modulating adaptive immune responses ${ }^{41}$. Some of the nonimmune factors that are associated with the development and progression of CAV include arteritis ${ }^{42-43}$, myocardial ischemia, donortransmitted coronary atherosclerosis, cytomegalovirus status, deficient fibrinolysis and immuno suppressive therapy ${ }^{26}$. 

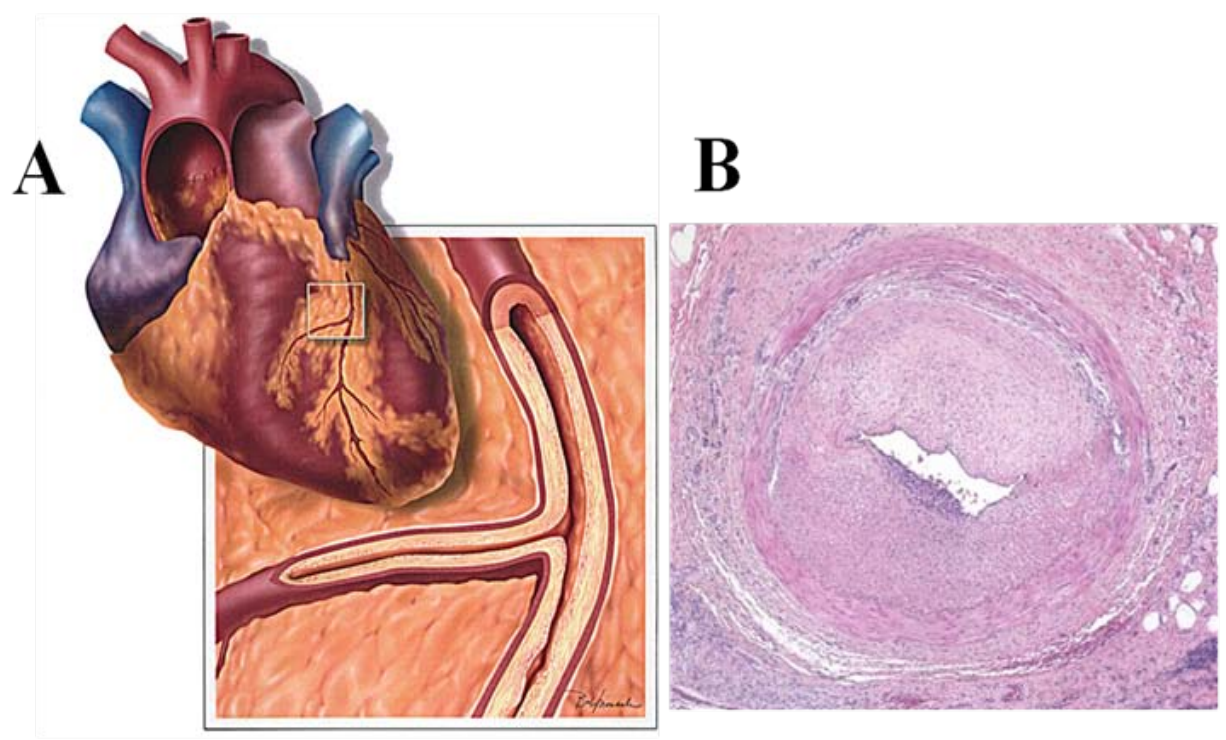

Figure 2. Schematic representation of a coronary artery, site of CAV (A) H\& E staining of human heart tissue showing pathology of cardiac allograft vasculopathy (B).

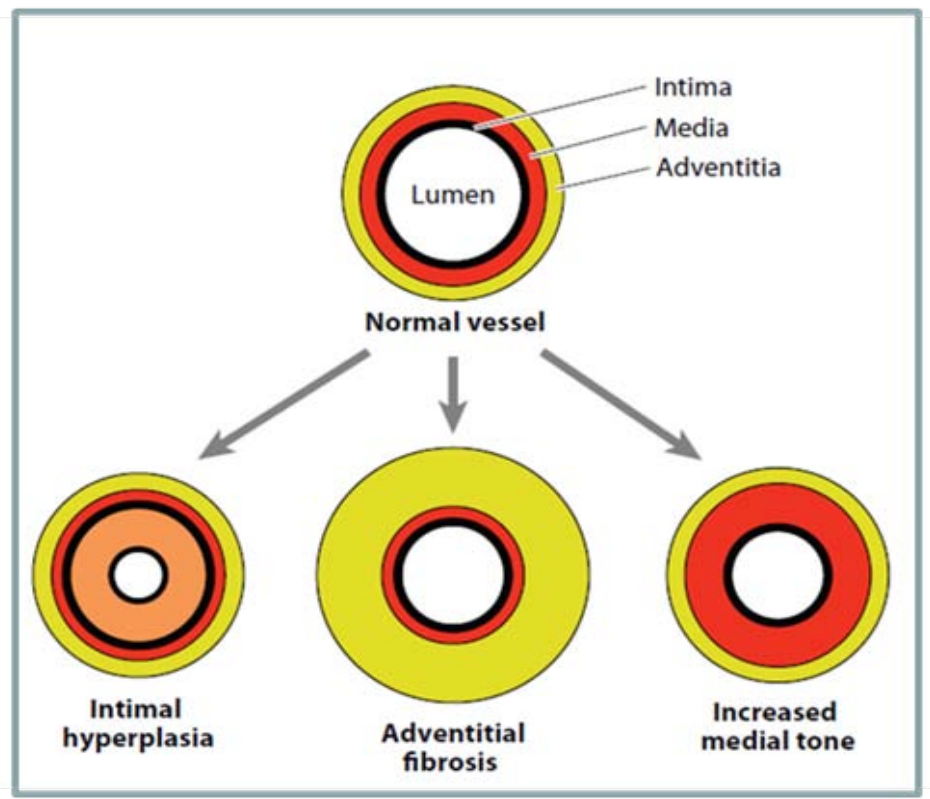

Figure 3. Schematic representation of vascular remodeling in CAV depicts mechanisms by which vascular remodeling can impact the vessel lumen. Intimal hyperplasia occurs 
through the recruitment of inflammatory cells and smooth muscle like cells and extension of extracellular matrix reduces luminal diameter. Adventitial fibrosis restricts positive remodeling of medial smooth muscle cells. Increased medial tone can also participate in intimal responses by increasing wall shear stresses (Mitchell et al 2009).

\subsubsection{Small Animal Models of Cardiac Allografts.}

In small animals, orthotopic cardiac transplantation is not technically feasible. Consequently, smaller animal models involve either heterotopic cardiac transplantation or vascular grafting. These approaches are complementary models for CAV.

In our laboratory, we are using heterotopic cardiac transplantation model (Figure 4). Abdominal heterotopic cardiac transplantation is the gold standard for studying cardiac allograft rejection; it is a primarily vascularized model. Graft beating is routinely used to assess ongoing graft function. CAV lesions develop within 6-12 weeks and accurately replicate most aspects of human disease, including histology and cellular

composition ${ }^{44-45}$. Isografts serve as controls: they do not develop CAV lesions and almost no T cells and macrophages infiltrate the graft. This is because isografts have no genetic incompatibilities with the recipient and therefore do not elicit an alloimmune response. CAV may occur if there is perioperative ischemic injury ${ }^{46}$. These isografts are used as controls to allograft.

There are certain limitations to the rodent heterotopic transplant model. The first and foremost is heterogeneity of CAV severity within a given allograft necessitating larger numbers of allografts to obtain meaningful data. Secondly, unlike human coronary 
arteries that have extensive epicardial segments, the murine coronary circulation is predominantly intramyocardial and could be more influenced by mediators present in adjacent areas of myocardial rejection. In addition, the rodent coronary diameters are also substantially smaller than their human counterparts and have a less well-developed media. Also in comparison to human vessels, murine endothelium does not constitutively express MHC II and is relatively resistant to neointimal lipid deposition and atherosclerosis.

In an orthotopic location, transplanted hearts have physiologic patterns of lymphatic drainage with associated lymph nodes, where antigen presentation and lymphocyte activation can occur. Although from heterotopic transplants vascular trafficking to the spleen likely occurs, it is unclear where the analogous antigen presentation takes place and whether it is comparable to the human situation ${ }^{26}$. 


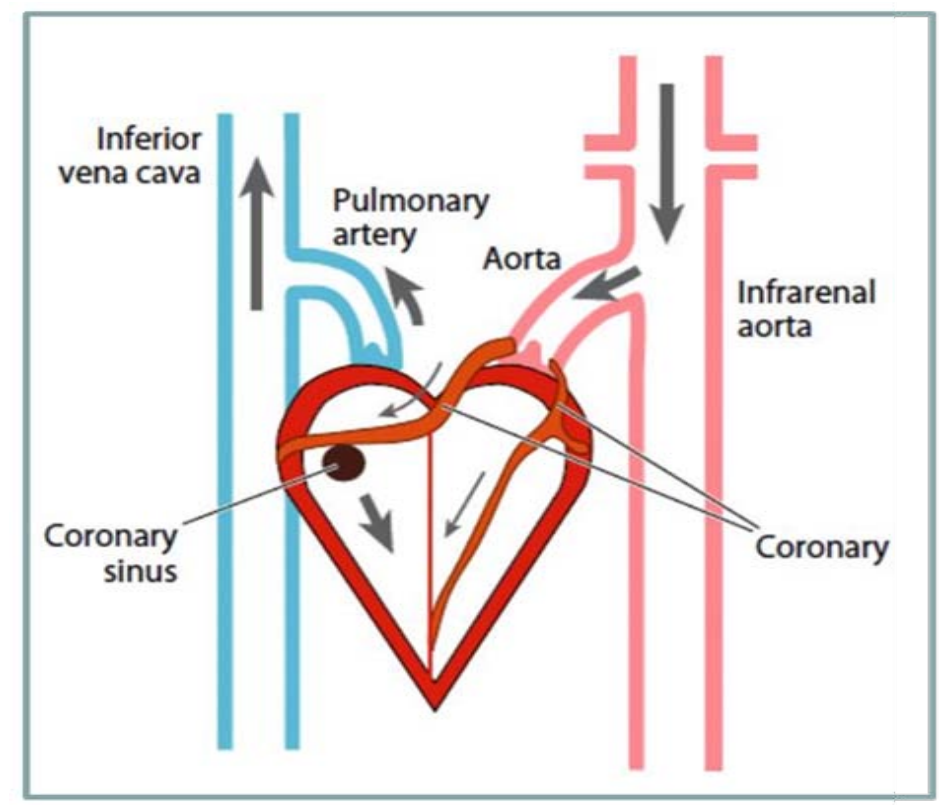

Figure 4. Schematic describing the heterotopic cardiac transplantation procedure. Cardiac allografts are primarily vascularized and beat but are not hemodynamically loaded; the host does not rely on the transplant to survive. The donor aorta is anastomosed to the host abdominal aorta, and the donor pulmonary vein is sewn to the host inferior vena cava. The aortic valve is initially competent and the coronary arteries and myocardium are perfused at aortic pressures; blood returns to the right atrium and into the host inferior vena cava (Mitchell et al 2009).

\subsection{Mechanisms controlling cardiac allograft re jection.}

\subsubsection{Role of Co-stimulatory molecules.}

$\mathrm{T}$ cells play an important role in acute and chronic cardiac allograft rejection ${ }^{47-48}$. Therefore, interfering with $\mathrm{T}$ cell activation offers the potential of prolonging graft survival through modulation of the alloresponse. The process of T cell activation (Figure

5) is now recognized to involve multiple signals and distinctly regulated pathways ${ }^{48}$. To 
fully activate naïve T cells, a second signal which is delivered by positive co-stimulatory molecules that are present on antigen presenting cells (APCs) is required. These APC's also express negative co-stimulatory molecules that are capable of inhibiting $\mathrm{T}$ cell activation. Now it is clear that integration of these positive and negative co-stimulatory signals by $\mathrm{T}$ cells will finally determine the fate and function of the $\mathrm{T}$ cell response. The best-studied co-stimulatory interactions are those of CD80 and/or CD86 molecules on antigen presenting cells (APCs) with CD28 or CTLA-4 on the T-cell surface ${ }^{49}$ and CD40 engagement of its transiently expressed ligand CD154 on the T-cell surface. A positive stimulus to T-cell activation results from each of these co-stimulatory interactions, with the exception of CTLA-4 ligation by CD80 or CD86, which results in a negative signal. Other positive co-stimulatory molecules are ICOS, CD134, CD30, 4-IBB, CD27 and CD70 which deliver positive co-stimulation under certain circumstances ${ }^{50}$. The negative co-stimulatory molecules delivering negative co-stimulation signal are Programmed death 1 (PD-1), and CTLA4 ${ }^{50}$. Mice that are genetically deficient for PD-1 develop lymphoproliferative and autoimmune diseases, demonstrating a role in lymphocyte deactivation and tolerance ${ }^{51-52}$.

PD-1 (CD279) is an inhibitory receptor expressed on activated T, B, and myeloid cells ${ }^{53}$. PD-1 is a member of the immunoglobulin (Ig) superfamily, shares a $23 \%$ identity with CTLA-4 and has two ligands with distinct expression patterns: PD-1 Ligand 1 (PDL1; B7-H1) and PD-L2 (B7-DC). PD-L1 is expressed on resting T cells, B cells, DCs, and macrophages and is further up-regulated upon activation ${ }^{54,55}$. PD-L1 has a tissue distribution profile distinct from that of the other B7 family members. PD-L1 has been 
detected in lymphoid as well as in nonlymphoid organs ${ }^{56-57}$, including vascular endothelial cells and pancreatic islet cells. In contrast, PD-L2 is inducibly expressed only on DCs and macrophages ${ }^{57}$. In-vitro studies have shown that engagement of PD1 by its ligands inhibits proliferation and cytokine production by antigen-specific CD4+ and CD8+ $\mathrm{T}$ cells ${ }^{58}$. In-vivo studies have shown that PD-L1 expressed on cardiac endothelial cells plays an important role in downregulating a cytotoxic T-cell-mediated form of transient myocarditis ${ }^{59}$.

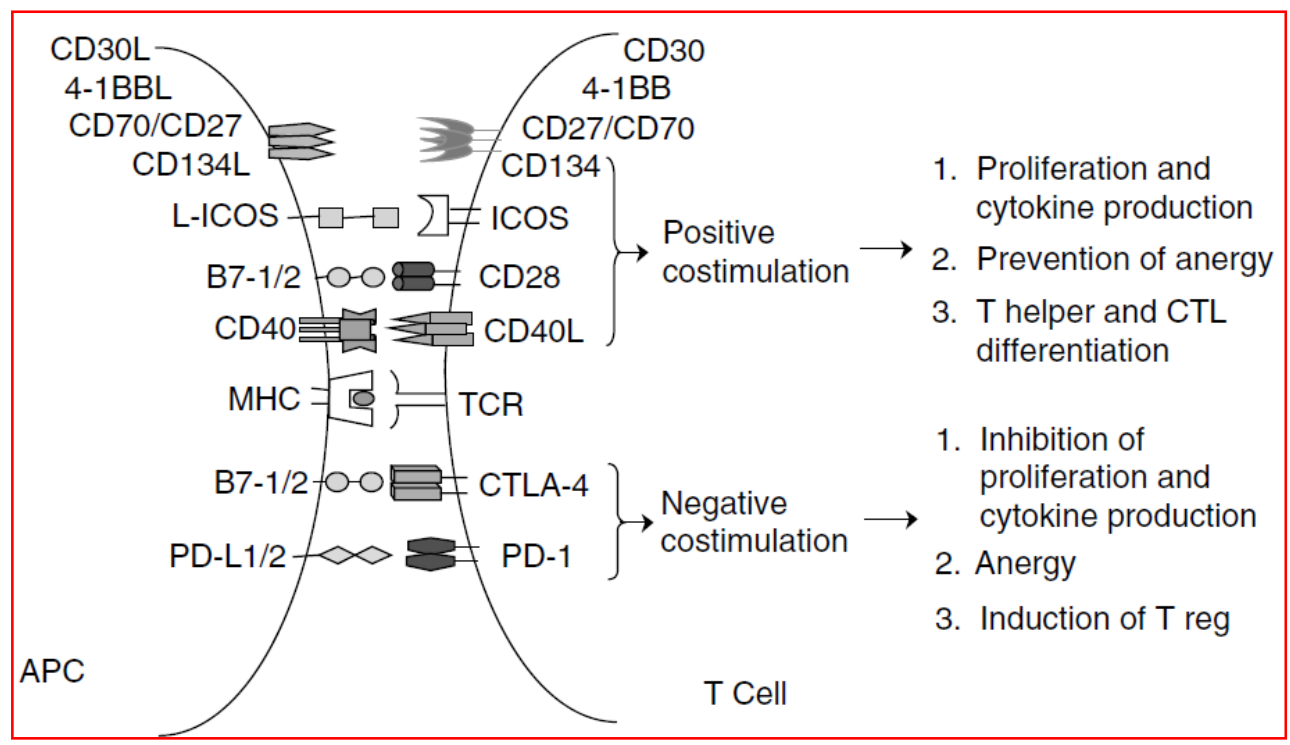

Figure 5. Schematic representation of Co-stimulatory molecules in T cell activation. Activation of $\mathrm{T}$ cell requires two signals, first engagement of $\mathrm{T}$ cell receptor with MHC peptide complex and ligation of co-stimulatory molecules on T cells with their respective ligands on antigen presenting cells. T cells receiving both signal 1 and positive costimulation will proliferate and will produce cytokine. However, co-stimulatory molecules such as CTLA4 and PD1, can lead to negative T cell signaling resulting in reduced cell proliferation and cytokine production (Gao, et al 2003). 


\subsubsection{Role of PD-1 and its ligand PD-L1 in transplantation:}

PD-1-PD-L1 interactions control engraftment of solid organ and graft versus host disease at several levels ${ }^{60}$. PD-1 and PD-L1 both are significantly upregulated on alloreactive $\mathrm{T}$ cells in transplant recipients ${ }^{61-62}$. Sandner et al showed that the administration of blocking anti-PD-L1 monoclonal antibody resulted in enhancement of alloantigen-driven $\mathrm{T}$ cell expansion in-vivo and promoted Th1 differentiation and accelerated graft rejection ${ }^{61}$. In a model of MHC class II- mismatched (bm12-into-B6 and B6-into-bm12 models) cardiac allografts it was shown that blocking PD-L1 expression caused accelerated rejection. This study also indicated that PD-L1 plays an important role in regulating CD4+ T-cell mediated alloimmune responses against cardiac allografts. In this allograft model, PD-L2 does not play an important role in regulating alloimmune response ${ }^{63}$. In contrast, administration of a PD-L1-Ig fusion protein that triggers PD-1 negative signaling prevents allograft rejection and facilitates tolerance induction when combined with anti-CD154 antibody or suboptimal doses of rapamycin

50. These studies demonstrate the negative regulatory function of the PD-1 pathway in organ transplantation. Noritaka et al showed that blockade of the PD-1/ PD-L1 pathway upregulated IFN gamma and TNF alpha and enhanced the proliferation of smooth muscle cells (SMCs) and $\mathrm{CAV}^{64}$. In some transplantation tolerance studies it has been shown that PD-L1 expression by the endothelium is required to achieve cardiac allograft tolerance in a fully allogeneic mismatched model ${ }^{65}$. Many other studies demonstrated the important role of PD-L1 for induction and maintenance of peripheral transplantation 
tolerance through its ability to alter the balance between pathogenic and regulatory $\mathrm{T}$ cells ${ }^{66}$.

\subsubsection{Cytokine and che mokine expression in cardiac allograft rejection.}

Chemokines are a large family of low-molecular-weight (8- to 11-kDa) cytokines that mediate cellular trafficking ${ }^{67}$. They are expressed by endothelial cells, lymphocytes and smooth muscle cells that attract and in turn activate a variety of inflammatory and non-inflammatory cells and thus mediate directional migration of immune cells to sites of inflammation and injury ${ }^{68}$. The chemokine superfamily is divided into 4 subfamilies $\mathrm{C}$, CC, CXC, and CX3C based on the presence of a conserved cysteine residue at the amino terminus. The C subfamily consists of XCL1 and XCL2, which attract lymphocytes. CC chemokines predominantly recruit mononuclear cells ${ }^{67}$. The CXC chemokines are further distnguished by the presence or absence of the sequence glutamic acid-leucinearginine (ELR) near the amino terminal. ELR+CXC chemokines are neutrophil chemoattractants with angiogenic properties. ELR-CXC chemokines are chemoattractants of lymphocytes with angiostatic properties ${ }^{69}$. The fourth subclass of chemokines is CX3C subfamily; CX3CL1 is the only known member of this subfamily ${ }^{67}$.

The Chemokine actions are mediated by binding to 7-transmembrane spanning $\mathrm{G}$ protein- coupled receptors (GPCR) ${ }^{70}$. These are heterotrimeric G proteins. The chemokine receptors undergo internalization and phosphorylation following ligand binding. Chemokines can also bind to glycosaminoglycan (GAG) on the cell-surface or 
within the extracellular matrix. Although this binding does not generate cell signals, it maintains stable concentration gradients from the site of chemokine production ${ }^{71}$. In addition to their trafficking properties, chemokines have also been shown to have several extrachemotactic properties, such as cellular activation and differentiation.

\subsubsection{Role of chemokines in acute and chronic cardiac allograft re jection.}

Multiple clinical studies have shown that donor endothelial cells, T cells, B cells and macrophages can all interact with each other and secrete different sets of chemokines ${ }^{69}$. Chemokines contribute to the onset of acute rejection. After transplantation the levels of chemokines such as CCL2 (MCP-1), CCL5 (RANTES), CXCL9 (MIG), CXCL10 (IP10), CCL3 (MIP-1alpha) and CCL4 (MIP-1beta) increases in cardiac allograft (Figure 6). 


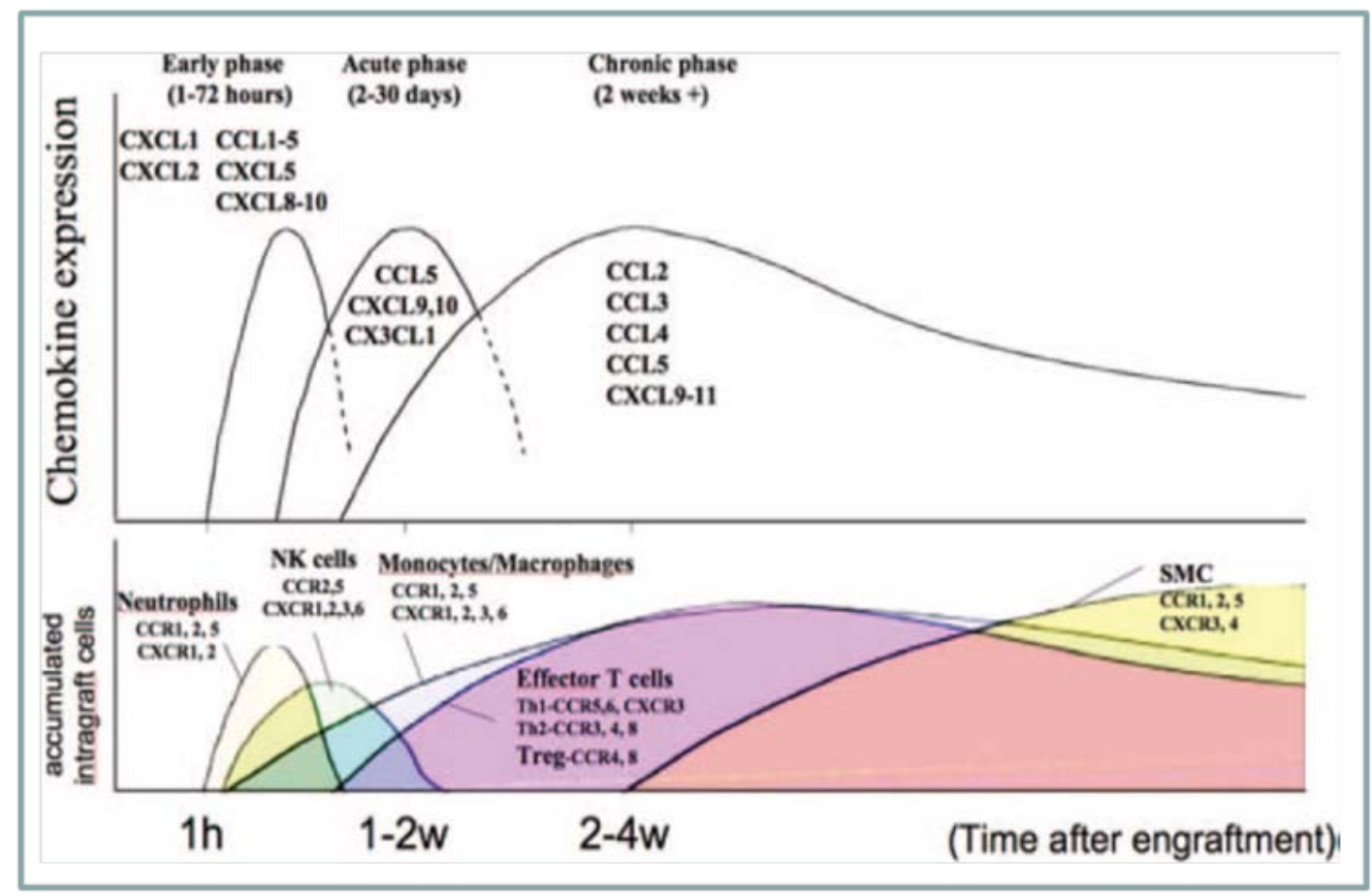

Figure 6. This plot depicts the expression of chemokines at various stages in immune responses to allografts. The early stages are dominated by neutrophils and monocytes, followed by NK cells, T lymphocytes, and macrophages, and eventually by smooth muscle-like cells and a number of chemokines are expressed such as MIG/CXCL9, CCL5 to form GAD lesion in later stage of transplant rejection (Shimizu et al 2003).

It has been shown that CCL3, CCL4, and CCL5/RANTES stimulate T-cell differentiation into Th-1 subtype. This effect is mediated both directly and indirectly via interleukin (IL)-12. In contrast, CCL2/MCP-1 polarizes T-lymphocyte differentiation to Th-2 subtype by suppressing IL-12 expression and stimulating IL-4 expression ${ }^{70}$. In addition, CCL2 also appears to have a direct effect on T-lymphocyte differentiation toward Th-2 subtype. Among CXCR3-binding chemokines, CXCL10/IP-10 has been shown to enhance generation of tumor-specific T cells and protective immunity in an IL12 gene therapy model. CXCL10/IP-10 has also been shown to be important in 
generation of T-lymphocyte effector function. Another study examined the extrachemotactic properties of CXCL9/MIG ${ }^{70}$. CXCL9/MIG was shown to stimulate Tlymphocyte proliferation and increase the number of interferon gamma (IFN g) producing T cells both in-vivo and in-vitro. These stimulatory effects are independent of IL-2, but are controlled by IFNg, and are found to occur in major histocompatibility complex (MHC) class I and II and totally mismatched cardiac transplants. These studies show the extrachemotactic properties of some chemokines that is similar to the role of several classic cytokines. In transplants these chemokine regulate the recruitment of monocyte/macrophages, activated T cells, NK cells and eosinophil and thus contribute to the onset of acute rejection ${ }^{72-73}$. The infiltrating macrophages have been identified as a source of this chemokine ${ }^{74}$. It is known that chemokines MCP-1/CCL2, and RANTES/CCL5 are the dominant mediators in recruiting monocytes to the rejecting organ ${ }^{75}$. Studies have demonstrated that blocking of either MCP-1 or RANTES substantially reduces intragraft macrophage and $\mathrm{T}$ cell accumulation and attenuates allograft rejection ${ }^{76-77}$. Chemokines also play an important role in cardiac allograft vasculopathy. Chemokines can directly contribute to vascular remodeling and angiogenesis. The chemokines can contribute to both recruitment and expansion of intimal cells in arterial lesions ${ }^{68}$. In endomyocardial biopsies increased expression of MIG/CXCL9 has been associated with acute rejection ${ }^{78}$.

\subsubsection{Role of IL1R1 and IL1R2 and their association with cardiac allograft re jection:}


The IL-1 family is comprised of 11 members. These members include IL1alpha, IL1beta, IL1 receptor antagonist, IL-18, IL-33 and IL1F5- IL1F-10. IL-1 functions as a growth factor for fibroblasts, keratinocytes, lymphocytes, and SMCs and enhances activation of $\mathrm{B}$ and $\mathrm{T}$ cells, many of the cell types implicated in inflammation ${ }^{79}$. Moreover, IL-1 is an activator of endothelial cell gene expression and is known to modulate the presence of cell adhesion molecules such as E-selectin on the endothelial surface. These IL1 family members signal through a group of closely related receptors. The receptors contain extracellular immunoglobulin domains and a Toll/ IL1 receptor (TIR) domain in the cytoplasmic portion ${ }^{80}$. IL-1 affects target cells through two distinct types of transmembrane receptors that have a nearly identical extracellular domain ${ }^{81}$. It is known that Interleukin-1 (IL-1) alpha and beta are major proinflammatory cytokines that function in immunomodulatory and inflammatory processes, which occur mainly via interactions with the IL-1 type I receptor (IL-1RI) ${ }^{81}$. IL-1R1 has a 213-amino acid cytoplasmic domain that is important for signal transduction. IL-1R1 is found mainly on T cells, fibroblasts, keratinocytes, and hepatocytes ${ }^{82}$. The IL-1/IL-1RI interaction has important effect on cardiovascular events, such as atherosclerosis, myocardial infarction, vascular wall remodeling, and the response to vascular injury ${ }^{83-85}$. However, IL-1 activity is tightly regulated by IL-1 receptor type II (IL1R2). IL-1R2 is a non-signaling decoy receptor that negatively regulates the activity of IL-1, a pro-inflammatory cytokine ${ }^{86}$. IL-1R2 has a shorter cytoplasmic domain and does not transduce the signal. IL-1R2 is found predominantly on B cells, macrophages, and neutrophils ${ }^{82}$. In the transplant setting it is known that proinflammatory cytokines mediate ischemia-reperfusion injury and stimulate immune responses that leads to acute graft rejection. Upregulation of 
interleukin-1 (IL-1) occurs very early after graft reperfusion ${ }^{87}$ as has been demonstrated in human heart transplants ${ }^{88}$. It has been demonstrated in a rat model that soluble IL-1 type-2 receptor gene transfer lessens cardiac allograft rejection ${ }^{82}$.

In the Cardiac Allograft Rejection Gene Expression Observational (CARGO) study 11 genes were validated on RNA extracted from peripheral blood mononuclear cells. This gene expression profiling was correlated with findings in endomyocardial biopsies that had moderate to severe cardiac allograft rejection. In this study, IL-1R2 was found to correlate most strongly with resolution of acute rejection and stable graft function ${ }^{89-90}$.

\subsubsection{Pattern recognition molecules and their endogenous ligands (Toll like receptor, Hyaluronan).}

Toll like receptors (TLRs) are a family of pattern recognition proteins that detect both microbes and host derived molecular patterns. These pattern recognition proteins are expressed on macrophages, dendritic cells and epithelial cells. When ligands bind to TLRs, they activate transcription factors that lead to production of inflammatory mediators. These TLRs play an important role in the innate immune response and subsequently lead to induction of adaptive immune response against pathogens ${ }^{91}$. There are at least 11 mammalian TLRs that have been identified. Each TLR recognizes distinct pathogen associated molecular patterns (PAMPs). Some of the examples of exogenous ligands for TLRs are Triacyl lipopeptides, peptidoglycans, dsRNA, LPS, Flagellin and unmethylated CpG DNA. In addition to the exogenous ligands, it is known that TLRs are receptors for endogenous stimulators that are released from damaged tissues and thus 
lead to noninfectious inflammatory response ${ }^{92-93}$. The endogenous TLR ligands do not interact with corresponding receptors in quiescent conditions because of their different cellular compartmentalization. But in certain pathological conditions, these endogenous molecules are released from injured or necrotic tissues and cells through non-

conventional lysosomal route ${ }^{94-95}$. These endogenous molecules activate TLRs and initiate a protective inflammatory response and the repair of damaged tissues. For this reason endogenous ligands for TLRs are called alarmins and serve as early warning signals. As alarmins are released after tissue injury and cell death, they have similar response as PAMPs and thus are collectively called as damage associated molecular patterns (DAMPs) ${ }^{96}$. Some of the examples of endogenous ligands for TLRs are hyaluronan ${ }^{97}$. HMGB1, CD138, HSP60 and HSP70 ${ }^{98-99}$.

\subsubsection{Hyaluronan}

Hyaluronan (HA) is an important structural component of the extra cellular matrix (ECM). HA is a glycosaminoglycan polymer composed of repeating disaccharides of beta glucuronic acid and $\mathrm{N}$-acetyleglucosamine covalently bound end to end into a simple linear glycosaminoglycan ${ }^{100}$. HA is synthesized locally in the tissue by various isoforms of hyaluronic acid synthase that is present in the plasma membrane of mesenchymal cells as high molecular weight polymer, its molecular weight is up to $107 \mathrm{Da}^{101-102}$. A local degradation of HA occurs in the tissue and it is also cleared through the lymphatics. The HA clearance from the blood is extremely rapid and occurs within minutes ${ }^{101}$. Even 
though reticuloendothelial cells in the lymph nodes catabolize a large proportion of hyaluroran, some reaches the general circulation. Most of the circulating hyaluronan is taken up via receptor mediated endocytosis and degraded by liver sinusoidal endothelial cells ${ }^{103-104}$. The damage to the sinusoidal endothelial cells, such as from ischemia or drug toxicity, is, therefore reflected by an increased serum content of hyaluronan ${ }^{105}$.

HA can be broken down into fragments by a number of enzymatic and nonenzymatic processes ${ }^{99}$. Small molecular weight $\mathrm{HA}$ has been implicated in several biological processes including angiogenesis, cell proliferation, maturation, migration, activation of protein tyrosine kinase cascades, and inflammatory gene expression ${ }^{106}$. These small or low molecular weight HA fragments are increasingly being characterized as an endogenous danger signal that promotes the expression of immune mediators. Small HA fragments may therefore activate repair processes and signal the immune recognition system that injury has occurred ${ }^{107}$. Tesara et al showed in murine models that these fragments of HA induce DCs to upregulate co-stimulatory molecules CD40 and CD86 and produce the proinflammatory cytokine TNF-alpha ${ }^{108}$.

It has been established that the cell surface adhesion molecule CD44 is the principal receptor for hyaluronic acid in mouse and human. CD44 has been implicated in lymphocyte homing, embryonic development, T cell activation. CD44 is also expressed on monocyte/macrophages ${ }^{109}$. 


\subsubsection{Hyaluronan Role in transplantation:}

Some studies involving solid organ transplants have found an association between TLR4 and allograft rejection. One study linked expression of TLR4 activation on the cardiac allograft to the development of CAV. In a number of human heart transplant recipients, expression of TLR4 and resultant IL-12 and TNF- $\alpha$ production was significantly elevated in patients with allograft endothelial dysfunction, which is a predictor of subsequent development of CAV ${ }^{110}$. McDaniel et al demonstrated that increased expression of TLR2 and TLR4 correlated with cardiac allograft rejection ${ }^{111}$. Johnsson et al showed that during allograft rejection there is local accumulation of hyaluronan within the transplanted organ. Accumulation of HA has been seen in cases of cardiac, renal and intestinal transplants. The increased tissue content of hyaluronan can most probably be attributed to an increased synthesis that is stimulated by cytokine released by graft infiltrating immunocompetent cells ${ }^{112}$. In murine orthotopic lung transplant model it has been demonstrated that accumulation of HA could contribute to Bronchiolitis Obliterans Syndrome by directly activating innate immune signaling pathways that promote allograft rejection and neutrophilia ${ }^{113}$. In one of the study it was suggested that fragments of hyaluronan can act as innate immune agonists that activate alloimmunity. Using a murine invitro culture it was shown that $135 \mathrm{KDa}$ fragment of HA induces DC maturation and initiate alloimmunity and this priming of alloimmunity by HA activated DCs was dependent on signaling via TIR associated protein and TLR2 and TLR4. Moreover in a murine skin graft model, the same group demonstrated that HA is accumulated during skin transplant rejection ${ }^{108}$. 
It has been proposed in the setting of transplantation that both antigen independent and dependent mechanisms initiate graft injury leading to production of HA fragments (Figure 7) ${ }^{108}$. After transplantation the allograft undergoes ischemia reperfusion injury allowing the release of fragments of hyaluronan. The hyaluronan fragments are recognized by DCs (of either donor or recipient origin) mostly via TLR4 but with some minor participation of TLR 2.

The TLR signal adaptor TIRAP, which is downstream of TLRs 2 and 4 is important for the upregulation of co-stimulatory molecules and the production of inflammatory cytokines by fragmented hyaluronan activated DCs. It has been shown that TIRAP signaling is important for fHA-activated DCs to prime allogeneic T cells. Primed allogeneic T cells then contribute to alloantigen-dependent graft injury. MyD88 is also critical for the inflammatory response and Trif participates in this response ${ }^{108}$. 


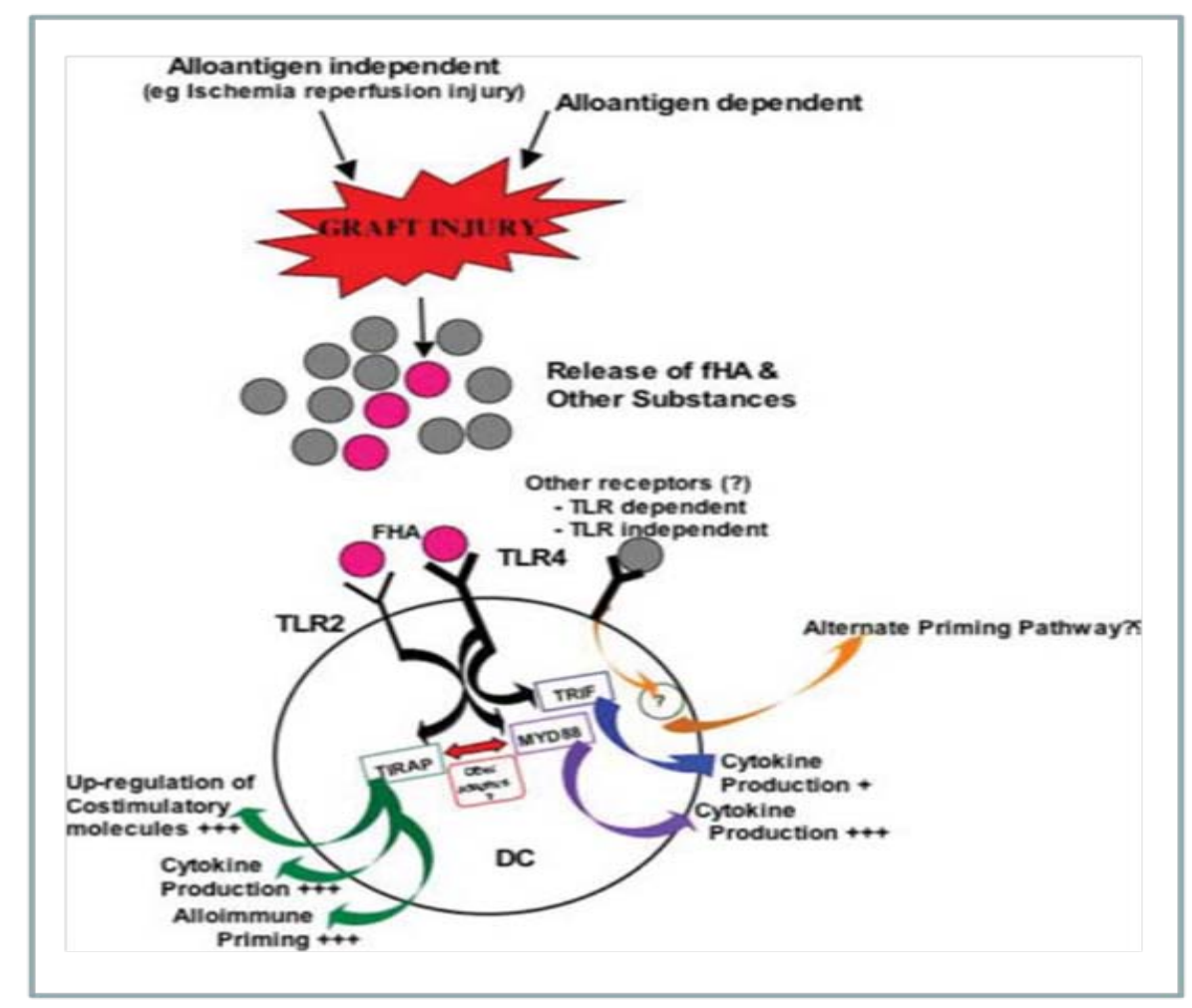

Figure 7. Schematic representation of TLRs and hyaluronan fragments in allograft rejection (Tesar et al 2006).

\subsection{Compartme ntalization of Acute and Chronic Rejection.}

Although we know that immune responses to cardiac allografts can result in acute and chronic rejection, it is unclear what directs the immune response to localize to different compartments of the heart. Acute rejection is characterized by interstitial infiltrates $\mathrm{T}$ cells and macrophages. However, chronic rejection is characterized by narrowing of the coronary arteries. Acute and chronic rejection attack two different compartments of heart. The mechanisms underlying this compartmentalization of acute and chronic rejection are not known. In this dissertation we will examine the role of different biological molecules that are involved in the cardiac allograft rejection. 


\section{CHAPTER II}

\section{ACUTE AND CHRONIC REJECTION: COMPARTMENTALIZATION AND KINETICS OF COUNTERBALANCING SIGNALS IN CARDIAC TRANSPLANTS}

\subsection{Abstract}

Acute and chronic rejection impact distinct compartments of cardiac allografts. Intramyocardial mononuclear cell infiltrates define acute rejection, whereas chronic rejection affects large arteries. Hearts transplanted from male to female C57BL/6 mice undergo acute rejection with interstitial infiltrates at 2 weeks that resolve by 6 weeks when large arteries develop arteriopathy. These processes are dependent on $\mathrm{T}$ cells because no infiltrates developed in T cell deficient mice and transfer of CD4 T cells restored $\mathrm{T}$ cell as well as macrophage infiltrates and ultimately neointima formation. Markers of inflammatory macrophages were upregulated in the interstitium acutely and decreased as markers of wound healing macrophages increased chronically. Programmed cell death protein, a negative co-stimulator, and its ligand PDL1 were upregulated in the 
interstitium during resolution of acute rejection. Blocking PDL1:PD1 interactions in the acute phase increased interstitial $\mathrm{T}$ cell infiltrates. Toll Like Receptor 4 and its endogenous ligand hyaluronan were increased in arteries with neointimal expansion. Injection of hyaluronan fragments increased intragraft production of chemokines. Our data indicate that negative co-stimulatory pathways are critical for the resolution of acute interstitial infiltrates. In the arterial compartment recognition of endogenous ligands including hyaluronan by the innate toll like receptors may support the progression of arteriopathy.

\subsection{Introduction}

Immune responses to cardiac allografts can result in acute and chronic rejection. In addition to differences in kinetics, acute and chronic rejection attack two different compartments of the heart. Acute rejection is defined by interstitial mononuclear cell infiltrates with associated myocyte damage as seen in endomyocardial biopsies ${ }^{1}$. In contrast, chronic rejection primarily involves large coronary arteries. Chronic rejection is characterized by diffuse intimal hyperplasia containing mononuclear leukocyte infiltrates. Additional mononuclear leukocyte infiltrates are frequently present in the media and adventitia ${ }^{2-4}$. This pathological process is diagnosed by angiography or intravascular ultrasound and is labeled cardiac allograft vasculopathy (CAV). The incidence of interstitial pathology decreases with time after transplantation in most patients, and one multicenter study concluded that routine endomyocardial biopsies were not of diagnostic value after 5 years except in patients with high risk for acute rejection ${ }^{5}$. In contrast, the 
incidence of CAV increases progressively after transplantation. As a result, advanced CAV is often reported with little or no infiltrates in endomyocardial biopsies ${ }^{2}$.

Mechanisms underlying compartmentalization of acute and chronic rejection are not known. However, the infiltrates in acute and chronic rejection are predominantly comprised of $\mathrm{T}$ cells and macrophages, which are regulated by many positive and negative co-stimulatory signals. The most extensively studied co-stimulatory receptors on $\mathrm{T}$ cells belong to the CD28 family and include the activating receptor CD28 and inhibitory receptor CTLA-4, both of which bind B7-1/CD80 and B7-2/CD86 ligands. Another member of the CD28 family is PD1 (CD279), an inhibitory receptor that binds to PDL1 and PDL2 (CD274 and CD273) that are expressed on antigen presenting cells ${ }^{6-8}$. In addition, PDL1 is constitutively expressed by various parenchymal cells including cardiomyocytes and can be induced on endothelial cells ${ }^{6}, 9$. Therefore, compartmentalized pathology could result from differentially expressed ligands for positive and negative co-stimulatory receptors on $\mathrm{T}$ cells during the process of rejection. T cells in turn produce cytokines that direct macrophages to differentiate into performing acute inflammatory functions or chronic wound healing functions ${ }^{10}$. Clinically, macrophages are routinely identified in biopsies by a universal macrophage marker, such as CD68 1, 11, 12. Inflammatory macrophages (M1 macrophages) release cytokines including IL-1beta and TNFalpha, chemokines such as MIG/CXCL9 and MCP-1/CCL2, as well as reactive oxygen species that promote acute interstitial infiltrates ${ }^{10}$. Increased expression of MIG/CXCL9 in endomyocardial biopsies has been associated with acute rejection in clinical studies ${ }^{13}$, and infiltrating macrophages have been identified as a 
source of this chemokine ${ }^{12}$. In contrast, wound healing macrophages (M2 macrophages) produce growth factors such as TGF beta and VEGF that are elevated in fibrotic processes. The balance between inflammatory and wound healing macrophages has not been investigated in either acute or chronic rejection of cardiac transplants.

Another set of genes associated with acute rejection was identified in the multicentered Cardiac Allograft Rejection Gene Expression Observational (CARGO) study. This study was designed to establish gene profiles in peripheral blood mononuclear cells that distinguish patients with stable transplants from patients who developed acute rejection ${ }^{14}$. In the CARGO study, the gene encoding the decoy receptor for IL-1 (IL-1R2) correlated most strongly with resolution of acute rejection and stable graft function ${ }^{15,16}$. Although IL-1R2 is the predominant receptor for IL-1 on monocytes ${ }^{17}$, the expression of this decoy receptor has not been examined on macrophages in the interstitial or arterial compartments of cardiac transplants.

Based on these clinical observations, we hypothesized that differential expression of critical molecules in the interstitial and arterial compartments accounts for the distinct localization of acute and chronic rejection in cardiac transplants. To test this hypothesis, we examined cardiac allografts that were transplanted from male to female C57BL/6 (B6) mice. These allografts elicit an acute rejection that spontaneously resolves and progresses to CAV. This enabled us to analyze the pathological process in the interstitial and arterial compartments at different stages. Using immunohistology and cell transfers, we demonstrated that CD4 T cells are required to orchestrate acute and chronic infiltrates 
of inflammatory macrophages. An extensive PCR screen of microdissected tissue samples revealed sets of genes that were differentially expressed in the interstitial and arterial compartments. During acute rejection B7-1/CD80 and B7-2/CD86, which are ligands for both positive and negative co-stimulatory receptors on $\mathrm{T}$ cells, were more highly upregulated in the interstitial than arterial compartment. In addition PDL1/CD274 was upregulated in the intersititium. The functional relevance of negative co-stimulation to the resolution of the acute interstitial infiltrate was tested by treatment with a blocking antibody to PDL1. This increased interstitial but not arterial infiltrates of PD1 expressing $\mathrm{T}$ cells and resulted in acute rejection of cardiac allografts. Acute rejection was accompanied by a significant increase in chemokines in the interstitial compartment, particularly MIG/CXCL9 that has been found in endomyocardial biopsies from patients

with findings of acute cellular rejection ${ }^{12,13}$. Finally, IL-1R2 was upregulated during acute rejection in both the interstitial and arterial compartments and then subsided in chronic rejection. These data localize clinically relevant markers in the context of pathological findings.

\subsection{Materials and Methods}

\subsubsection{Mice}

Male B6 (H2b), Female B6 and Female B6.129S7-Rag1 ${ }^{\text {tm1Mom/J }}$ (SCID) mice were purchased from Jackson Laboratories (Bar Harbor, ME) for use at 8-12 weeks of 
age. The B6.129S7-Rag1 $1^{\text {tm1Mom/J }}$ (SCID) are homozygous for the Rag1 $1^{\text {tm1Mom }}$ mutation and produce no mature $\mathrm{T}$ cells or B cells. These mice have a non-leaky severe combined immunodeficiency phenotype. The female C57BL/10NA;-(Tg)TCR Marilyn-(KO) Rag2 N11, N2 mice (H-2 , Marilyn), age 6 to 8 weeks, were obtained as a generous gift from Polly Matzinger (National Institutes of Health, Bethesda, MD) and Olivier Lantz (INSERM, Paris, France). All animal studies were approved by the institutional animal care and use committee at the Cleveland Clinic Foundation.

\subsubsection{Heterotopic heart transplantation}

Male C57BL/6 hearts were transplanted into female C57BL/6 or SCID. Heterotopic heart transplantation was performed under pentobarbital anesthesia. The donor aorta and pulmonary artery were anastamosed to the recipient's abdominal aorta and inferior vena cava respectively. Oral Tylenol was used at a dose of $3 \mathrm{mg} / \mathrm{ml}$ of drinking water as an analgesic three days following surgery. Graft function was monitored every week till the end of the experiment. These animals were sacrificed either at 2, 6, 8 or 10 weeks after transplantation.

\subsubsection{CD4 T cell isolation, sorting and transfer}

CD4 T-cells were isolated from female Marilyn CD4 T-cell receptor transgenic mice, in which all $\mathrm{T}$ cells are specific for the male minor transplantation antigen presented by H-2I-Ab MHC. Spleens from these transgenic mice were teased into single 
cell suspensions in PBS $+2 \%$ fetal bovine serum. The red blood cells were lysed using ACK lysis buffer (Gibco, Life Tecnologies, Grand Island, NY). Cells were washed and incubated with the following mixture of FITC-labeled antibodies from BD Pharmingen (San Jose, CA) for negative selection: CD8a, CD19, CD11c, CD11b, CD117, NK1.1 at 1:500 dilution. Labeled cells were removed by flow sorting and the unlabeled CD4 cells were transferred to SCID mice 7 days following cardiac transplantation. These cells were $>95 \%$ CD4+ by flow cytometry. The time of transfer was designed to avoid the effects of nonspecific inflammation from the surgical procedures.

\subsubsection{Treatment with blocking antibo dy or hyaluronan fragments}

Recipients were injected intraperitoneally with 3 doses of 200ug of purified IgG2a rat monoclonal antibody to PDL1 (clone 10F.9G2) or 200ug of isotype control (clone LTF-2) antibody (BioXCell, West Lebanon, NH) on alternate days in the second week or sixth week after transplantation.

Highly purified fragment preparations of hyaluronan (Lifecore Biomedical, LLC) were electrophoretically separated as previously described ${ }^{19}$. A 100ug dose of low molecular weight (4.7 or $35 \mathrm{kD}$ ) hyaluronan was administered intraperitoneally daily from the day of transplantation for 2 weeks. Controls were administered equal volumes of the PBS diluent. 


\subsubsection{Histology and immunohistochemistry}

Full cross-sections through the cardiac grafts were obtained at the time of sacrifice and fixed in methanol acetic acid (60\% methanol; $10 \%$ anhydrous acetic acid; $30 \%$ water). Deparaffinization and antigen retrieval were achieved with 2 incubations in Trilogy (Cell Marque, Rocklin, CA) for 30 minutes in a pressure cooker (125C). The deparaffinized slides were cooled, rinsed with water and incubated 20 minutes in $0.3 \%$ hydrogen peroxide in $80 \%$ methanol followed by 10 minutes in Protein Block (Dako, Carpinteria, CA). Sections were incubated with primary antibodies diluted with AB Diluent (Dako Carpinteria, CA) for 1-2 hours at room temperature. For rabbit primary antibodies Super picture polymer detection kit (Invitrogen, Carlsbad, CA) was used, and for rat and goat primary antibodies Rat and Goat HRPPolymer (Biocare medical, Concord, CA) were used. Staining was visualized with DAB substrate kit for peroxidase (Vector Laboratories Inc, Burlingame, CA) before counterstaining with hematoxylin. The following primary reagents were used: polyclonal rabbit antibody to CD3 (Abcam, Cambridge, MA), rat monoclonal antibody to mouse Galectin-3 (Mac-2; Cedarlane, Burlington, 8 NC), rabbit polyclonal antibody to Chitinase 3-like 3 (Ym-1; Stem Cell Technologies, Vancouver, Canada), polyclonal goat antibody to PD-1 (R\&D systems Inc, Minneapolis, MN), rat monoclonal antibody to mouse Foxp3 (eBiosciences, San Diego, CA), rabbit polyclonal antibody to Ki67 (Novacastra, Buffalo Grove, IL), rat monoclonal antibody to mouse CD44 (Abcam, Cambridge, MA), and biotinylated hyaluronic acid binding protein (Millipore, Billerica, MA). 


\subsubsection{Laser capture microdissection and real time RT PCR}

Frozen sections on PET-Membrane slides (Leica, Buffalo Grove, IL) stained with Arcturus Histogen solution (Life Technologies, Grand Island, NY) were microdissected on a Leica AS-LMD microscope. Samples were collected in RNAlater. Total RNA was isolated using the RNeasy micro kit and reverse transcribed with the RT2 PreAMP cDNA synthesis kit (QIAGEN, Gaithersburg, MD). Expressions of 86 genes (Table 1) was screened with a customized PCR array kit (QIAGEN). Eighteen genes were analysed in additional samples by qPCR using the ddCT method ${ }^{21}$, calibrated to (control sample) and normalized to B-actin. TaqMan assay numbers for all genes measeured are listed in (Table 2). 
Table 1. Complete list of genes on microarray.

\begin{tabular}{|c|c|c|c|}
\hline $\begin{array}{l}\text { Gene } \\
\text { Symbol }\end{array}$ & Refseq \# & Official Full Name & Category \\
\hline Ccl1 & NM_011329 & Chemokine (C-C motif) ligand 1 & Chemokine \\
\hline Ccl11 & NM_011330 & Chemokine (C-C motif) ligand 11 & Chemokine \\
\hline $\mathrm{Ccl} 17$ & NM_011332 & Chemokine (C-C motif) ligand 17 & Chemokine \\
\hline Ccl19 & NM_011888 & Chemokine (C-C motif) ligand 19 & Chemokine \\
\hline Ccl2 & NM_011333 & Chemokine (C-C motif) ligand 2 & Chemokine \\
\hline Ccl5 & NM_013653 & Chemokine (C-C motif) ligand 5 & Chemokine \\
\hline Ccl7 & NM_013654 & Chemokine (C-C motif) ligand 7 & Chemokine \\
\hline Cxcl11 & NM_019494 & Chemokine (C-X-C motif) ligand 11 & Chemokine \\
\hline Cxcl13 & NM_018866 & Chemokine (C-X-C motif) ligand 13 & Chemokine \\
\hline Cxcl2 & NM_009140 & Chemokine (C-X-C motif) ligand 2 & Chemokine \\
\hline Cxc19 & NM_008599 & Chemokine (C-X-C motif) ligand 9 & Chemokine \\
\hline Ccr1 & NM_009912 & Chemokine (C-C motif) receptor 1 & Chemokine receptor \\
\hline Ccr2 & NM_009915 & Chemokine (C-C motif) receptor 2 & Chemokine receptor \\
\hline Ccr3 & NM_009914 & Chemokine (C-C motif) receptor 3 & Chemokine receptor \\
\hline Ccr4 & NM_009916 & Chemokine (C-C motif) receptor 4 & Chemokine receptor \\
\hline Ccr6 & NM_009835 & Chemokine (C-C motif) receptor 6 & Chemokine receptor \\
\hline Cxcr6 & NM_030712 & Chemokine (C-X-C motif) receptor 6 & Chemokine receptor \\
\hline Cd274 & NM_021893 & CD274 antigen & costimulation \\
\hline $\mathrm{Cd} 4$ & NM_013488 & CD4 antigen & costimulation \\
\hline Cd80 & NM_009855 & CD80 antigen & costimulation \\
\hline Cd86 & NM_019388 & CD86 antigen & costimulation \\
\hline Ctla4 & NM_009843 & Cytotoxic T-lymphocyte-associated protein 4 & costimulation \\
\hline Havcr2 & NM_134250 & Hepatitis A virus cellular receptor 2 & costimulation \\
\hline Icos & NM_017480 & Inducible T-cell co-stimulator & costimulation \\
\hline$\| 1 b$ & NM_008361 & Interleukin 1 beta & Cytokine \\
\hline 1110 & NM_010548 & Interleukin 10 & Cytokine \\
\hline $1112 b$ & NM_008352 & Interleukin 12B & Cytokine \\
\hline II13 & NM_008355 & Interleukin 13 & Cytokine \\
\hline $1117 a$ & NM_010552 & Interleukin 17A & Cytokine \\
\hline 1118 & NM_008360 & Interleukin 18 & Cytokine \\
\hline ॥12 & NM_008366 & Interleukin 2 & Cytokine \\
\hline$\| 21$ & NM_021782 & Interleukin 21 & Cytokine \\
\hline 114 & NM_021283 & Interleukin 4 & Cytokine \\
\hline II5 & NM_010558 & Interleukin 5 & Cytokine \\
\hline$\| 9$ & NM_008373 & Interleukin 9 & Cytokine \\
\hline Lep & NM_008493 & Leptin & cytokine \\
\hline Tgfa & NM_031199 & Transforming growth factor alpha & Cytokine \\
\hline Tgfb1 & NM_011577 & Transforming growth factor, beta 1 & Cytokine \\
\hline Tgfb2 & NM_009367 & Transforming growth factor, beta 2 & Cytokine \\
\hline Tgfb3 & NM_009368 & Transforming growth factor, beta 3 & Cytokine \\
\hline Tnf & NM_013693 & Tumor necrosis factor & Cytokine \\
\hline$\| 1 \mathrm{rl} 1$ & NM_010743 & Interleukin 1 receptor-like 1 & Cytokine receptor \\
\hline$\| 1 \mathrm{r} 1$ & NM_008362 & Interleukin 1 receptor, type I & Cytokine receptor \\
\hline$\| 1 \mathrm{r} 2$ & NM_010555 & Interleukin 1 receptor, type II & Cytokine receptor \\
\hline Il12rb2 & NM_008354 & Interleukin 12 receptor, beta 2 & Cytokine receptor \\
\hline Il13ra1 & $\mathrm{NM}_{-} 133990$ & Interleukin 13 receptor, alpha 1 & Cytokine receptor \\
\hline II17re & NM_145826 & Interleukin 17 receptor $\mathrm{E}$ & Cytokine receptor \\
\hline II18r1 & NM_008365 & Interleukin 18 receptor 1 & Cytokine receptor \\
\hline II18rap & NM_010553 & Interleukin 18 receptor accessory protein & Cytokine receptor \\
\hline
\end{tabular}


Table 2. PCR primer sequences.

\begin{tabular}{|l|l|}
\hline Gene & Assay ID \\
\hline MIG(CXCL9) & TaqMan Gene Expression Assay ID\# Mm00434946_m1 \\
\hline RANTES(CCL5) & TaqMan Gene Expression Assay ID\# Mm01302427_m1 \\
\hline MCP-1(CCL2) & TaqMan Gene Expression Assay ID\# Mm00441242_m1 \\
\hline PDL-1(CD 274) & TaqMan Gene Expression Assay ID\# Mm00452054_m1 \\
\hline PD1(pdcd1) & TaqMan Gene Expression Assay ID\# Mm01285676_m1 \\
\hline IL1R1 & TaqMan Gene Expression Assay ID\# Mm00434237_m1 \\
\hline IL-1 $\beta$ & TaqMan Gene Expression Assay ID\# Mm00434228_m1 \\
\hline IL-6 & TaqMan Gene Expression Assay ID\# Mm00446190_m1 \\
\hline IL-15 & TaqMan Gene Expression Assay ID\# Mm00434210_m1 \\
\hline IL-18 & TaqMan Gene Expression Assay ID\# Mm00434225_m1 \\
\hline TNF $\alpha$ & TaqMan Gene Expression Assay ID\# Mm00443258_m1 \\
\hline Nos2 & TaqMan Gene Expression Assay ID\# Mm00440502_m1 \\
\hline YM-1 & TaqMan Gene Expression Assay ID\# Mm00657889_mH \\
\hline Fizz1 & TaqMan Gene Expression Assay ID\# Mm00445109_m1 \\
\hline VEGF & TaqMan Gene Expression Assay ID\# Mm01281449_m1 \\
\hline TGF $\beta$ & TaqMan Gene Expression Assay ID\# Mm00441724_m1 \\
\hline CD 206(Mrc1) & TaqMan Gene Expression Assay ID\# Mm00485148_m1 \\
\hline IL-10 & TaqMan Gene Expression Assay ID\# Mm00439616_m1 \\
\hline & \\
\hline
\end{tabular}




\subsubsection{Isolation of graft infiltrating cells for flow cytometry}

Cells infiltrating the graft were isolated as previously described ${ }^{18}$. Briefly, grafts were removed after perfusing the recipient with RPMI media to flush cells from the circulation. The apical half of the graft was weighed and incubated $1 \mathrm{~h}$ at 37C in RPMI with Type II collagenase (Sigma- Aldrich) before pressing through a $40 \mu \mathrm{m}$ filter. The collected cells were washed twice in RPMI, counted and stained for phenotypic surface markers (CD45, CD4, CD11b, F4/80, PDL1, PD1 and IL1-R2 from BD Bioscience, San Jose, CA; eBioscience, San Diego, CA, USA). Flow cytometry was performed using a FACSCalibur (BD Biosciences) cytometer and FlowJo analysis software (Tree Star Inc., Ashland, OR, USA). The forward scatter and FL1 (CD45+) channels were used to gate on leukocytes followed by analysis of the specific leukocyte populations. For each sample, $2 \times 10^{5}$ events were accumulated.

\subsubsection{Quantitation of che mokines, hyaluronan and $\mathrm{IL-1}$ receptors in allografts}

Grafts were removed and homogenized in 500ul of proteinase inhibitor. Then 1 ml of $1.5 \%$ Triton X-100 in PBS was added before shaking 30 minutes at 4C. After pelleting cell debris, the supernatants were collected and total protein concentration quantified by Coomassie Plus Protein Assay Reagent kit (Pierce, Thermo Fisher Scientific, Rockford, IL). Protein concentrations were determined using ELISA kits for CXCL9, CCL5, CCL2 and hyaluronan from R\&D Systems (Minneapolis MN), and IL1R1 and IL-1R2 from US Biological (Marblehead MA). 


\subsubsection{Analysis of gene expression by quantitative RT-PCR}

Total RNA was isolated from interstitium and arterial compartment using RNeasy micro kit (Qiagen, Gaithersburg, MD) followed by cDNA preparation using RT2 PreAMP cDNA synthesis kit (QIAGEN, Gaithersburg, MD). PCR was performed with FAM dyelabeled probes (Applied Biosystems, Grand Island, NY) for mouse cd274 (PDL1), TLR2, TLR4, Actb and Mrpl32 (gene assay ID nos. Mm00452054_m1, Mm00442346_ml, Mm00445273_ml, Mm00607939_Sh and Mm00777741sH, respectively). The expression level of the housekeeping gene is subtracted from the expression level for each test gene. These gene expression levels were compared to the isograft controls.

\subsubsection{Statistical Analysis}

Statistical analyses were performed using GraphPad Prism 5.0 software (GraphPad Software Inc. San Diego, CA). Differences between groups for cell numbers and chemokine content were evaluated using an unpaired Student's t-test. 


\subsection{Results:}

\subsubsection{Hearts transplanted from male to female B6 undergo acute rejection that transitions into chronic re jection.}

Female recipients of male B6 hearts were sacrificed 2 or 6 weeks after transplantation to assess acute and chronic manifestations of rejection. At 2 weeks, allografts contained diffuse interstitial infiltrates of $\mathrm{T}$ cells and macrophages with limited periadventitial involvement of larger arteries (Figure 8A,B). By 6 weeks interstitial infiltrates diminished, and about half of the large arteries developed adventitial and intimal mononuclear infiltrates predominantly composed of macrophages (Figure 8C,D). Isograft controls did not exhibit pathological changes (Figure 9A- D).

Most macrophages in the acute and chronic lesions were intensely positive for Galectin-3, a marker of activated macrophages that contribute to cardiovascular disease 22, 23 . These macrophages were elongated with cytoplasmic projections and frequently formed clusters (Figure 8B inset). Few macrophages in either the acute or chronic infiltrates were positive for Ym-1, a marker for M2 macrophages ${ }^{10}$. Moreover, these M2 macrophages were scattered as individual large ovoid cells (Figure 10A,B). We also 
found limited numbers of Foxp3 positive regulatory $\mathrm{T}$ cells in interstitial and arterial compartments (Figure 10C,D).
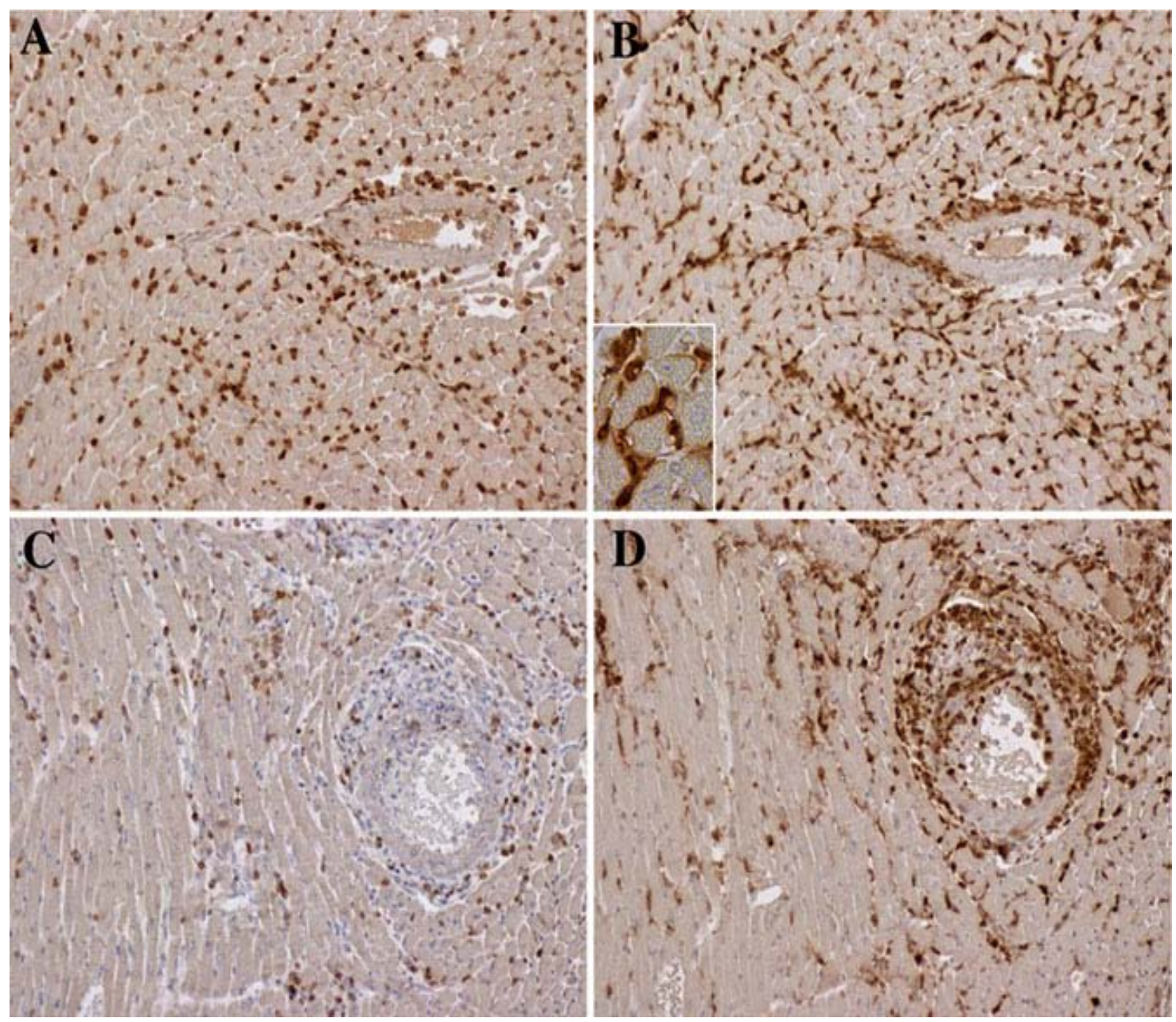

Figure 8. Immunoperoxidase stains of acute and chronic infiltrates in cardiac allografts. At 2 weeks (top row), allografts contained a diffuse interstitial infiltration of CD3 T cells (A) and Galectin- $3^{+}$macrophages (B) with limited periadventitial involvement of larger arteries (right side of figures). The macrophages displayed cytoplasmic projections on high power (inset). At 6 weeks, the interstitial infiltrates diminished, and large arteries developed adventitial and intimal infiltrates composed of CD3 T cells (C) and larger numbers of macrophages (D). Original magnifications 200x (inset 600x). 

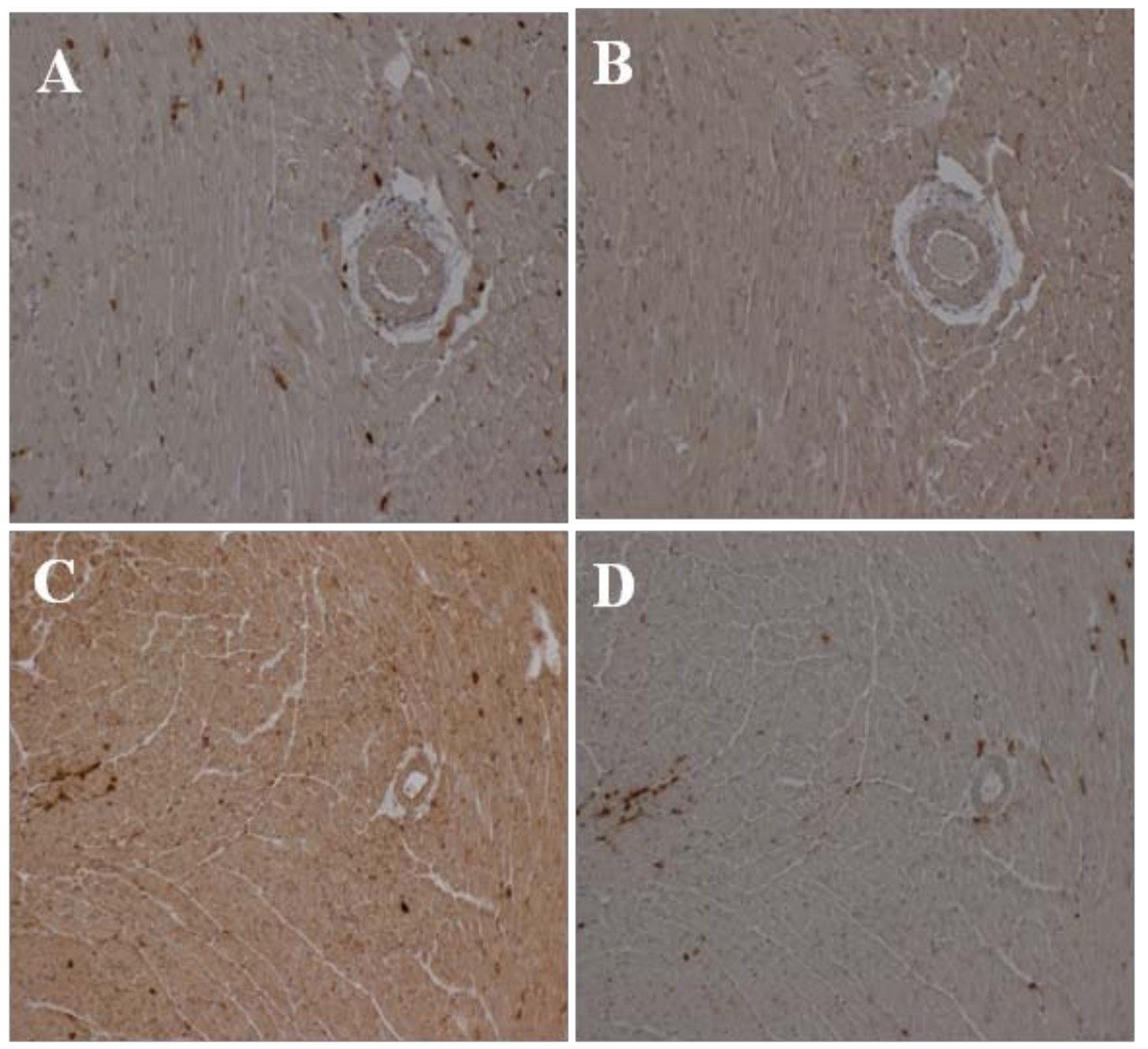

Figure 9. Immunoperoxidase stains of mononuclear infiltrates in cardiac isograft at 2 and 6 weeks in wild type recipients. At 2 weeks (top row), male cardiac isografts to wild type male recipients contained few CD3 T cells (A) and Galectin-3 positive macrophages (B) with no pathology. At 6 weeks (second row), the male cardiac isografts to wild type male recipients contained few CD3 T cells (C) and Galectin-3 positive macrophages (D) with no pathology. Original magnifications 200x. 

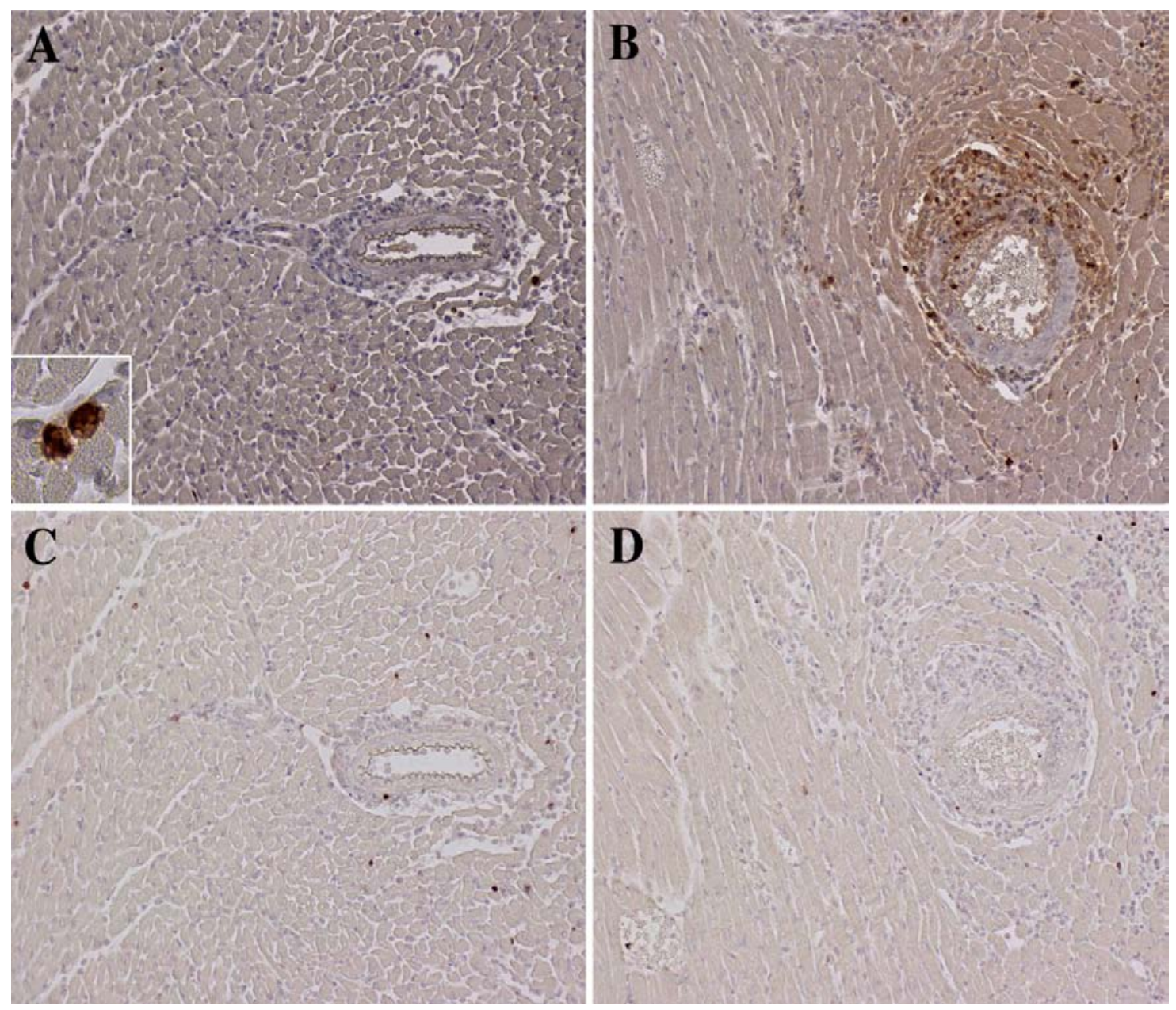

Figure 10. Only limited numbers of macrophages in either the 2 week (A) or 6 week (B) infiltrates were positive for Ym-1 (Chitinase 3-like 3) a marker for M2 macrophages. These M2 macrophages were scattered as individual large ovoid cells (inset). Limited numbers of Foxp3 positive regulatory T cells were present both in interstitial and arterial compartments at 2 weeks (C) and 6 weeks (D).

\subsubsection{CD4 T-cells orchestrate acute and chronic rejection}

Because H-Y peptides are presented in the context of MHC class II molecules, we tested the requirement for CD4 T cells in generating acute and chronic pathology. Hearts 
were transplanted from wild type male B6 mice into female B6 Rag1 deficient recipients (B6.RAG-/-), which lack mature $\mathrm{T}$ and $\mathrm{B}$ cells. One week later we reconstituted the recipients with 2-3x10 $4 \mathrm{CD} 4 \mathrm{~T}$ cells from transgenic female $\mathrm{B} 6$ mice that express $\mathrm{T}$ cell receptors for H-Y peptides in the context of H2-IAb (Marilyn mice). Female B6.RAG-/recipients were sacrificed at 2 and 6 weeks after cell transfer. Two control groups were used: Isografted hearts from female B6 mice into female B6.RAG-/- recipients, which were reconstituted with $2 \times 10^{4} \mathrm{CD} 4 \mathrm{~T}$ cells from Marilyn transgenic mice, and allografted hearts from male B6 mice into female B6.RAG-/- recipients, which were not reconstituted. In the absence of $\mathrm{T}$ cell reconstitution, no infiltrates developed in the male B6 cardiac allografts to female B6.RAG-/- recipients (Figure 11A, B). Similarly, CD4 T cells from Marilyn mice did not cause infiltrates in isografts to female B6.RAG-/recipients at either 2 (Figure 11C, D) or 6 (Figure 11E, 4F) weeks. However, CD4 T cells from Marilyn mice reconstituted acute interstitial infiltrates that progressed to CAV in male B6 cardiac allografts to female B6.RAG-/- recipients. As in wild type recipients, both acute and chronic infiltrates were composed of $\mathrm{T}$ cells and macrophages, but activated macrophages predominated (Figure 12A-D). An additional group of mice sacrificed at 10 weeks had more extensive arterial lesions in their allografts, but the $\mathrm{T}$ cells had diminished (Figure 12E), and macrophages increased (Figure 12F). At this time, the neointima had progressed to contain alpha-smooth muscle expressing cells (Figure 13). 

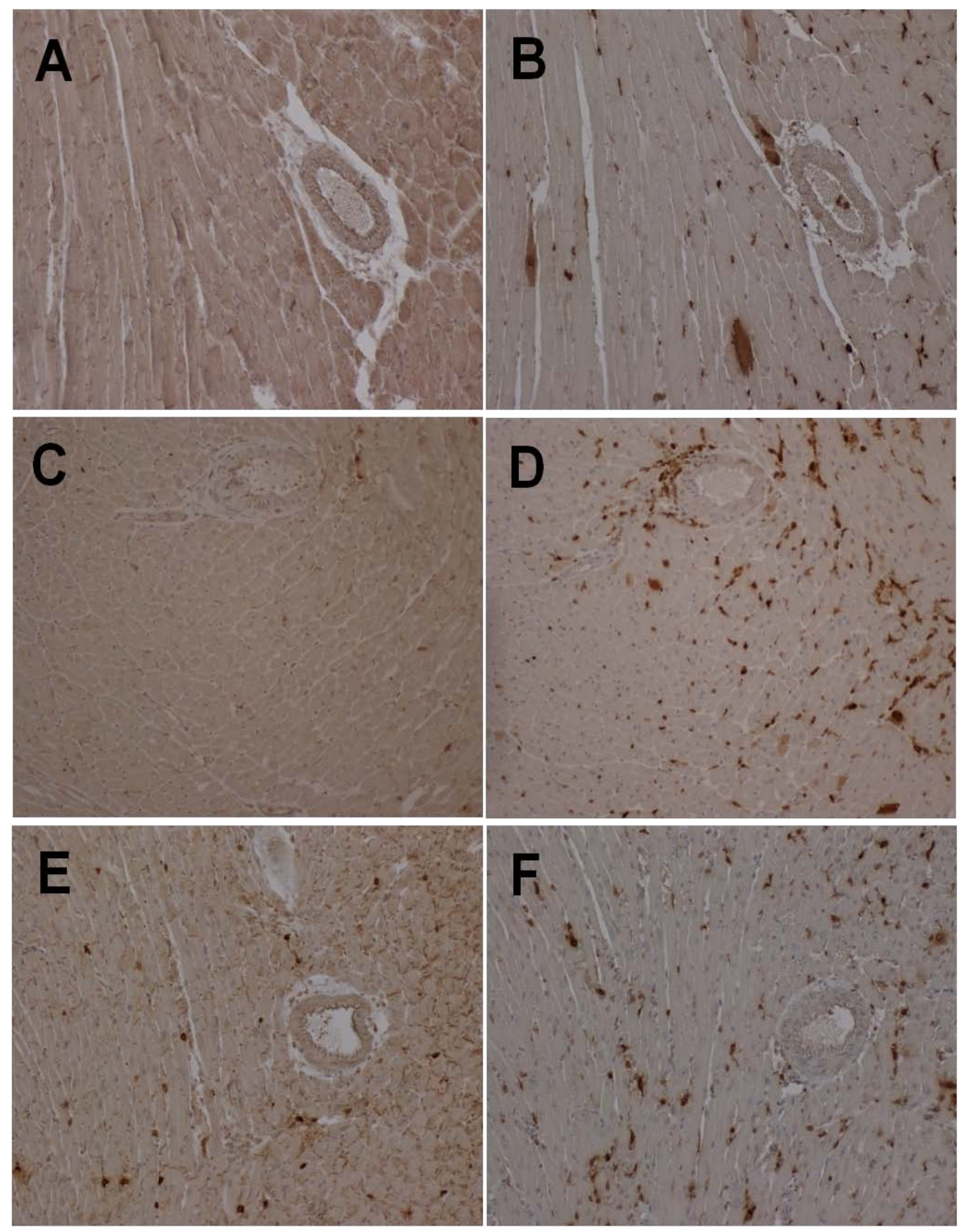

Figure 11. Immunoperoxidase stains of mononuclear infiltrates of CD3 (A) and Macrophages (B) in cardiac allograft at 2 weeks in Rag1-/- recipients with male wild type heart. Female wild type heart transplanted to female $\mathrm{RAG}^{-/-}$recipients reconstituted with Marilyn CD4 T cells, contained few CD3 T cells (C) and Galectin-3 positive macrophages (D) at 2 weeks. At 6 weeks, no arteries developed vaculopathy and only few CD3 $T$ cells (E) and few Galectin-3 positive macrophages (F). Original magnifications 200x. 

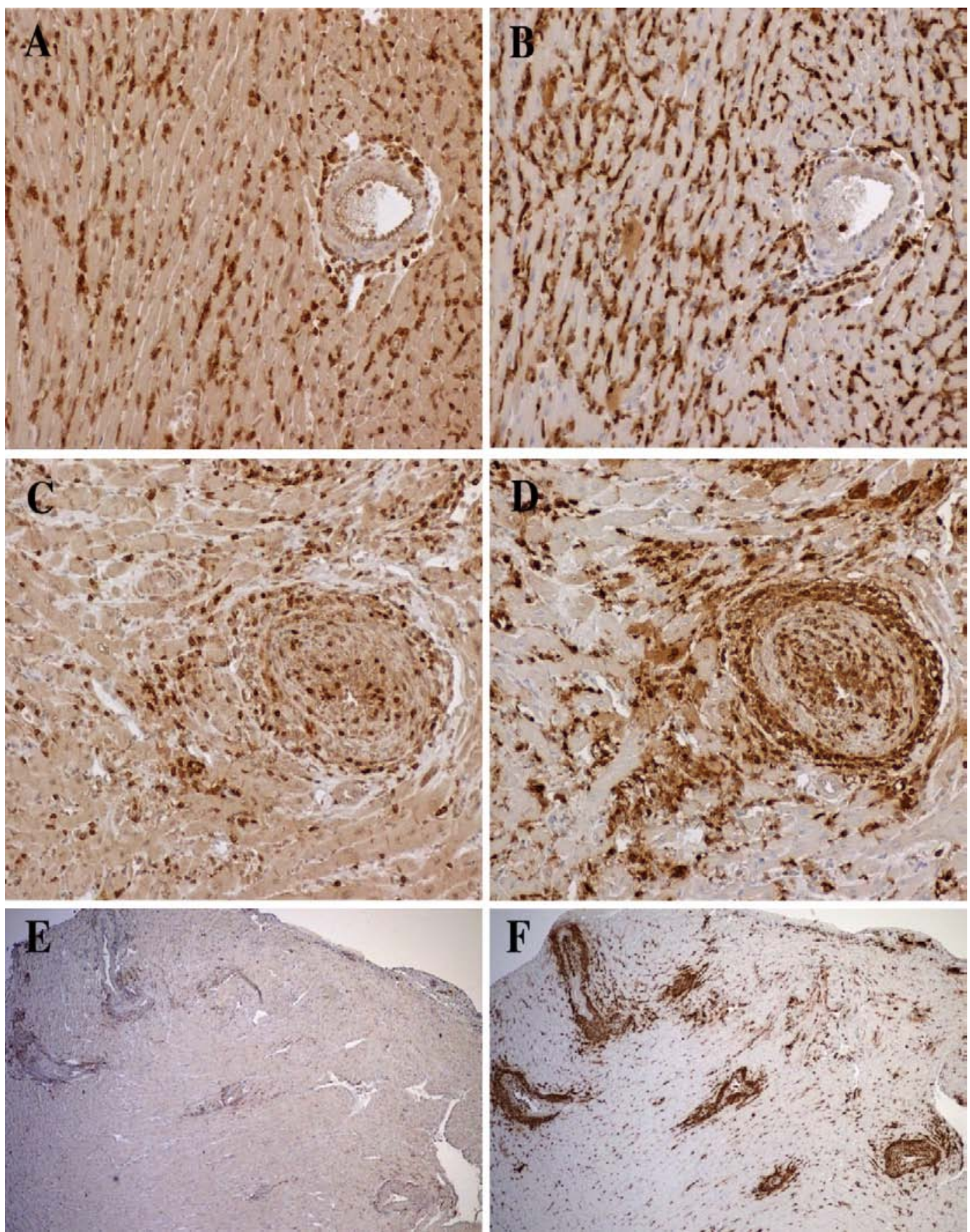

Figure 12. Male hearts transplanted to female $\mathrm{RAG}^{-/}$recipients reconstituted with Marilyn CD4 T cells. At 2 weeks, allografts contained diffuse interstitial infiltrates of 
CD3 $\mathrm{T}$ cells (A) and Galectin- $3^{+}$macrophages (B) with limited periadventitial involvement of larger arteries. At 6 weeks, the interstitial infiltrates diminished, and large arteries developed adventitial and intimal infiltrates of CD3 T cells (C) and large numbers of macrophages (D). At 10 weeks, the arterial lesions contained decreased numbers of CD3 T cells (E), and increased macrophages (F). Original magnifications 200x (A-D) and 40x (E, F).
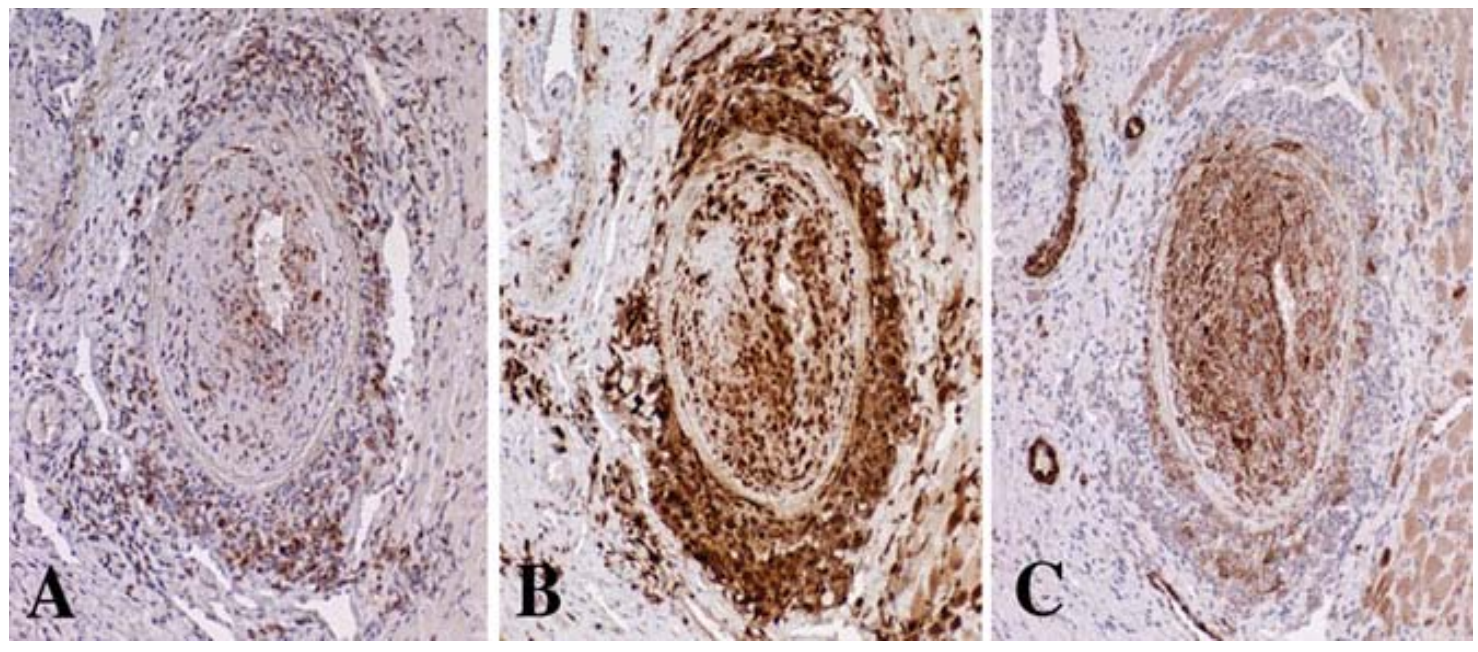

Figure 13. Male hearts transplanted to female $\mathrm{RAG}^{-/}$recipients reconstituted with Marilyn CD4 T cells and sacrificed at 10 weeks. Large artery with limited numbers of T cells (A), large numbers of macrophages in the neointima as well as adventitia (B), and alpha-smooth muscle expressing cells in the neointima (C). Original magnifications 200x.

\subsubsection{Mediators expressed more highly in the interstitial than in the arterial compartments during acute and chronic rejection}

Laser capture microdissection was used to isolate tissue from the interstitial and arterial compartments of allografts and isografts (Figure 14). Real Time PCR array 
analysis was performed on tissue captured from the two compartments to evaluate the expression of 86 different genes in a single plate. Table 3 lists the most highly upregulated genes in the interstitium of allografts compared to isografts at 2 and 6 weeks. These included the chemokines MIG (CXCL9), RANTES (CCL5) and MCP-1 (CCL2); the co-stimulatory molecules B7-1/ CD80, B7-2/ CD86, and PDL1 (CD274); IL-1 receptors (IL1R1 and IL1R2); the Toll like Receptors TLR2 and TLR4. The chemokine genes were more highly upregulated at 2 weeks than at 6 weeks in the interstitium of allografts compared to isografts. In contrast, TLR2 and 4 increased with time after transplantation.

Because MIG and MCP-1 are produced by M1 inflammatory macrophages, additional microdissections were performed and the captured tissues were probed for 6 markers for M1 macrophages (IL-1beta, IL-6, IL-15, IL-18, TNFalpha and Nos2), all of which were increased more in the interstitium than in the arterial compartment at 2 weeks (Figure 15B). By 6 weeks, all of the M1 markers had decreased in the interstitium and increased in the arterial compartment. Changes in MIG and MCP-1 were congruent with the M1 markers in these samples (Figure 15A). The converse was found for five markers for M2 macrophages (Ym1, Fizz1, VEGF, TGFbeta, and CD206), which were more elevated in the arterial compartment than in the interstitum at 2 weeks (Figure 15C). By 6 weeks, these M2 markers had decreased in the arterial compartment and increased in the interstitium. The exception to this pattern was IL-10, which was most elevated acutely in the interstitium, but was elevated in at 2 and 6 weeks in both compartments (Figure 15C). 
Chemokine expression was confirmed on the protein level by ELISA on tissue homogenates of allografts. These homogenates were prepared from the apex of the heart that contains myocardium but no large arteries, and therefore, sampled the interstitial compartment. MIG, RANTES and MCP-1 were all elevated at 2 weeks and diminished by 6 weeks in parallel with interstitial infiltrates (Figure 16A).

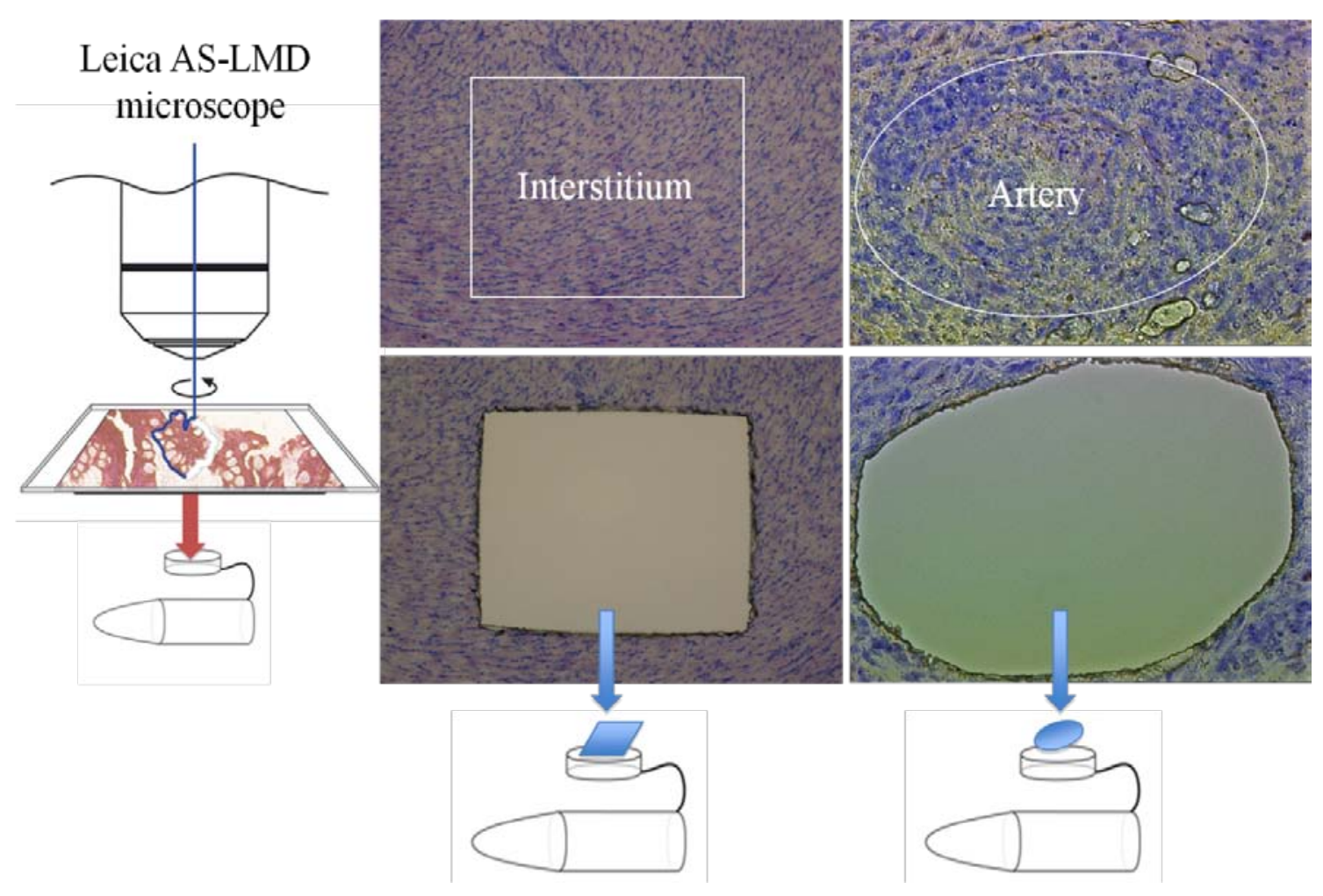

Figure 14. Procurement of individual vascular compartments laser capture microdissection method allowed for the separate dissection of the mouse interstitium and coronary arteries. 
Table 3. Genes upregulated in microdissected allografts expressed as fold change compared to isograft.

\begin{tabular}{|l|l|l|l|l|}
\hline GENE & $\begin{array}{l}2 \text { week } \\
\text { Interstitium }\end{array}$ & $\begin{array}{l}\text { 6 week } \\
\text { Interstitium }\end{array}$ & $\begin{array}{l}\text { 2 week } \\
\text { Artery }\end{array}$ & $\begin{array}{l}\text { 6 week } \\
\text { Artery }\end{array}$ \\
\hline MIG (CXCL9) & 139 & 21 & 16 & 51 \\
\hline RANTES (CCL5) & 46 & 12 & 7.5 & 34 \\
\hline MCP-1 (CCL2) & 15 & 7 & 4.5 & 8 \\
\hline CD80/B7-1 & 50 & 6 & 2.5 & 2 \\
\hline CD86/B7-2 & 225 & 225 & 41 & 8 \\
\hline CTLA4 & 7 & 4 & 2.5 & 2 \\
\hline CD274 (PDL1) & 70 & 40 & 47 & 8.5 \\
\hline IL1R1 & 10 & 20 & 10 & 20 \\
\hline IL1R2 & 205 & 4 & 540 & 2 \\
\hline TLR2 & 10 & 175 & 30 & 11 \\
\hline TLR4 & 75 & 225 & 76 & 700 \\
\hline
\end{tabular}




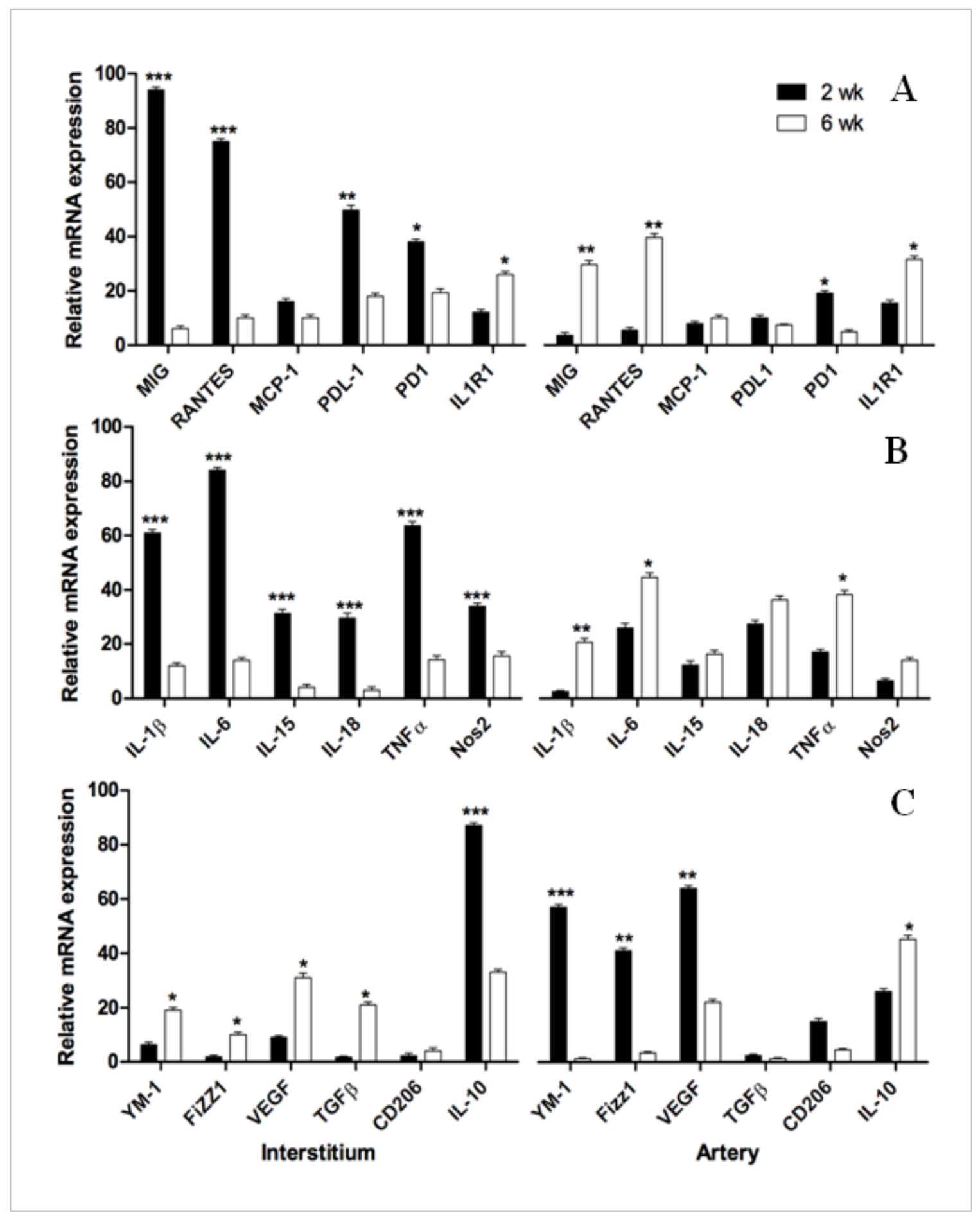

Figure 15. Quatitative PCR on 3 microdissected allografts at 2 and 6 weeks expressed as fold change relative to isografts from the same time points. Confirmation of key cytokines, receptors and ligands from the initial PCR array (A). Markers for M1 inflammatory macrophages are consistently higher in the interstium (left panel) at 2 weeks (filled bars) than at 6 weeks (open bars), whereas in the arterial compartment (right panel) these markers are low at 2 weeks and increase by 6 weeks (B). In contrast, 
the converse occurs for markers of M2 wound healing macrophages with the exception of IL-10 (C). Error bars represent standard errors of the mean of 3 allografts. Differences between 2 and 6 week values were significant at the $\mathrm{P}<0.05^{*}$; $<0.01^{* *}$; or $<0.001^{* * *}$ level as indicated.
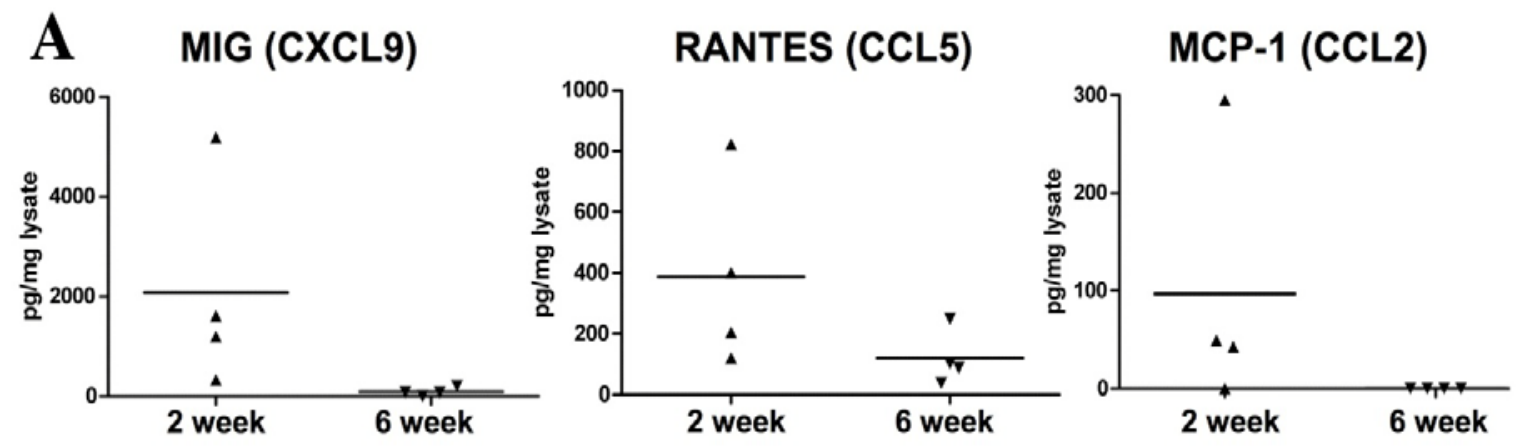

Figure 16A. Confirmation of expression of chemokines by ELISA. MIG, RANTES and MCP-1 were elevated at 2 weeks and then diminished by 6 weeks in the homogenates of myocardium from cardiac allografts (A).

\subsubsection{Expression of IL-1R2 and PDL1 by cells in the circulation and infiltrating grafts}

Because of the potential importance of the decoy receptor for IL-1 and negative co-stimulatory signals for $\mathrm{T}$ cells in resolving the acute interstitial infiltrates, we investigated the expression of IL-1R2 and PDL1 in more detail. IL-1R2 protein was elevated in the graft homogenates at 2 weeks by ELIS A (Figure 16B).

The increase in PDL1 in interstitial compared to arterial tissue at 2 weeks and 6 weeks was confirmed by qPCR analysis (Figure 16G). Flow cytometry on cells isolated from the allografts at 2 weeks demonstrated that about 25-30\% of CD45 labeled cells were F4/80+ macrophages, and PDL1 was expressed by almost $80 \%$ of these 
macrophages (Figure 16C). This represented a major enrichment compared to the low percentage of circulating monocytes that expressed PDL1 (16 $\pm 0.6 \%$; Figure 16D). Local expansion may contribute to the enrichment of PDL1 expressing macrophages in the graft because many of the macrophages labeled with the proliferation marker Ki67 in the interstitial and arterial compartments (Fig 16E, 16F).

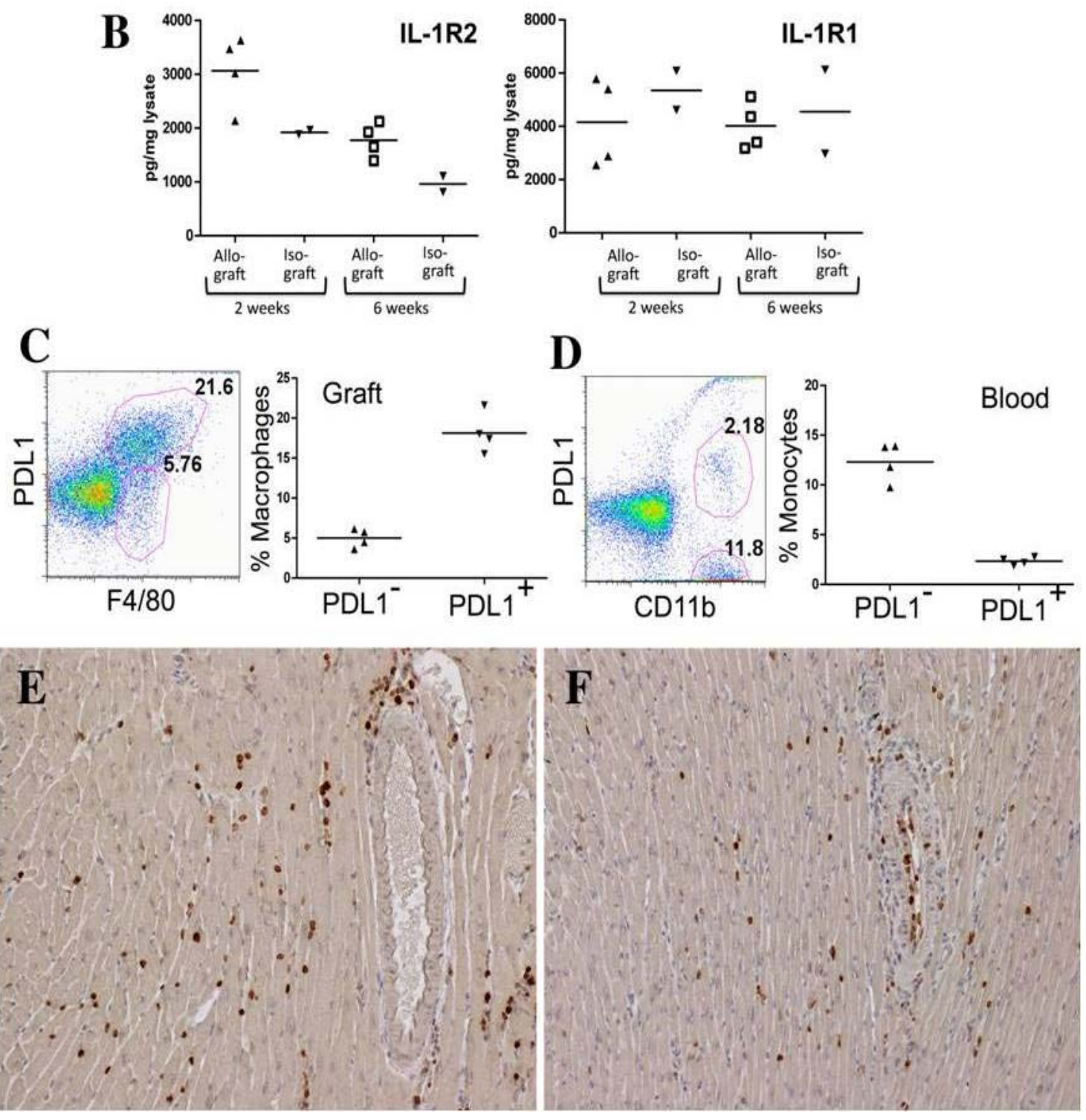




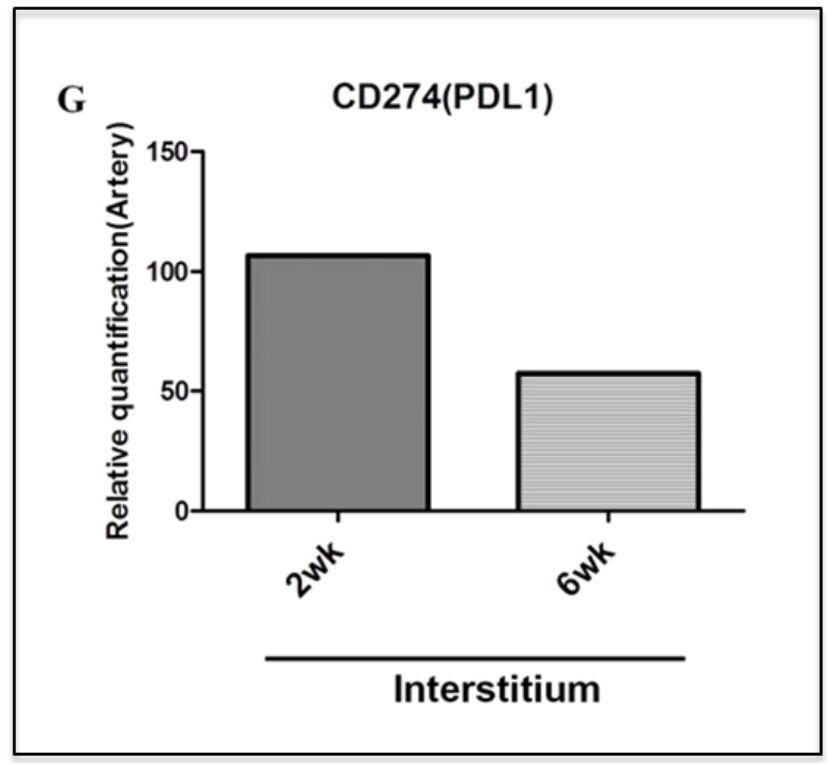

Figure 16 (B-G). Confirmation of expression of the decoy receptor for IL-1 and negative co-stimulatory ligand PDL1 by ELIS A and flow cytometry. IL-1R2 was also elevated in the allograft compared to isograft homogenates at 2 weeks and to a lesser degree at 6 weeks by ELISA (B). Flow cytometry demonstrated that PDL1 was expressed by majority the $\mathrm{F} 4 / 80^{+}$macrophages that were infiltrating the allografts at 2 weeks $(\mathrm{C})$. This represented a major enrichment compared to the limited percentage of circulating monocytes that expressed PDL1 (D). Local expansion may contribute to the enrichment of PDL1 expressing macrophages in the graft because many of the macrophages labeled with the proliferation marker Ki67 at 2 weeks (E) and 6 weeks (F). Each symbol in the scattergams represents data from an individual animal. Levels of CD274 (PDL1) mRNA in interstitial compared to arterial tissue in allografts at 2 weeks and 6 weeks as measured by qPCR (G).

\subsubsection{Blocking PDL1 early prevents resolution of acute interstitial infiltrates}

The effects of blocking the negative signals delivered by PDL1 on acute interstitial infiltrates was tested by treating female B6 recipients of male cardiac allografts with monoclonal antibody to PDL1 or isotype control antibody on days 8, 10 
and 12. By 15 days, $50 \%$ of animals treated with antibodies to PDL1 had completely rejected their allografts while no grafts were rejected in the control group (Table 4). The grafts were removed at this time for evaluation. Blockade of PDL1 caused a greater than two-fold increase in interstitial infiltrates of CD3+ $\mathrm{T}$ cells and PD1expressing cells compared to the control group (Figure 17A-E), but did not increase arterial pathology. Double staining demonstrated that many cells co-expressed CD3 and PD1; single positive CD3 and PD1 cells were also detected (Figure 18).

To determine whether blockade of PDL1 would modulate chronic arterial pathology, we delayed treatment with antibody to PDL1 to days 34,36 and 38 . All the allografts continued functioning in recipients treated either with antibody to PDL1 or isotype controls and sacrificed at 6 weeks after transplantation. Blocking PDL1 caused about a 2 fold increase in number of CD3 and PD1 cells in the interstitium compared to control treated group, but the absolute numbers of cells was almost $50 \%$ lower than at 2 weeks after transplantation (Figure 17E,F). Treatment with PDL1 antibody at this later period after transplantation did not increase vascular pathology. 
Table 4. Cardiac allograft survival after treatment with blocking antibodies to

\section{PDL1.}

\begin{tabular}{|c|l|}
\hline Group & Survival (days) \\
\hline Acute $^{*}$ & $>15(4)$ \\
\hline Control & $15,15,>15(2)$ \\
\hline Anti-PDL1 & \\
\hline Chronic** & $>42(4)$ \\
\hline Control & $>42(4)$ \\
\hline Anti-PDL1 & \\
\hline
\end{tabular}

* Recipients were injected intraperitoneally with 3 doses of 200ug of purified IgG2a rat monoclonal antibody to PDL1 (clone 10F.9G2) or 200ug of isotype control (clone LTF2) antibody (BioXCell, West Lebanon, NH) on days 8, 10 and 12 and sacrificed on day 15.

** Recipients were injected intraperitoneally with 3 doses of 200ug of purified IgG2a rat monoclonal antibody to PDL1 (clone 10F.9G2) or 200ug of isotype control (clone LTF2) antibody (BioXCell, West Lebanon, NH) on days 34, 36 and 38 and sacrificed on day 42. 

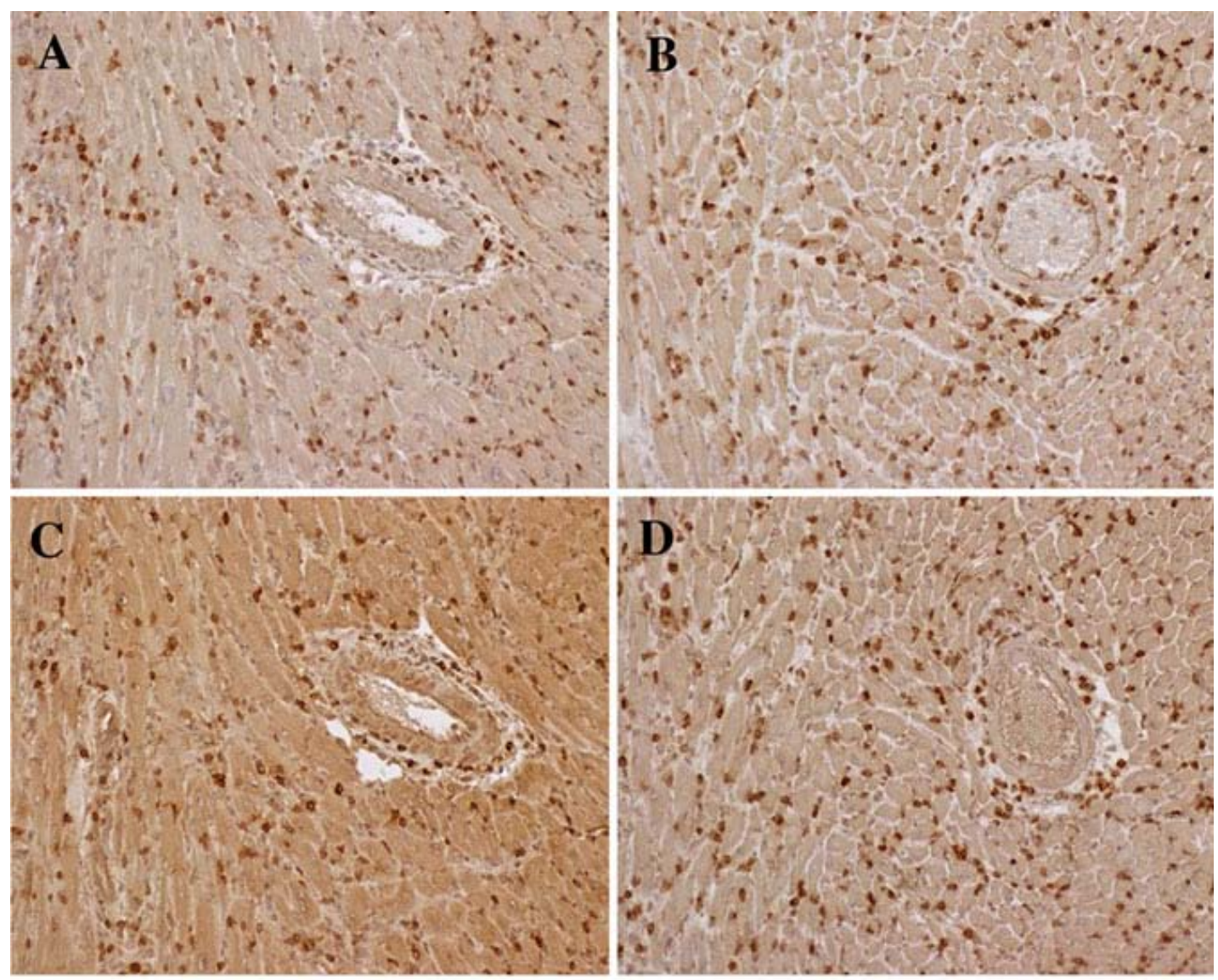

$\mathbf{E}$

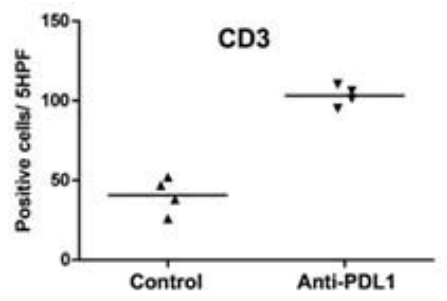

$\mathbf{F}$

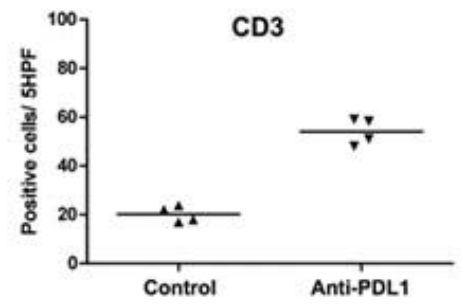

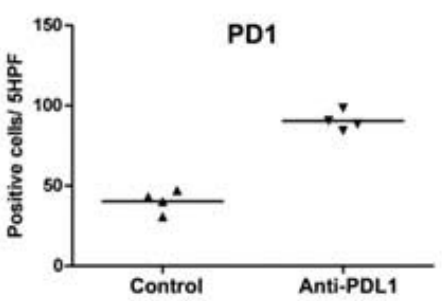

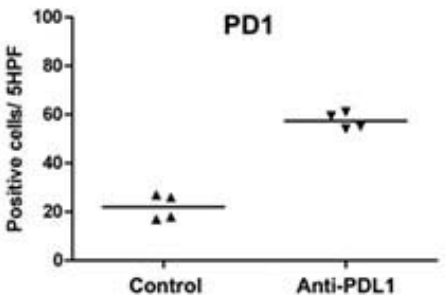

Figure 17. Immunohistology and cell counts from mice treated with blocking antibodies to PDL1. Administering blocking antibody to PDL1 on days 8, 10 and 12 increased interstitial infiltrates of $\mathrm{CD}^{+}$T cells (B) and $\mathrm{PD}^{+}$(D) cells compared to controls (A and $\mathrm{C}$, respectively) at 2 weeks. Blocking PDL1 did not increase arterial pathology at 2 weeks 
(right side of panels A-D). Cell counts per 5 high power fields verified about a 2-fold increase in CD3 and PD1 expressing cells at 2 weeks (E) and 6 weeks (F), but there was an overall decrease in cells from 2 to 6 weeks. Each symbol in the scattergrams represents an individual animal. All differences between control and anti-PDL-1 treated mice were significant $<0.05$.

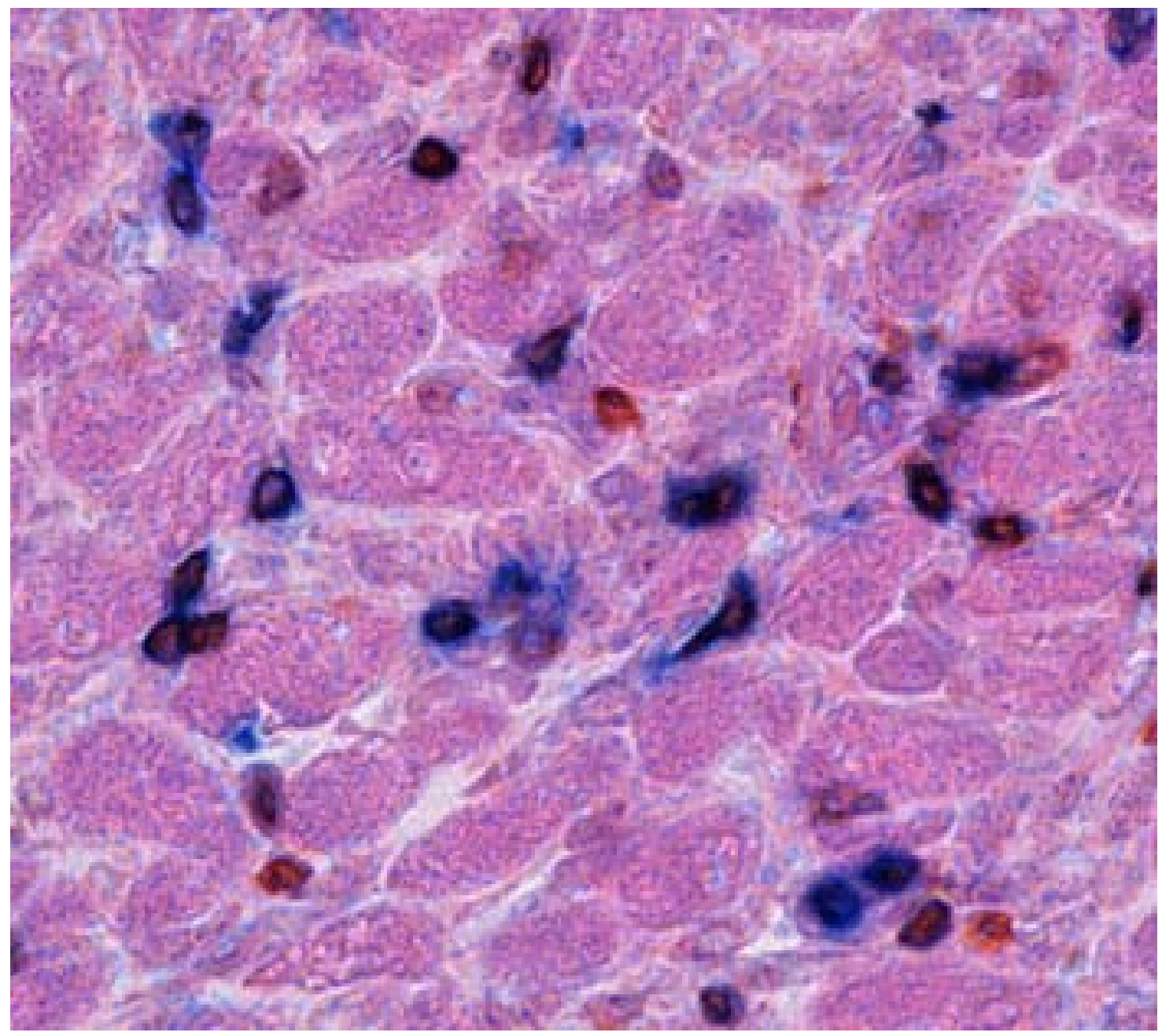

Figure 18. Immunohistology of acute interstitial infiltrates in allograft following treatment with blocking antibodies to PDL1. Double stain for CD3 (brown) and PD1 (blue) demonstrates the majority of cells express both CD3 and PD1 (original magnification 600x). 


\subsubsection{Effect of blocking PDL1 early on mediators in the interstitial and arterial compartments}

Allografts to recipients treated with blocking antibody to PDL1 and control recipients were microdissected for PCR analysis to determine changes associated with accelerated rejection. Blocking PDL1:PD1 interactions caused an additional increase in MIG, RANTES, MCP-1 and IL-1R1 as well as IL-1beta, IL-6, TNFalpha and Nos2 in the interstitium, but not in the arterial compartment at 2 weeks (Figure 19B,C). M2 macrophage markers were increased to a lesser extent (Figure 19D).

The chemokine expression was confirmed on the protein level by ELIS A on homogenates of control and experimental allografts. All three chemokines were upregulated by treatment with antibodies to PDL1 (Figure 19A). However, these chemokines were more highly expressed at 2 weeks than at 6 weeks. 

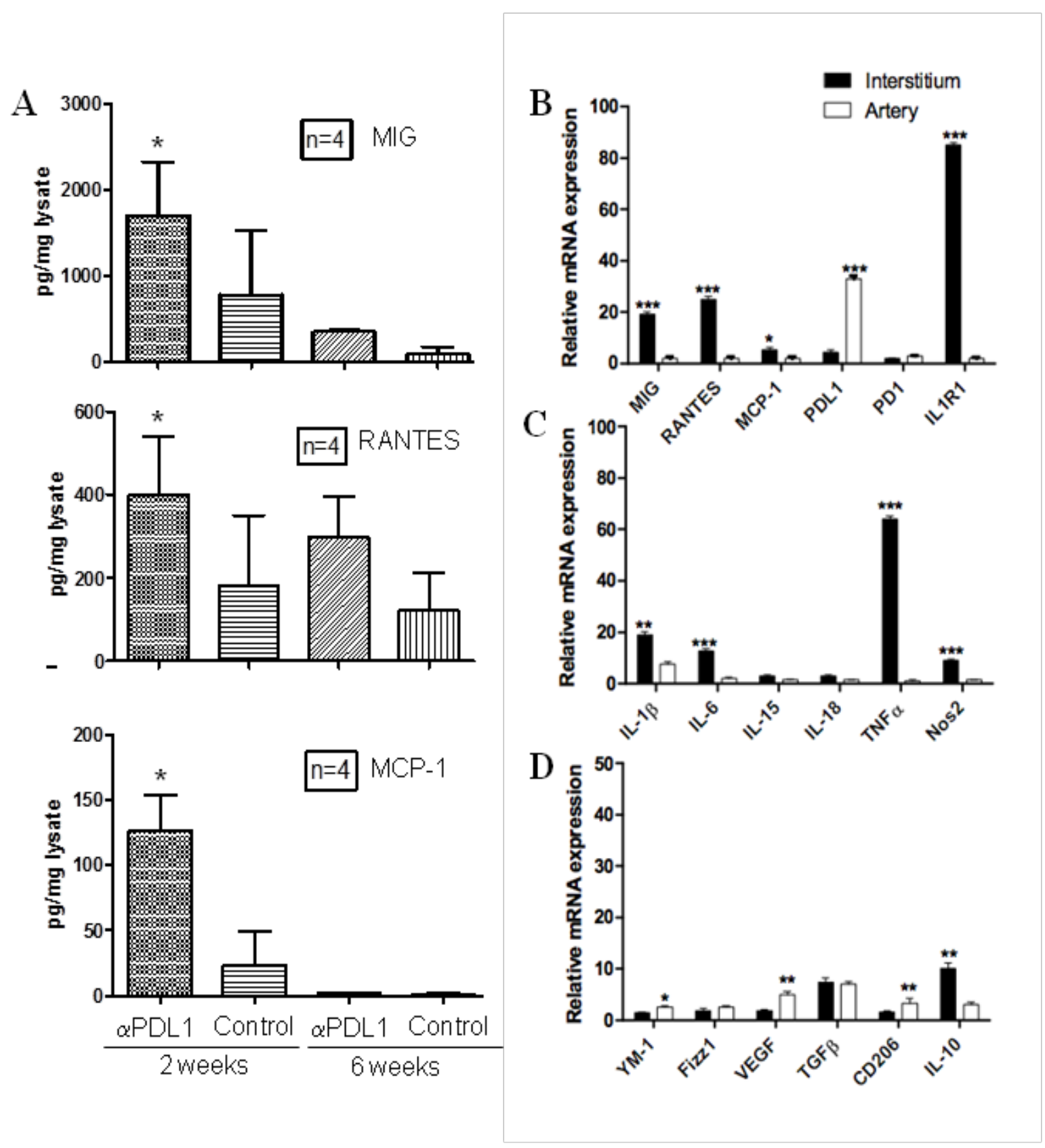

Figure 19. Treatment with blocking antibodies to PDL1 resulted in increased expression of MIG, RANTES and MCP-1 in allografts by ELIS A that was greater at 2 weeks than 6 weeks (A). These samples were taken from the apex of the hearts which contains few large arteries. Microdissection of allografts at 2 weeks demonstrated levels of MIG, RANTES, MCP-1, IL-1R1, IL-1beta, IL-6 TNFa and Nos2 were greater in the interstitium than the arterial compartment $(\mathrm{B}, \mathrm{C})$. M2 macrophage markers were changed to a lesser extent (D). Bars represent average of 3-4 samples in each group. PCR results represent fold changes compared to allografts treated with control antibody. Differences 
between interstitial and arterial values were significant at the $\mathrm{P}<0.05^{*}$; $<0.01^{* *}$; or $<0.001^{* * *}$ level as indicated.

\subsubsection{TLR4 and hyaluronan are upregulated in the arterial compartme nt during chronic rejection}

PCR array analysis showed IL1R2 and TLR4 were the most upregulated genes in the microdissected arterial compartment in allografts compared to isografts at 2 weeks. By 6 weeks, IL1R2 had decreased and TLR4 had dramatically increased (Table 3). This was confirmed by qPCR analysis (Figure 20).

Among the endogenous ligands reported for TLR4 is fragmented hyaluronan, an extracellular matrix component that is known to be upregulated in various forms of arterial injury. Increased amounts of hyaluronan were detected by ELISA in homogenates of allografts at 2 and 6 weeks compared to isografts (Figure 21A). Immunohistology demonstrated increased hyaluronan in the interstitium at 2 weeks and in the neointimal lesions and surrounding adventitial infiltrates of arteries as well as the interstitium of cardiac allografts at 6 weeks (Figure 21B). Immunofloresence on allograft artery showed HA expression (Figure 22A) compared to non specific control (Figure 22B). In isografts, hyaluronan was present as a compact band in the adventitia (Figure 21C). CD44, which is

the dominant receptor for hyaluronan, was expressed by the cells infiltrating the neointima and adventitia (Figure 23). 

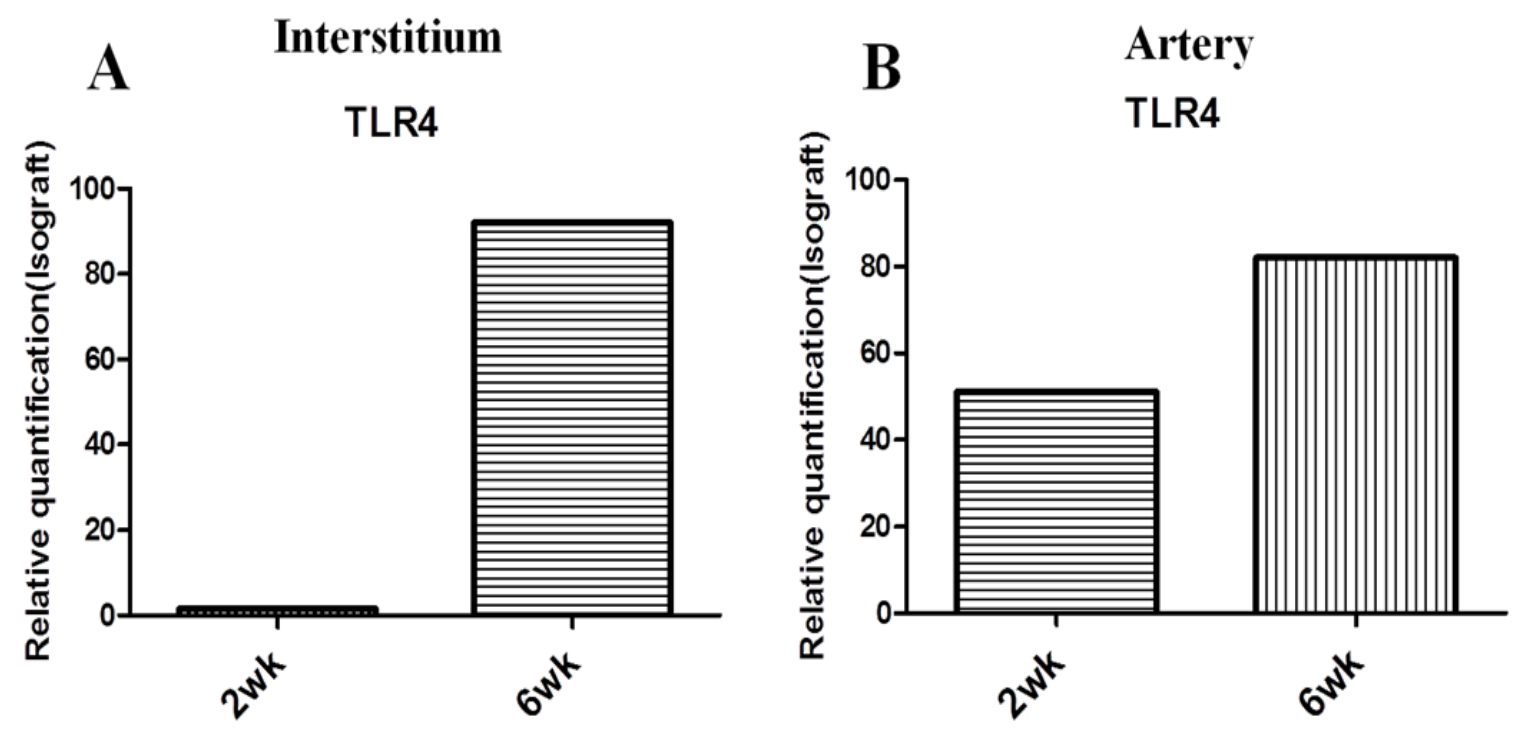

Figure 20. TLR4 quantification by qPCR analysis on interstital and arterial tissue from allografts relative to isografts at 2 and 6 weeks. 


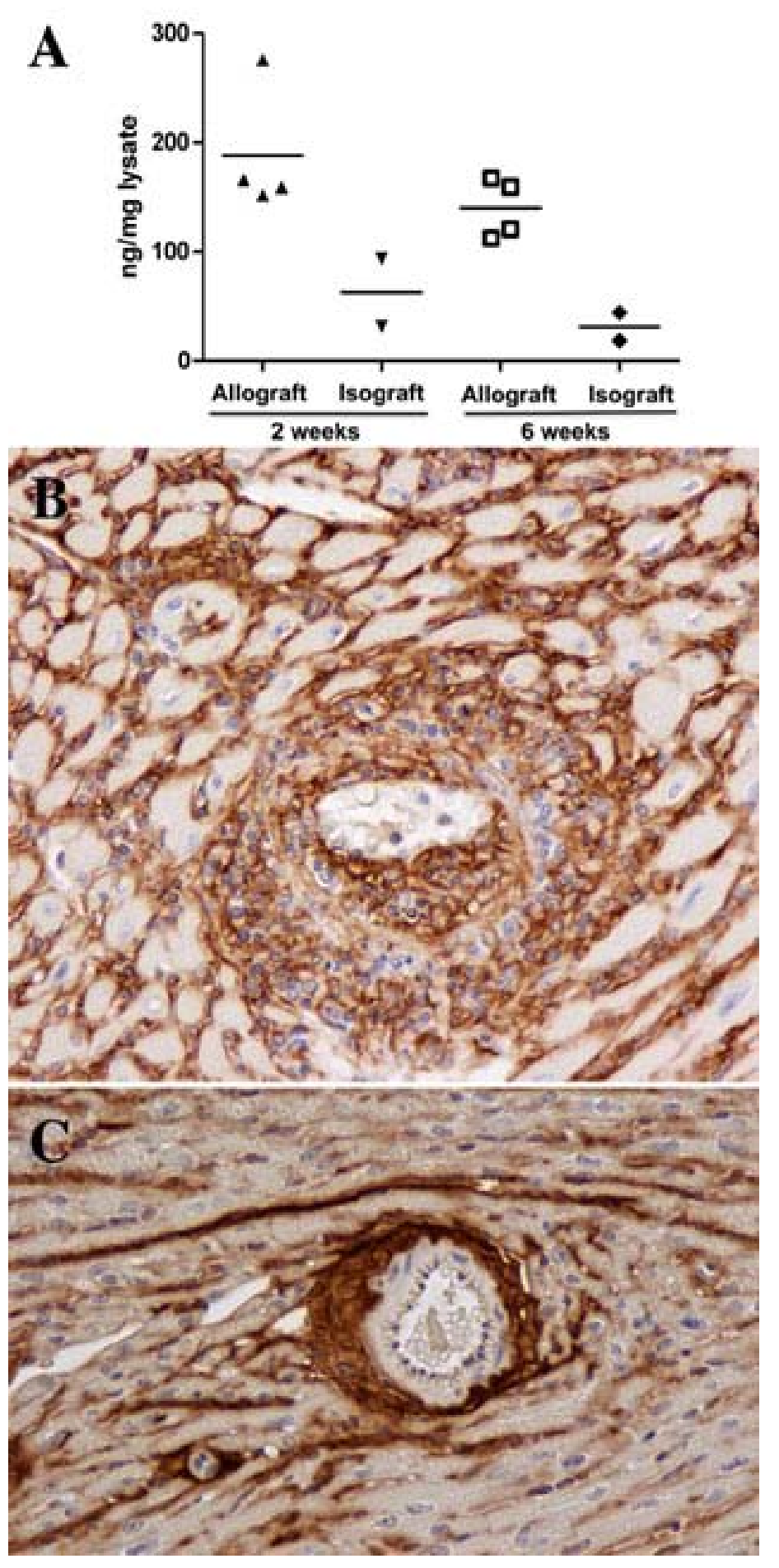

Figure 21. Upregulation of hyaluronan in the arterial compartment at 6 weeks. ELISA measurements of hyaluronan in allografts and isografts (A). Differences at 6 weeks were significant $\mathrm{P}<0.01$. Hyaluronan surrounded infiltrating mononuclear cells in the neointimal lesions and adventitia of arteries as well as the interstitium of the graft (B). In 
isografts, hyaluronan formed a compact band in the adventitia of large and smaller arteries with limited amounts in the interstitum (C). Original magnifications 200x.

6 week Artery-HA

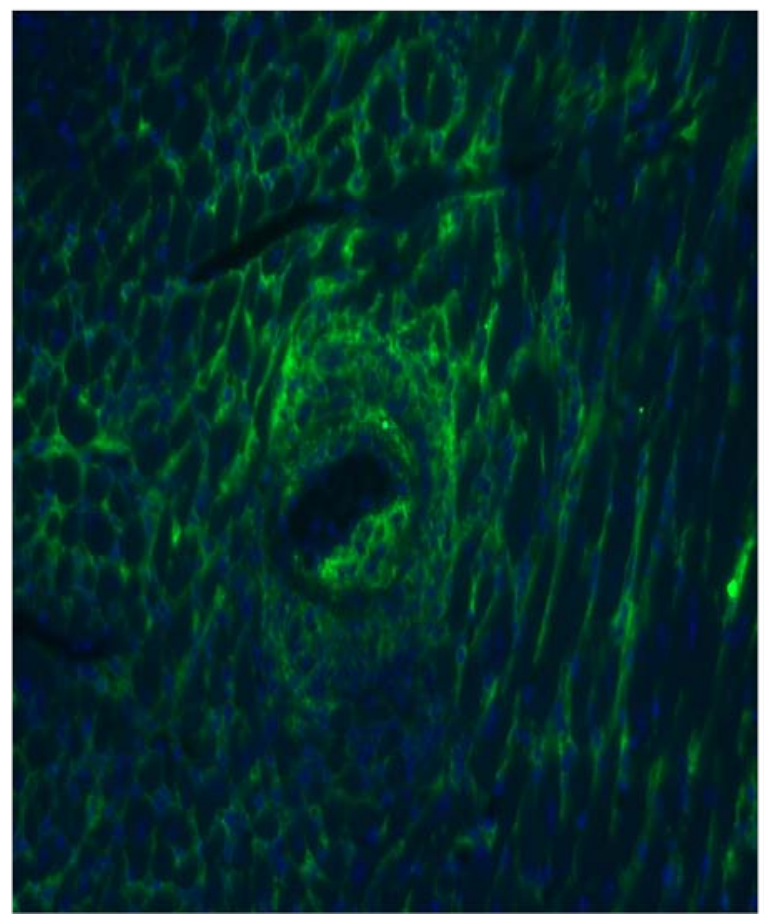

6 week Artery-Nonspecific control

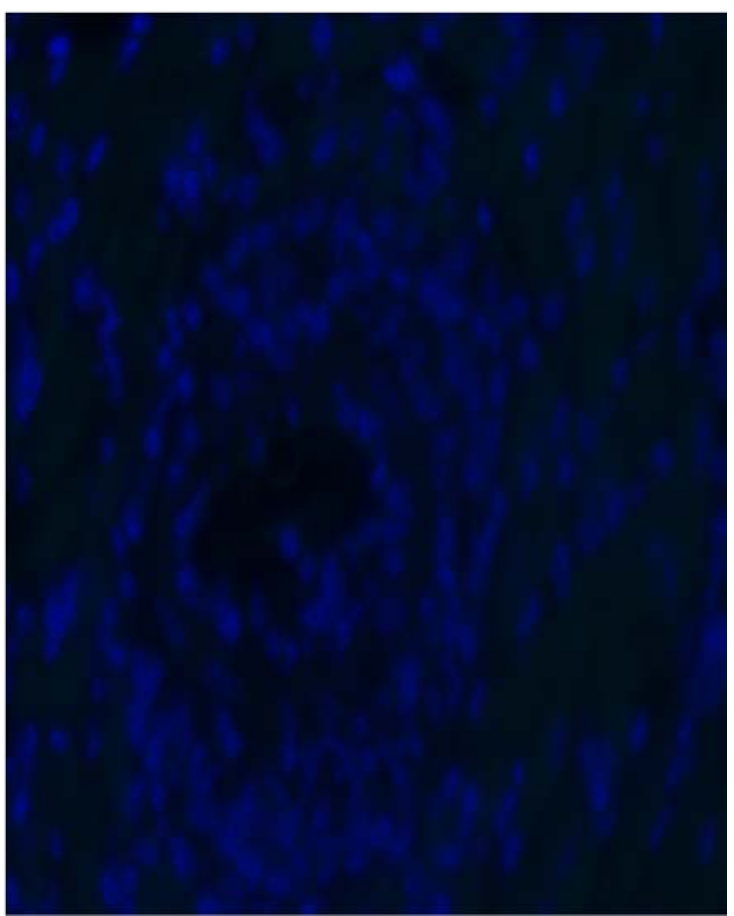

Figure 22. Immunofloresence showing HA expression in allograft artery (A) and non specific control(B).
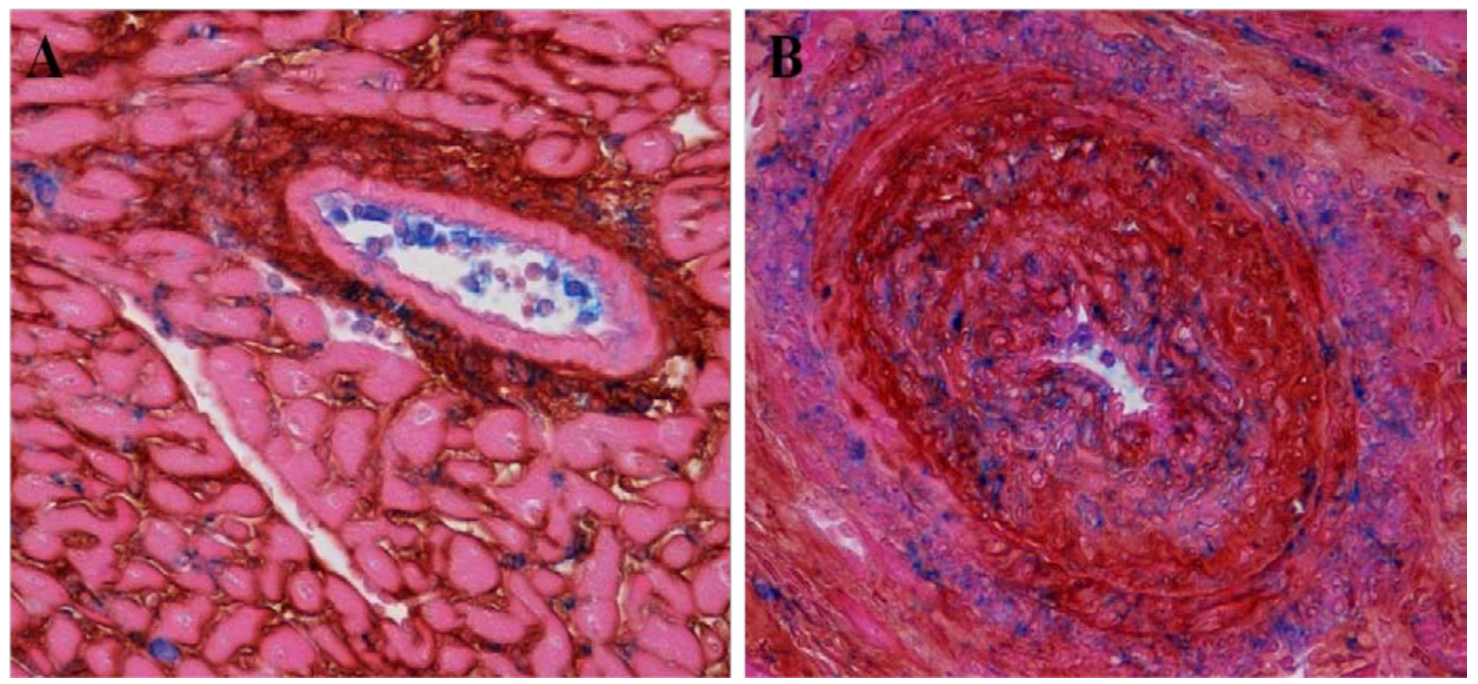
Figure 23. CD44, which is the dominant receptor for hyaluronan, was expressed by the cells infiltrating the neointima and adventitia of the wild type artery (A) and SCID artery with passive transfer of transgenic CD4 T cells (B) at 6 weeks.

\subsubsection{Low molecular weight hyaluronan increases MIG and MCP-1 production in cardiac allografts}

Inflammation can cause fragmentation of hyaluronan and different sized fragments of hyaluronan can promote or modulate chemokine production. Circulating hyaluronan fragments have been found to stimulate chemokine production by macrophages through a TLR4- and TLR2-dependent mechanism ${ }^{24}$. To test whether hyaluronan fragments increased MIG and MCP- 1 in cardiac allografts, we administered 100ug of low molecular weight hyaluronan daily to female recipients of male allografts intraperitoneally. Controls were administered an equal volume of the PBS diluent. Both 4.7 or $35 \mathrm{kD}$ fragments of hyaluronan stimulated MIG and MCP-1 production in the cardiac allografts by 2 weeks (Figure 24A). Infiltrating cells were isolated from cardiac transplants to mice treated with PBS or 35kD fragments of hyaluronan, and after cell sorting for F4/80 expressing macrophages, mRNA was isolated and markers of M1 and M2 macrophages were probed by PCR. In addition to MIG and MCP-1, the M1 markers IL-6, IL-15, IL-18, TNFa and Nos2 were increased (Figure 24B-D). 

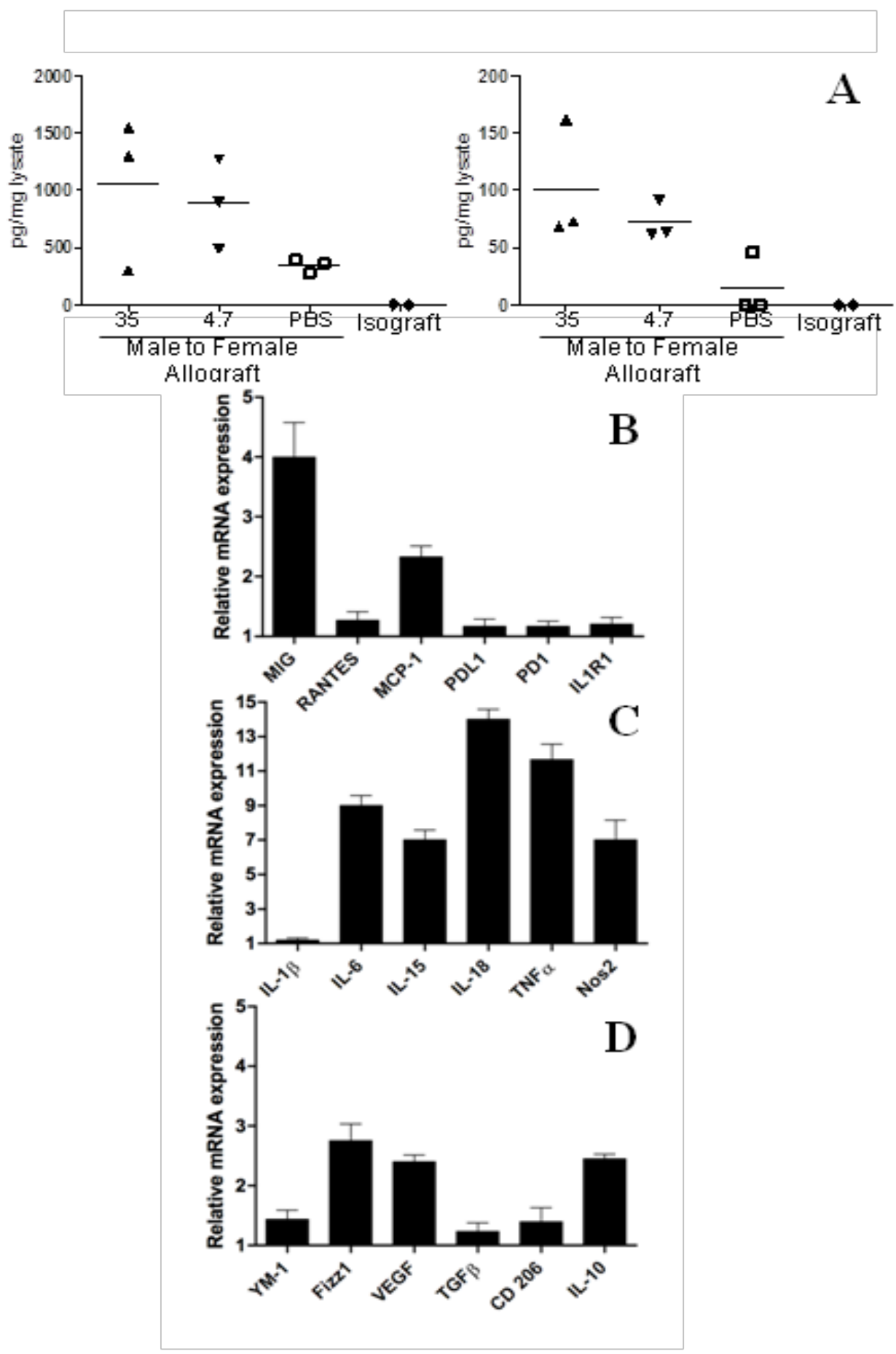

Figure 24. Both 4.7 or $35 \mathrm{kD}$ fragments of hyaluronan stimulated MIG (top left) and MCP-1 (top right) measure by ELISA on homgenates from the apex of cardiac allografts at 2 weeks (A). PCR on macrophages isolated from 3 heart allografts at 2 weeks demonstrated increased expression of MIG and MCP-1 as well as even greater increases in IL-6, IL-15, IL-18 TNH $\square$ and Nos2 (B,C). Markers for M2 macrophages were changed to a lesser extent (C). Each symbol in the ELISA scattergram represents results 
from an individual allograft. PCR results are expressed as fold increase in macrophages from mice treated with hyaluronan fragments compared to PBS $(n=3)$.

\subsection{Discussion}

This study was designed to discover mediators that differentially modulate acute mononuclear infiltrates in the myocardium and chronic infiltrates in the large arteries. As in human cardiac transplants, the infiltrates in acute and chronic rejection were predominantly composed of mononuclear cells with macrophages outnumbering T cells ${ }^{1}$,

11. However, the acute and chronic pathology were dependent on $\mathrm{T}$ cells because no infiltrates developed in the absence of $\mathrm{T}$ cells, and passive transfer of CD4 $\mathrm{T}$ cells restored not only the characteristic $\mathrm{T}$ cell infiltrates, but also the extensive macrophage infiltrates and ultimately neointima formation with smooth muscle cells.

Macrophages are identified routinely in clinical endomyocardial biopsy by universal macrophage markers, such as CD68 ${ }^{1,11,12}$. Subpopulations of macrophages are now recognized to have critical functional differences ${ }^{10}$. The most clearly defined types of macrophages are classically activated or inflammatory M1 macrophages and alternatively activated or wound healing M2 macrophages. Sustained production of IFNg by $\mathrm{T}$ helper 1 (Th1) cells induces inflammatory macrophages during adaptive immune responses; whereas wound healing macrophages develop in response to production of IL4 by $\mathrm{T}$ helper 2 (Th2) cells. No clinical or experimental studies have assessed macrophage subpopulations in cardiac allografts, but Famulski et al ${ }^{25}$ have reported that M2 macrophages increase with time during $\mathrm{T}$ cell-mediated rejection in mouse renal 
allografts. We found relatively few Ym-1 expressing M2 macrophages in the acute interstitial infiltrates and they increased modestly with time. Moreover, the M2 macrophages were largely ovoid without cytoplamic extensions. These histological findings were supported by 5 molecular markers of M2 macrophages (Ym1, Fizz1, VEGF, TGFb, and CD206), which were expressed at low levels in the interstitium and increased at 6 weeks.

In contrast, six markers of M1 macrophages (IL-1b, IL-6, IL-15, IL-18, TNFa and Nos2) were markedly elevated in the interstitium at 2 weeks and decreased by 6 weeks. These changes in M1 markers paralleled the numbers and morphology of galectin-3 expressing macrophages, which had many cytoplasmic extensions that made contact with endothelial cells and myocytes. In hearts, galectin-3 has been associated with fibrosis ${ }^{22}$. Furthermore, MIG, a signature cytokine produced by inflammatory macrophages, was elevated in interstitial samples by microarray and ELISA. MIG has been reported to colocalize with infiltrating $\mathrm{CD}^{+} 8^{+}$macrophages in clinical endomyocardial biopsies during acute cellular rejection ${ }^{12}$.

In the transition to chronic rejection, galectin-3-expressing macrophages and MIG decreased in the interstitium, and increased in the arterial compartment. In vitro, galectin3 stimulates human macrophages to upregulate inflammatory genes including RANTES and MCP-1 ${ }^{23}$. These 2 chemokines were upregulated acutely in the macrophage-rich interstitium and chronically in the arterial compartment. 
In addition to increased expression of chemoattractants for macrophages and $\mathrm{T}$ cells, ligands for both positive and negative co-stimulatory receptors on $\mathrm{T}$ cells were upregulated in the intersititum. While CD80 and CD86 can stimulate T cells through CD28, PDL1 delivers a negative signal to $\mathrm{T}$ cells that express PD1. The majority of $\mathrm{T}$ cells in the interstitium expressed PD1 on immunohistology. The functional relevance of the interaction between PDL1 and PD1 was demonstrated by treating mice with a blocking antibody to PDL1. Blocking PDL1:PD1 interaction has been reported to increase acute and chronic rejection of cardiac allografts in other murine models depending upon the histoincompatibility and treatment schedule ${ }^{9,26-28}$. In our model, treatment in the acute phase caused a doubling of the number of PD1 positive cells in the interstitium and resulted in increased tissue injury. Blocking PDL1 in the chronic phase also increased the number of PD1 positive cells in the interstitium, but to a lesser extent than in the acute phase. Increased infiltrates of macrophages and $\mathrm{T}$ cells were accompanied by increased MIG and RANTES production in the interstitium. Yang et al ${ }^{29}$ reported that blocking PDL1 decreased FoxP3 expressing T regulatory cells in the spleen, but not in cardiac allografts. We also found only limited numbers of FoxP3 cells in the interstitium or arterial compartment of cardiac allografts. Of note, blocking PDL1 changed the balance of IL-1 receptors. At 2 weeks IL-1R2 predominated in untreated mice, but blocking PDL1 resulted in the upregulation of IL-1R1. IL-1R2 is structurally similar to IL-1R1, but has a truncated cytoplasmic domain that prevents transmembrane signaling ${ }^{17}$. IL-1R2 competes with IL-1R1 for ligands and for the IL-1 receptor accessory protein. By acting as a decoy receptor for IL-1 on macrophages, IL-1R2 modulates the inflammatory effects of IL-1. The counterbalance between IL-1R2 and 
PD1 in our model parallels the clinical findings in the multicenter CARGO study of gene profiles in peripheral blood mononuclear cells, which reported that IL-1R2 was the gene most highly correlated with stable graft function and PD1 with acute rejection of cardiac transplants ${ }^{15,16}$. Our examination of graft infiltrates by flow cytometry indicated that macrophages were equipped to modulate acute rejection because the majority expressed PDL1.

By microdissecting tissue sections from cardiac allografts rather than homogenizing entire samples, we examined the compartmentalization of mediators and ligands. On microarray screen, only IL-1R2, TLR2 and 4 were more highly expressed in the arterial than interstitial compartment in the acute phase. By 6 weeks, TLR4 increased in both compartments, but more in arteries. TLR4 has several endogenous ligands that are upregulated in injured arteries including galectin-3 and hyaluronan ${ }^{30,31}$. The extracellular matrix macromolecule hyaluronan has been found to increase in the hyperplastic intima of restenotic arteries ${ }^{32}$. Macrophages engage in extracellular matrix remodeling both degrading and synthesizing hyaluronan ${ }^{33}$. Changes in distribution of hyaluronan are not studied routinely in clinical cardiac transplants, but have been implicated in rejection of human lung transplants ${ }^{34,35}$. Hyaluronan levels are also increased in male skin 2 weeks after allotransplantation to female recipients ${ }^{35}$. Similarly, in our model, hyaluronan was increased in homogenates of cardiac transplants at 2 and 6 weeks. In addition, we demonstrated that increased amounts of hyaluronan were localized in the neointima of arteries in cardiac allografts, which contained activated macrophages that could contribute to fragmentation of the hyaluronan. Circulating hyaluronan fragments 
stimulate chemokine production by macrophages through a TLR4- and TLR2-dependent mechanism ${ }^{24}$. In our model the administration of low molecular weight hyaluronan fragments stimulated MIG and MCP-1 expression as well as M1 markers in macrophages isolated from allografted hearts.

In summary, we found a differential expression of inflammatory signals in the interstitial and arterial compartments of cardiac transplants that changed from the acute to chronic phases of rejection. Our data indicate that upregulation of PDL1 in the interstitium contributes to the resolution of acute interstitial infiltrates. In the arterial compartment recognition of endogenous ligands including hyaluronan by TLR4 may promote progression of arteriopathy. Importantly, our model localizes molecular markers that have been associated with acute and chronic rejection in clinical studies of cardiac transplants. 


\section{CHAPTER III}

\section{CONCLUSION AND FUTURE WORK}

Cardiac allograft vasculopathy (CAV) ${ }^{1-2}$ continues to be the major cause of chronic graft failure while advances in the treatment strategies for cardiac transplant patients have controlled acute rejection to a large extent. The studies presented in this thesis were designed to examine the mechanisms that are involved in the compartmentalization of acute (localized in interstitium) and chronic (localized in large arteries) rejection. Our results in cardiac allografts between mice mismatched at a minor histoincompatability showed that infiltrates in acute and chronic rejection were composed of macrophages and $\mathrm{T}$ cells ${ }^{3,4}$. These results were similar to human cardiac transplants. Using immunodeficient mice, we were able to show that both the acute and chronic pathology was dependent on CD4 T-cells because no infiltrates developed in the absence of T cells, and passive transfer of CD4 T-cells restored not only the characteristic T cell infiltrates, but also the extensive macrophage infiltrates. Even in human cardiac transplants, CD4 T-

cells have been shown to be a major component of acute and chronic infiltrates ${ }^{5}$. However, these experiments did not answer why acute infiltrates were more intense in the 
interstitium than in arteries. It is known that endothelial cells activated by T cell-derived cytokines and macrophages express class II MHC, adhesion molecules, and costimulatory molecules. These can present antigen and thereby recruit more $\mathrm{T}$ cells, amplifying the rejection process. It has also been reported that activated capillary endothelial cells express more message for leukocyte adhesion molecules than arterial endothelial cells ${ }^{6}$. This greater expression of adhesion ligands by capillary endothelial cells together with the slower blood flow in the narrow lumen of the vessels permits low affinity interactions of lectin-like adhesion glycoproteins, called the selectins to effectively mediate leukocyte rolling. Leukocyte rolling precedes the firm adhesion and subsequent transendothelial migration of leukocytes mediated by the interaction of integrins (CD11/CD18, VLA-4) on leukocytes with immunoglobulin-like adhesion molecules on ECs (e.g., ICAM-1, VCAM-1). The importance of adhesion molecules on capillary endothelium to early interstitial $\mathrm{T}$ cell infiltrates has been shown with cardiac allografts from ICAM-1 deficient donors. Fewer T cells infiltrate these grafts at 4 days, but these grafts still develop chronic $\mathrm{CAV}^{7}$.

In contrast to acute rejection, CAV is caused by infiltrates expanding in the arterial compartment over time. The transfer of CD4 $\mathrm{T}$ cells to immunodeficient recipients of cardiac grafts demonstrated that CD4 T cells caused the chronic arterial pathology as well as the acute interstitial infiltrates. Moreover, the numbers of macrophages increased in these arterial lesions from 6 weeks to 10 weeks. The proliferation marker Ki67 showed that many of the cells in the graft had recently divided. This marker does not indicate whether the cells underwent mitosis in the arterial lesion or 
had proliferated in the lymphoid tissues and then migrated to the graft because the Ki-67 protein is present during all active phases of the cell cycle (G(1), S, G(2), and mitosis), but is absent from resting cells $(\mathrm{G}(0))^{8}$. However, the exact location where proliferation was initiated remains unclear, more specifically whether cells proliferated in the graft or in the spleen. This could be tested by performing splenectomy at different times after transplantation. Additionally, FTY720 (fingolimod) could be used to inhibit lymphocyte release from secondary lymphoid tissues ${ }^{9}$

T-cells can produce cytokines that direct macrophages to differentiate into M1 inflammatory macrophages or M2 wound healing macrophages ${ }^{10}$. Macrophages are differentiated into M1 phenotype by INFg and M2 phenotype by IL-4. These M1/M2type macrophages necessarily direct $\mathrm{T}$ cells towards Th1- or Th2- like activities, respectively. Macrophages initiate and direct virtually all immune responses ${ }^{11}$ (Figure 25). 


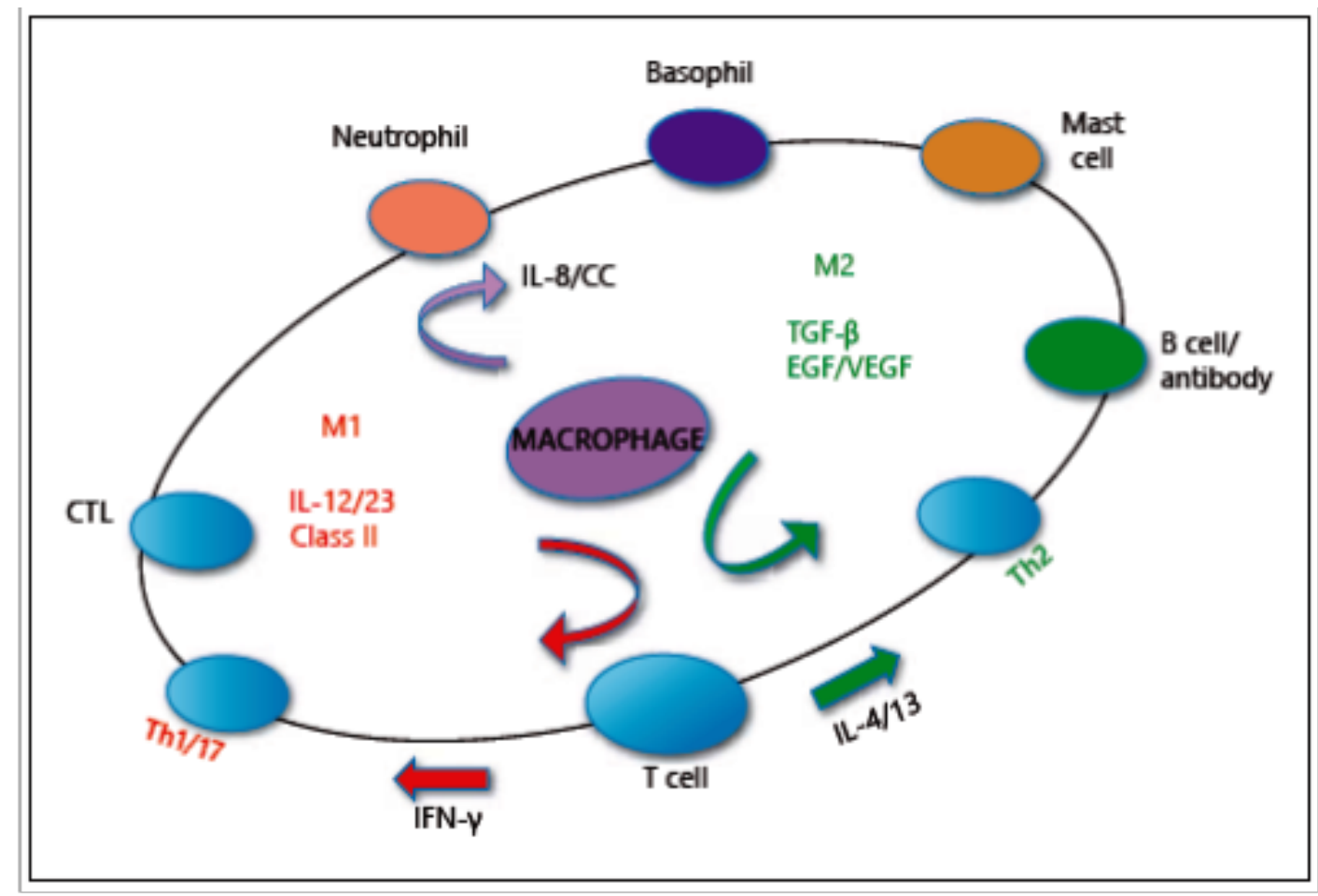

Figure 25. Schematic showing macrophages initiate and direct virtually all immune responses (Mill's et al, 2014).

Our PCR and ELISA results on tissue homogenates of graft show upregulation of chemokines, MIG (CXCL9), RANTES (CCL5) and MCP-1 (CCL2) that are involved in the graft rejection. Manipulations of chemokines, MIG, RANTES and MCP-1 or their receptors in the system can further elucidate the mechanisms involved in the activation, co-stimulation, and interactions between inflammatory cells. Multiple strategies such as using antibodies to block chemokines and their receptors or using knockout animals to block cellular interactions could be used for future studies. MIG, RANTES and MCP-1 are interferone gamma inducible chemokines. Other possible targets indicated by our PCR results include IL-1 $\beta$ that could be addressed by treatment with the soluble form of the IL-1 decoy receptor IL-1R2 as discussed below. 
T-cells are regulated by many positive and negative co-stimulatory signals. Our results exhibit upregulation of PD-L1, a ligand for PD-1 which is a negative co-stimulatory molecule in the interstitium. We demonstrated functional relevance of negative co-stimulation to the resolution of the acute interstitial infiltrate by treating mice with a blocking antibody to PD-L1. These results indicated that early blocking of PD-L1 prevents resolution of acute interstitial infiltrates. However, it did not modulate chronic arterial pathology. Blocking PD-L1:PD-1 interaction not only caused an additional increase in chemokine level, IL-1R1, IL-1beta, IL-6, TNF alpha and Nos2 in the interstitium at 2 weeks but also changed the balance of IL-1 receptors. At 2 weeks, IL1R2 predominated in untreated mice, but blocking PDL1 resulted in the upregulation of IL-1R1. In our model, the counterbalance between IL-1R2 and PD1 parallels the clinical findings in the multicenter CARGO study of gene profile that reported IL-1R2 is the most highly correlated gene with the stable graft function and PD1 with acute rejection of cardiac transplants ${ }^{12,13}$. The results on graft infiltrates by flowcytometry in this work, show that macrophages were able to modulate acute rejection because the majority expressed IL-1R2 and PDL1. Manipulations in the IL-1 receptors in the system can further clarify if resolution of acute interstitial infiltrate in anti PD-L1 treated group is dependent on IL1R1.

Toll like receptors (TLRs) are a family of pattern recognition proteins that detect both microbe and host derived molecular patterns. In our study TLR2 was increased in the arterial more than in the interstitial compartment of cardiac allografts in the acute phase. However, TLR4 and hyaluronan were upregulated in the arterial 
compartment during chronic rejection. Hyaluronan is one of the endogenous ligands for TLR2 and TLR4 ${ }^{14}$. In our model, hyaluronan was increased in tissue homogenates of cardiac allografts at 2 and 6 weeks. This increased amount of hyaluronan was localized in the neointimal lesions and surrounding adventitial infiltrates of arteries in cardiac allografts. Additionally, administration of low molecular weight hyaluronan increased MIG and MCP-1 production in cardiac allografts. We attempted to address this question by transplanting hearts from male TLR4 knockout donors into female recipients. However, this produced an unexpected phenotype of a dilated myocarditis ${ }^{15}$. Alternatively, de la Motte and others have shown that intermediate sized fragments of HA can deliver anti-inflammatory signals ${ }^{16}$. Therefore, the effects of different sizes of HA fragments could be assessed as inhibitors of CAV.

The results presented in this thesis were obtained in a mouse model. It would be important to translate these findings in human specimens. This is important because of the anatomical and physiological differences between mouse and human coronary arteries. Only a short segment of the mouse coronary is epicardial; then majority is intramyocardial. In contrast the major branches of human coronaries that develop CAV remain on the epicardial surface surrounded by adipose tissue. Moreover, the large epicardial coronary arteries of humans are nourished by vasa vasorum. The absence of vasa vasorum in the intramyocardial coronary arteries is one factor that is thought to offer them relative protection from arteriosclerosis. The application of the panel of probes used in the mouse model to samples from human transplants would verify markers that are common to the development of CAV. 


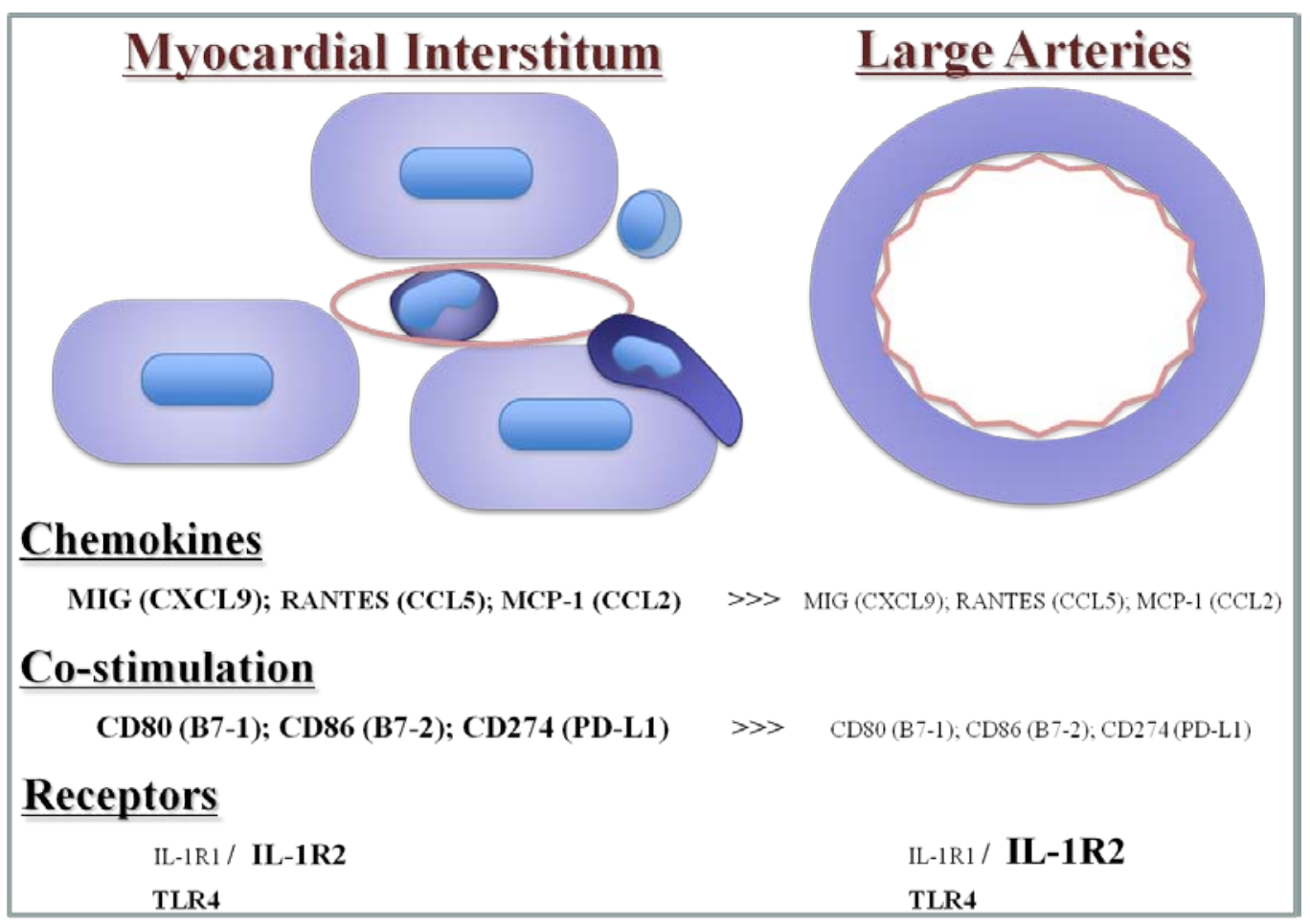

Figure 26. Schematic representation of Acute Balance of Immunity between Compartments 


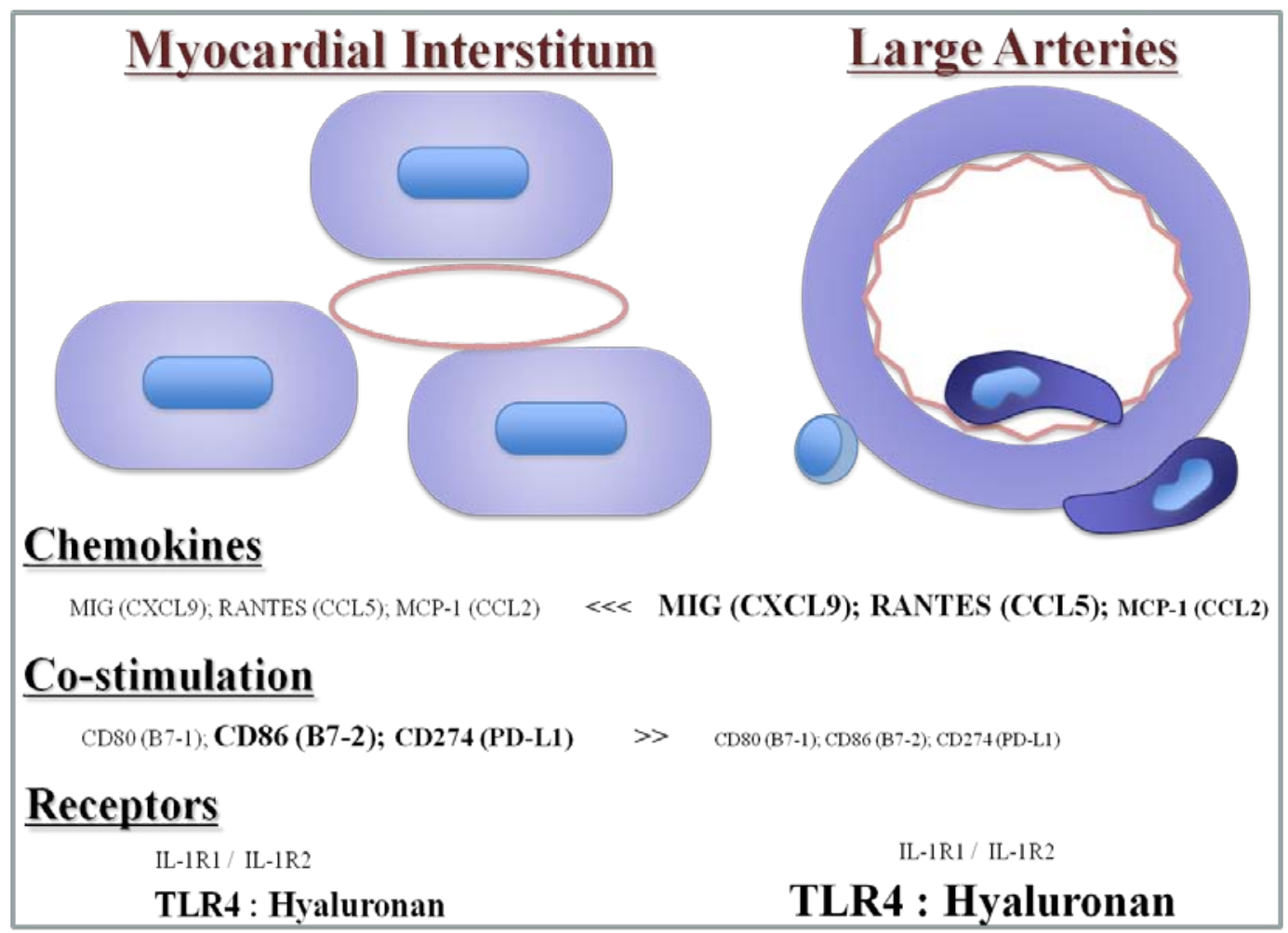

Figure 27. Schematic representation of Chronic Balance of Immunity between Compartments

The studies presented in this thesis show differential expression of inflammatory signals in the interstitial and arterial compartments of cardiac transplants that changed from acute to chronic phases of rejection (see Figures 26 and 27). Negative co-stimulatory pathways are critical for the resolution of acute interstitial infiltrates. In the arterial compartment recognition of endogenous ligands including hyaluronan by the innate TLR4 may cause cardiac allograft vasculopathy to progress. The findings from these and future experimental studies will further our understandings and treatments for human cardiac allograft rejection. 
To conclude, our results show that there is acute (Figure 26) and chronic (Figure 27) balance of immunity between interstitial and arterial compartments. 


\section{BIBLIOGRAPHY}

Chapter I

1. Barker CF and Markmann JF. Historical Overview of Transplantation. Cold Spring Harb Perspect Med. 2013;3:a014977.

2. Medawar PB. The Behavior and Fate of Skin Autografts and skin Homografts in rabbits. Journal of Anatomy. 1944;78(5):176-199.

3. Simonsen M. The impact on the developing embryo and newborn animal of adult homologous cells. Acta Pathol Microbiol Scand. 1957; 40: 480-500.

4. Mitchison NA. Passive transfer of transplantation immunity. Nature. 1953; 171:267268.

5. Billigham RE, Brent L and Medawar PB. Quantitative studies on tissue transplantation immunity. II. The origin, strength and duration of actively and adoptively acquired immunity. Proc.R.Soc.Lond. 1954;vo;143,910:58-80.

6. Haeney M. The immunological background to transplantation, $J$ Antimicrob Chemother. 1995;36B:1-9.

7. Murray JE, Merrill JP and Harrison JH. Renal Homotransplantation in Identical Twins. Surg. Forum. 1955;6:432.

8.Murray JE, Merrill JP and Harrison JH. Kidney Transplantation Between Seven Pairs of Identical Twins. Annals of Surgery. 1958;148:343-357.

9. Main JM, Prehn RT. Successful skin homografts after the administration of high dosage x radiation and homologous bone marrow. J Natl Cancer Inst. 1955; 15: 10231029 
10. Starzl TE,Marchioro TL,Waddell WR. The reversal of rejection in human renal homografts with subsequent development of homograft tolerance. Surg GynecolObstet. 1963. 117: 385-395.

11. Starzl TE, Klintmalm GBG, Porter KA, Iwatsuki S, Schroter GPJ. 1981. Liver transplantation with use of cyclosporine A and prednisone. N Engl J Med 305: 266-269.; Miniati DN, Robbins RC. Heart transplantation: a thirty-year perspective. Annu Rev Med. 2002;53:189-205.

12. Ajith kumar TV, Parkinson CA, Butler A, Hatcher HM. Management of solid tumours in organ-transplant recipients. Lancet Oncol. 2007;8(10):921-932.

13. Miniati DN, Robbins RC. Heart transplantation: a thirty-year perspective. Annu Rev Med. 2002;53:189-205.

14. Millington TM, Madsen JC. Innate immunity and cardiac allograft rejection. Kidney Int Suppl. 2010;(119):S18-21.

15. Stehlik J, Edwards LB, Kucheryavaya AY, Benden C, Christie JD, Dobbels F, Kirk R, Rahmel AO and Hertz MI. The Registry of the International Society for Heart and Lung Transplantation: Twenty-eighth Adult Heart Transplant Report-2011. The journal of Heart and Lung transplantation. 2011;

16. Tan CD, Baldwin WM, 3rd, Rodriguez ER. Update on cardiac transplantation pathology. Arch Pathol Lab Med. 2007;131:1169-91

17. Arakelov A, Lakkis FG. The alloimmune response and effector mechanisms of allograft rejection. Semin Nephrol. 2000;20:95-102. 
18. Ozduran V, Yamani MH, Chuang HH. Survival beyond 10 years following heart transplantation: The Cleveland Clinic Foundation experience. Transplant Proc. 2005;37:4509-4512.

19. McGoon MD, Frantz RP. Techniques of immunosuppression after cardiac transplantation. Mayo Clin Proc. 1992;67:586-95.

20.Woodley SL, Renlund DG, O'Connell JB, Bristow MR. Immunosuppression following cardiac transplantation. Cardiol Clin. 1990;8:83-96.

21. Abbas AK, Lichtman AH and Pillai S. Basic Immunology functions and disorders of the Immune system. Fourth edition.

22. Terasaki PI. Humoral theory of transplantation. American J Transplantation. 2003; 3: 665-673.

23. Mulley WR and Kanellis J. Understanding crossmatch testing in organ transplantation: A case-based guide for the general nephrologist. Nephrology. 2011;16:125-133.

24. Chalasani G, Li Q, Konieczny BT, Diggs LS, Wrobel B, Dai Z, Perkins DL, Baddoura FK and Lakkis FG. The Allograft defines the type of Rejection (Acute versus Chronic) in the face of an established effector Immune Response. The journal of Immunology. 2004;172:7813-7820.

25. Ramzy D, Rao V, Brahm J, Miriuka S, Delgado D, Ross HJ. Cardiac Allograft Vasculop athy: a review. Can J Surg. 2005;48:319-327.

26. Mitchell RN. Graft Vascular disease: Immune Response Meets the vessel wall. Annu Rev. Pathol. Mech. Dis. 2009;4:19-47. 
27. Starling RC, Pham M, Valantine H. Molecular testing in the management of cardiac transplant recipients: Initial clinical experience. J Heart Lung Transplant. 2006;25:13891395.

28. Bonow RO, Mann DL, Zipes DP, Libby P: Braunwald's Heart Disease: A Textbook of Cardiovascular Medicine. 9th ed. Philadelphia: Elsevier Saunders; 2011.

29. Stewart S, Winters GL, Fishbein MC, Tazelaar HD, Kobashigawa J, Abrams J. Revision of the 1990 working formulation for the standardization of nomenclature in the diagnosis of heart rejection. $J$ Heart Lung Transplant. 2005;24(11):1710-1720.

30. Lechler RI, Sykes M, Thomson AW, Turka LA. Organ transplantation-how much of the promise has been realized? Nature Medicine. 2005;11:605-613.

31. Arakelov A, Lakkis FG. The alloimmune response and effector mechanisms of allograft rejection. Semin Nephrol. 2000;20:95-102.

32. Taylor DO, Edwards LB, Boucek MM, Trulock EP, Aurora P, Christie J. Registry of the International Society for Heart and Lung Transplantation: twenty-fourth official adult heart transplant report-2012. J Heart Lung Transplant. 2012;26(8):769-781.

33. Minami E, Laflammen M, Saffitz J, Murry C. Extracardiac progenitor cells repopulate most major cell types in the transplanted human heart. Circulation. 2005;112:2951-2958.

34. Shimizu K, Sugiyama S, Aikawa M, Fukumoto Y, Rabkin E. Host bone marrow cells are a source of donor intimal smooth muscle like cells in murine aortic transplant arteriopathy. Nature Medicine. 2001;7:738-741.

35. Tuzcu EM, Kapadia SR, Sachar R. Intravascular ultrasound evidence of angiographically silent progression in coronary atherosclerosis predicts long-term 
morbidity and mortality after cardiac transplantation. J Am Coll Cardiol. 2005;45 (9): 1538.

36. Hosenpud JD, Everett JP, Morris TE, Mauck KA, Shipley GD,Wagner CR. Cardiac allograft vasculopathy: association with cell-mediated but not humoral alloimmunity to donor-specific vascular endothelium. Circulation. 1995;92:205- 211.

37. Hammond EH, Yowell RL, Price GD. Vascular rejection and its relationship to allograft coronary artery disease. J Heart Lung Transplant. 1992;11:S111-S119.

38. Hess ML, Hastillo A, Mohanakumar T. Accelerated atherosclerosis in cardiac transplantation: role of cytotoxic B-cell antibodies and hyperlipidemia. Circulation. 1983;68:II94-1101.

39. Briscoe DM, Yeung AC, Schoen FJ. Predictive value of inducible endothelial cell adhesion molecule expression for acute rejection of human cardiac allografts. Transplantation. 1995. 59:204-211.

40. Libby P, Tanaka H. The pathogenesis of coronary arteriosclerosis ("chronic rejection’’) in transplanted hearts. Clin Transplant. 1994;8(3 pt 2):313-318.

41. Tellides G, Pober J. Interferon- $\gamma$ axis in graft arteriosclerosis. Circulation Res. 2007;100:622.

42. Valantine HA. Role of lipids in allograft vascular disease: a multicenter study of intimal thickening detected by intravascular ultrasound. J Heart Lung Transplant. 1995;14(6 pt 2):S234-S237.

43. Johnson MR. Transplant coronary disease: nonimmunologic risk factors, $J$ Heart Lung Transplant. 1992;11:S124-S132. 
44. Russell P, Chase C, Win H, Colvin R. Coronary atherosclerosis in transplanted mouse hearts. I. Time course and immunogenetic and immunopathological considerations. American J Pathol. 1994;144:260-74.

45. Nagano H, Mitchell R, Taylor M, Hasegawa S, Tilney N. Interferon- $\gamma$ deficiency necessary for GVD prevents coronary arteriosclerosis but not myocardial rejection in transplanted mouse hearts. J Clin Invest. 1997;100:550-557.

46. Furukawa Y, Libby P, Stinn J, Becker G, Mitchell R. Cold ischemia enhances cytokine/cell adhesion molecule expression and induces graft arterial disease in isografts, but does not accentuate alloimmune responses of non-immuno suppressed hosts. American J Pathol. 2002;160:1077-87.

47. Bromley SK, Iaboni A, Davis SJ. The immunological synapse and CD28-CD80 interactions. Nat Immunol. 2001;2:1159-1166.

48. Li XC, Rothstein DM, Sayegh MH. Costimulatory pathways in transplantation: challenges and new development. J .2009;229:271-293.

49. Walunas TL, Lenschow DJ, Bakker CY. CTLA-4 can function as a negative regulator of T cell activation. Immunity. 1994;1:405-413.

50. Gao W, Demirci G, Strom T. B, and Li X. C. Stimulating PD-1-negative signals concurrent with blocking CD154 co-stimulation induces long-term islet allograft survival. Transplantation. 2003;76:994-999.

51. Nishimura H, Nose M, Hiai H, Minato N, Honjo T. Development of lupus-like autoimmune diseases by disruption of the PD-1 gene encoding an ITIM motif-carrying immunoreceptor. Immunity. 1999;11:141-151. 
52. Nishimura H, Honjo T. PD-1 an inhibitory immunoreceptor involved in peripheral tolerance. Trends Immunol. 2001;22:265-268.

53. Ishida Y, Agata Y, Shibahara K, Honjo T. Induced expression of PD-1, a novel member of the immunoglobulin gene superfamily, upon programmed cell death. Embo J. 1992;11:3887-3895.

54. Rothstein DM, Sayegh MH. T-cell costimulatory pathways in allograft rejection and tolerance. Immunol Rev. 2003;196:85-108.

55. Khoury SJ, Sayegh MH. The roles of the new negative T cell costimulatory pathways in regulating auto immunity. Immunity. 2004;20 529-538.

56. Freeman GJ, Long AJ, Iwai Y, Bourque K, Chernova T, Nishimura H, Fitz LJ, Malenkovich N, Okazaki T, Byrne MC, Horton HF, Fouser L, Carter L, Ling V, Bowman MR, Carreno BM, Collins M, Wood CR, Honjo T. Engagement of the PD-1 immunoinhibitory receptor by a novel B7 family member leads to negative regulation of lymphocyte activation. J Exp Med. 2000;192:1027-1034.

57. Yamazaki T, Akiba H, Iwai H, Matsuda H, Aoki M, Tanno Y, Shin T, Tsuchiya H, Pardoll DM, Okumura K, Azuma M, Yagita H. Expression of programmed death 1 ligands by murine T cells and APC. J Immunol. 2002;169:5538 -5545.

58. Brown, JA, Dorfman DM, Ma FR, Sullivan EL, Munoz O, Wood CR, Greenfield EA and Freeman GJ. Blockade of programmed death-1 ligands on dendritic cells enhances T cell activation and cytokine production. J. Immunol. 2003;170: 1257-1266.

59. Grabie N, Gotsman I, DaCosta R, Pang H, Stavrakis G, Butte MJ, Keir ME, Freeman GJ, Sharpe AH, Lichtman AH. Endothelial programmed death-1 ligand 1 (PD-L1) regulates CD8 T-cell-mediated injury in the heart. Circulation. 2007; 116:2062-2071. 
60. Keir ME, Butte MJ, Freeman GJ, and Sharpe AH. PD-1 and Its Ligands in Tolerance and Immunity. Annual Review of Immunology. 2008;26:677-704.

61. Sandner SE, Clarkson MR, Salama AD, Sanchez-Fueyo A, Domenig C. Role of the Programmed death-1 pathway in regulation of alloimmune responses in vivo. $J$. Immunology. 2005;174:3408-3415.

62. Tao R, Wamg L, Han R, Wang T, Ye Q. Differential effects of B \& T lymphocyte attenuator and programmed death-1 on acceptance of partially versus fully MHCmismatched cardiac allografts. J Immunology. 2005;175:5774-5782

63. Yang J, Popoola J, Khandwala S, Vadivel N, Vanguri V, Yuan X, Dada S, Guleria I, Tian C, Ansari JM, Shin T, Yagita H, Azuma M, Sayegh MH, Chandraker A. Critical role of donor tissue expression of Programmed Death Ligand-1 in regulating cardiac allgraft rejection and vasculopathy. Circulation. 2008;117:660-669

64. Noritaka Koga, Jun-ichi Suzuki, Hisanori Kosuge, Go Haraguchi, Yasuyuki Onai, Hideki Futamatsu, Yasuhiro Maejima, Ryo Gotoh, Hitoshi Saiki, Fumihiko Tsushima, Miyuki Azuma and Mitsuaki Isobe. Blockade of the Interaction Between PD-1 and PDL1 Accelerates Graft Arterial Disease in Cardiac Allograft. Arterioscler Thromb Vasc Biol. 2004;24:2057-2062.

65. Riellaa LV, Watanabea T, Sageb PT, Yanga J, Yeunga M, Azzia J, Vanguric V, Chandrakera A, Sharpeb AH, Sayegha MH and Najafiana N. Essential Role of PDL1 Expression on Nonhematopoietic Donor Cells in Acquired Tolerance to Vascularized Cardiac Allografts. American J Transplantation. 2011;11:832-840.

66. PDL1 for induction and maintenance of peripheral transplantation tolerance by its ability to alter the balance between pathogenic and regulatory $\mathrm{T}$ cells. Expression of 
PDL1 in donor tissue is critical for prevention of in situ graft pathology and chronic rejection, J Immunol 2007; 179:5204-5210).

67. Luster AD. Chemokines-chemotactic cytokines that mediate inflammation, The New England J Med. 1998;338:436-445.

68. Shimizu K, Mitchell RN. Chemokine-mediated recruitment of inflammatory and smooth muscle cells in transplant-associated arteriosclerosis. Curr Opin Organ Transplant. 2003;8:55-

69. Belperio JA, Keane MP, Arenberg DA, Addison CL, Ehlert JE, Burdick MD, Strieter RM. CXC chemokines in angiogenesis. J Leukocyte Biology. 2000;68:1- 8.

70. Zlotnik A, Yoshie O. Chemokines: a new classification system and their role in immunity. Immunity. 2000;12:121-12.

71. Proudfoot AE, Handel TM, Johnson Z, Lau EK, Wang PL, Clark-Lewis I, Borlat F, Wells TNC, Kosco-Vilbois MH. Glycosaminoglycan binding and oligomerization are essential for the in vivo activity of certain chemokines. Proc Natl Acad Sci. 2003;100:1885-1890.

72. Yun JJ, Fischbein MP, Laks H, Fishbein MC, Espejo ML, Ebrahimi K, Irie Y, Berliner J, Ardehali A. Early and late chemokine production correlates with cellular recruitment in cardiac allograft vasculopathy. Transplantation. 2000;69:2515-2524.

73. Di Carlo E, D’Antuono T, Contento S, Di Nicola M, Ballone E, Sorrentino C. Quilty effect has the features of lymphoid neogenesis and shares CXCL13-CXCR5 pathway with recurrent acute cardiac rejections. American J Transplantation. 2007;7:201-210.

74. Zhao DX, Hu Y, Miller GG, Luster AD, Mitchell RN, Libby P. Differential expression of the IFN-gamma-inducible CXCR3-binding chemokines, IFN-inducible 
protein 10, monokine induced by IFN, and IFN-inducible T cell alpha chemoattractant in human cardiac allografts: association with cardiac allograft vasculopathy and acute rejection. J Immunol. 2002;169:1556-1560.

75. Pattison J, Nelson PJ, Huie P, von Leuttichau I, Farshid G, Sibley RK, Krensky AM. RANTES chemokine expression in cell-mediated transplant rejection of the kidney. Lancet. 1994;343:209 -211.

76. Gao W, Faia KL, Csizmadia V, Smiley ST, Soler D, King JA, Danoff TM, Hancock WW. Beneficial effects of targeting CCR5 in allograft recipients. Transplantation. 2001;72:1199-1205.

77. Gao W, Topham PS, King JA, Smiley ST, Csizmadia V, Lu B, Gerard CJ, Hancock WW. Targeting of the chemokine receptor CCR1 suppresses development of acute and chronic cardiac allograft rejection. J Clin Invest. 2000;105:35- 44.

78. Fahmy NM, Yamani MH, Starling RC, Ratliff NB, Young JB, McCarthy PM, Feng J, Novick AC, Fairchild RL. Chemokine and chemokine receptor gene expression indicates acute rejection of human cardiac transplants. Transplantation. 2003;75:72-78.

79. Dinarello CA. Interleukin-1. Cytokine Growth Factor Rev. 1997;8:253-265.

80. Sims JE \& Smith DE. The IL-1 family: regulators of immunity. Nature Reviews Immunology. 2010;10:89-102.

81. Dinarello CA. Immunological and inflammatory functions of the interleukin-1 family. Annu Rev Immunol. 2009;27:519-50.

82. Simeoni E, Dudler J, Fleury S, Li J, Pagnotta M, Pascual M, Segesser LKV, Vassalli G. Gene transfer of a soluble IL-1 type 2 receptor-Ig fusion protein improves 
cardiac allograft survival in rats. European Journal of Cardio-thoracic Surgery. 2007;31(2):222—228.

83. Jiang Z, Berceli SA, Pfahnl CL, Wu L, Killingsworth CD, Vieira FG. Impact of IL1beta on flow-induced outward arterial remodeling. Surgery. 2004;136:478-82.

84. Kusuhara M, Isoda K, Ohsuzu F. Interleukin-1 and occlusive arterial diseases. Cardiovasc Hematol Agents Med Chem. 2006;4:229-35.

85. Vicenova B, Vopalensky V, Burysek L, Pospisek M. Emerging role of interleukin-1 in cardiovascular diseases. Physiol Res. 2009;58:481-498.

86. Neumann D, Kollewe C, Martin MU, Boraschi D. The membrane form of the type II IL-1receptor accounts for inhibitory function. J Immunology. 2000;165, 3350-3357.

87. Dallman MJ, Larsen CP, Morris PJ. Cytokine gene transcription in vascularized organ grafts: analysis using semiquantitative Polymerase Chain reaction. J Exp Med. 1991;174(2):493-496.

88. Wu CJ, Kurbegov D, Lattin B, Burchard E, Finkle C, Valantine H, Billingham ME, Starnes VA, Clayberger C. Cytokine gene expression in human cardiac allograft recipients. Transpl Immunol. 1994;2:199-207.

89. Mehra MR, Kobashigawa JA, Deng MC, Fang KC, Klingler TM, Lal PG, Rosenberg S, Uber PA, Starling RC, Murali S, Pauly DF, Dedrick R, Walker MG, Zeevi A, Eisen HJ. Transcriptional signals of T-cell and corticosteroid-sensitive genes are associated with future acute cellular rejection in cardiac allografts. J Heart Lung Transplant. 2007;26:1255-1263.

90. Mehra MR, Kobashigawa JA, Deng MC, Fang KC, Klingler TM, Lal PG, Rosenberg S, Uber PA, Starling RC, Murali S, Pauly DF, Dedrick R, Walker MG, Zeevi A, Eisen 
HJ. Clinical implications and longitudinal alteration of peripheral blood transcriptional signals indicative of future cardiac allograft rejection. $J$ Heart Lung Transplant. 2008;27(3):297-301.

91. Yu L, Wang L, Chen S. Exogenous or endogenous Toll-like receptor ligands: which is the MVP in tumorigenesis? Cell Mol Life Science. 2012;69(6):935-49.

92. Scaffidi P, Misteli T, Bianchi ME. Release of chromatin protein HMGB1 by necrotic cells triggers inflammation. Nature. 2002;418(6894):191-195.

93. Zhai Y, Qiao B, Shen XD, Gao F, Bustuttil RW, Cheng G, Platt JL, Volk HD, Kupiec Weglinski JW. Evidence for the pivotal role of endogenous toll-like receptor 4 ligands in liver ischemia and reperfusion injury. Transplantation. 2008;85: 1016-1022.

94. Bonaldi T, Talamo F, Scaffidi P, Ferrera D, Porto A, Bachi A, Rubartelli A, Agresti A, Bianchi ME. Monocytic cells hyperacetylate chromatin protein HMGB1 to redirect it towards secretion. EMBO. 2003;22(20):5551-5560.

95. Gardella S, Andrei C, Ferrera D, Lotti LV, Torrisi MR, Bianchi ME, Rubartelli A. The nuclear protein HMGB1 is secreted by monocytes via a non-classical, vesicle mediated secretory pathway. EMBO. 2002;3:995-1001.

96. Matzinger P: The danger model: a renewed sense of self. Science. 2002; 296:301-305. 97. Jiang D, Liang J, Fan J, Yu S, Chen S, Luo Y, Prestwich GD, Mascarenhas MM, Garg HG, Quinn DA, Homer RJ, Goldstein DR, Bucala R, Lee PJ, Medzhitov R, Noble PW. Regulation of lung injury and repair by Toll like receptors and hyaluronan. Nature Medicine. 2005;11:1173-1179.

98. Apeto HL, Ghiringhelli F, Tesniere A, Obeid M, Ortiz C, Criolo A, Mignot G, Maiuri MC, Ullrich E, Saulnier P, Yang H, Amigorena S, Ruffel B, Barrat FS, Saftig P, Levi F, 
Lidereau R, Nogues C, Mira JP, Chompret A, Joulin V, Clavel-Chapelon F, Bournis J, Andre F, Delaloge S, Tursz T, Kroemer G and Zitvogel L. Toll like receptor 4 dependent contribution of the immune system to anticancer chemotherapy and radiotherapy. Nature Med. 2007;13:1050-1059.

99. Asea A, Rehli M, Kabingu E, Boch JA, Bare Q, Auron PE, Stevenson MA, Calderwood SK. Novel signal transduction pathway utilized by extracellular HSP70: role of toll like receptor 2 \& 4. J Biol Chem. 2002;277:15028-15034.

100. Stern R, Kogan G, Jedrzejas MJ, and Soltés L. The many ways to cleave hyaluronan. Biotechnol Adv. 2007;25:537-557.

101. Fraser JR, Laurent TC, and Laurent UB. Hyaluronan: its nature, distribution, functions and turnover. J Intern Med. 1997;242:27-33.

102. Tammi R, Saamanen AM, Maibach HI, and Tammi M. Degradation of newly synthesized high molecular mass hyaluronan in the epidermal and dermal compartments of human skin in organ culture. J Invest Dermatol. 1991;97:126-130.

103. Erikson S, Fraser JR, Laurent TC, Pertoft H, Smedsrod B. Endothelial cells are a site of uptake and degradation of hyaluronic acid in the liver. Exp Cell Res. 1983;144:223228.

104. Zhou B, Weigel JA, Fauss L, Weigel PH. Identification of the hyaluronan receptor for endocytosis. J Biol Chem. 2000;275:37733-37741.

105. Williams AM, Langley PG, Oseri-Hwediab J, Wendon JA, Hughes RD. Hyaluronic acid and endothelial damage due to paracetamol induced hepatotoxicity. Liver Int. 2003;23:110-115. 
106. Chen WY, and Abatangelo G. Functions of hyaluronan in wound repair. Wound Repair Regen. 1999;7(2):79-89.

107. Taylor KR, Trowbridge JM, Rudisill JA, Termeer CC , Simon JC, and Gallo RL. Hyaluronan Fragments Stimulate Endothelial Recognition of Injury through TLR4. Journal Biol Chem. 2004;279(17):17079-17084.

108. Tesara BM, Jiangb D, Liangb J, Palmerc SM, Nobleb PW and Goldsteina DR. The Role of Hyaluronan Degradation Products as Innate Alloimmune Agonists. American J Transplantation. 2006;6:2622-2635.

109. Noble PW, Lake FR, Henson PM, and Riches DW. Hyaluronate activation of CD44 induces insulin-like growth factor-1 expression by a tumor necrosis factor dependent mechanism in murine macrophages. J Clin Invest. 1993;91:2368-2377.

110. Methe H, Zimmer E, Grimm C. Evidence for a role of toll-like receptor 4 in development of chronic allograft rejection after cardiac transplantation. Transplantation. 2004;78:1324-1331.

111. McDaniel DO, Zhou X, Moore CK, Aru G. Cardiac allograft rejection correlates with increased expressions of Toll-like receptors 2 and 4 and allograft inflammatory fac. Transplantation proceedings. 2010;42(10):4235-7.

112. Johnsson C, Tufveson G. Serum hyaluronan--a potential marker of cardiac allograft rejection? J Heart Lung Transplant. 2006;25(5):544-549.

113. Tod JL, Wang X, Sugimoto S, Kennedy VE, Zhang HL, Pavlisko EN, Kelly FL, Huang H, Kreise D, Palmer SM, and Gelman AE. Hyaluronan Contributes to Bronchiolitis Obliterans Syndrome and Stimulates Lung Allograft Rejection through 
Activation of Innate Immunity. American J Respiratory and Critical Care Medicine. 2014;189(5):556-66.

\section{Chapter II}

1. Stewart S, Winters GL, Fishbein MC, Tazelaar HD, Kobashigawa J, Abrams J et al. Revision of the 1990 working formulation for the standardization of nomenclature in the diagnosis of heart rejection. J Heart Lung Transplant 2005;24(11):1710-1720.

2. Lu WH, Palatnik K, Fishbein GA, Lai C, Levi DS, Perens G et al. Diverse morphologic manifestations of cardiac allograft vasculopathy: a pathologic study of 64 allograft hearts. J Heart Lung Transplant 2011;30(9):1044-1050.

3. van Loosdregt J, van Oosterhout MF, Bruggink AH, van Wichen DF, van Kuik J, de Koning E et al. The chemokine and chemokine receptor profile of infiltrating cells in the wall of arteries with cardiac allograft vasculopathy is indicative of a memory T-helper 1 response. Circulation 2006;114(15):1599-1607.

4. Wehner JR, Fox-Talbot K, Halushka MK, Ellis C, Zachary AA, Baldwin WM, 3rd. B cells and plasma cells in coronaries of chronically rejected cardiac transplants. Transplantation 2010;89(9):1141-1148.

5. Stehlik J, Starling RC, Movsesian MA, Fang JC, Brown RN, Hess ML et al. Utility of long-term surveillance endomyocardial biopsy: a multi-institutional analysis. J Heart Lung Transplant 2006;25(12):1402-1409. 
6. Keir ME, Liang SC, Guleria I, Latchman YE, Qipo A, Albacker LA et al. Tissue expression of PD-L1 mediates peripheral T cell tolerance. The Journal of experimental medicine 2006;203(4):883-895.

7. Grabie N, Gotsman I, DaCosta R, Pang H, Stavrakis G, Butte MJ et al. Endothelial programmed death-1 ligand 1 (PD-L1) regulates CD8+ T-cell mediated injury in the heart. Circulation 2007;116(18):2062-2071.

8. Keir ME, Butte MJ, Freeman GJ, Sharpe AH. PD-1 and its ligands in tolerance and immunity. Annual review of immunology 2008;26:677-704.

9. Ozkaynak E, Wang L, Goodearl A, McDonald K, Qin S, O'Keefe T et al. Programmed death-1 targeting can promote allograft survival. J Immunol 2002;169(11):6546-6553.

10. Mosser DM, Edwards JP. Exploring the full spectrum of macrophage activation. Nature reviews 2008;8(12):958-969.

11. Michaels PJ, Kobashigawa J, Laks H, Azarbal A, Espejo ML, Chen L et al. Differential expression of RANTES chemokine, TGF-beta, and leukocyte phenotype in acute cellular rejection and quilty B lesions. J Heart Lung Transplant 2001;20(4):407416.

12. Zhao DX, Hu Y, Miller GG, Luster AD, Mitchell RN, Libby P. Differential expression of the IFN-gamma-inducible CXCR3-binding chemokines, IFN-inducible protein 10, monokine induced by IFN, and IFN-inducible $\mathrm{T}$ cell alpha chemoattractant in human cardiac allografts: association with cardiac allograft vasculopathy and acute rejection. J Immunol 2002;169(3):1556-1560. 
13. Fahmy NM, Yamani MH, Starling RC, Ratliff NB, Young JB, McCarthy PM et al. Chemokine and chemokine receptor gene expression indicates acute rejection of human cardiac transplants. Transplantation 2003;75(1):72-78.

14. Pham MX, Teuteberg JJ, Kfoury AG, Starling RC, Deng MC, Cappola TP et al. Gene-expression profiling for rejection surveillance after cardiac transplantation. The New England journal of medicine 2010;362(20):1890-1900.

15. Mehra MR, Kobashigawa JA, Deng MC, Fang KC, Klingler TM, Lal PG et al. Transcriptional signals of T-cell and corticosteroid-sensitive genes are associated with future acute cellular rejection in cardiac allografts. J Heart Lung Transplant 2007;26(12):1255-1263.

16. Mehra MR, Kobashigawa JA, Deng MC, Fang KC, Klingler TM, Lal PG et al. Clinical implications and longitudinal alteration of peripheral blood transcriptional signals indicative of future cardiac allograft rejection. J Heart Lung Transplant 2008;27(3):297-301.

17. Sims JE, Smith DE. The IL-1 family: regulators of immunity. Nature reviews 2010;10(2):89-102.

18. Setoguchi K, Hattori Y, Iida S, Baldwin WM, 3rd, Fairchild RL. Endogenous memory CD8 T cells are activated within cardiac allografts without mediating rejection. Am J Transplant 2013;13(9):2293-2307.

19. Hill DR, Kessler SP, Rho HK, Cowman MK, de la Motte CA. Specific-sized hyaluronan fragments promote expression of human beta-defensin 2 in intestinal epithelium. The Journal of biological chemistry 2012;287(36):30610-30624. 
20. Erdinc Sunay MM, Fox-Talbot K, Velidedeoglu E, Baldwin WM, 3rd, Wasowska BA. Absence of FcgammaRIII Results in Increased Proinflammatory Response in Fcgamma RIII-KO Cardiac Recipients. Transplantation 2013.

21. Livak KJ, Schmittgen TD. Analysis of relative gene expression data using real-time quantitative PCR and the 2(-Delta Delta C(T)) Method. Methods (San Diego, Calif 2001;25(4):402-408.

22. Sharma UC, Pokharel S, van Brakel TJ, van Berlo JH, Cleutjens JP, Schroen B et al. Galectin-3 marks activated macrophages in failure-prone hypertrophied hearts and contributes to cardiac dysfunction. Circulation 2004;110(19):3121-3128.

23. Papaspyridonos M, McNeill E, de Bono JP, Smith A, Burnand KG, Channon KM et al. Galectin-3 is an amplifier of inflammation in atherosclerotic plaque progression through macrophage activation and monocyte chemoattraction. Arteriosclerosis, thrombosis, and vascular biology 2008;28(3):433-440.

24. Jiang D, Liang J, Fan J, Yu S, Chen S, Luo Y et al. Regulation of lung injury and repair by Toll-like receptors and hyaluronan. Nature medicine 2005;11(11):1173-1179.

25. Famulski KS, Kayser D, Einecke G, Allanach K, Badr D, Venner J et al. Alternative macrophage activation-associated transcripts in T-cell-mediated rejection of mouse kidney allografts. Am J Transplant 2010;10(3):490-497.

26. Koga N, Suzuki J, Kosuge H, Haraguchi G, Onai Y, Futamatsu H et al. Blockade of the interaction between PD-1 and PD-L1 accelerates graft arterial disease in cardiac allografts. Arteriosclerosis, thrombosis, and vascular biology 2004;24(11):2057-2062. 
27. Tao R, Wang L, Han R, Wang T, Ye Q, Honjo T et al. Differential effects of B and T lymphocyte attenuator and programmed death-1 on acceptance of partially versus fully MHC-mismatched cardiac allografts. J Immunol 2005;175(9):5774-5782.

28. Yang J, Popoola J, Khandwala S, Vadivel N, Vanguri V, Yuan X et al. Critical role of donor tissue expression of programmed death ligand- 1 in regulating cardiac allograft rejection and vasculopathy. Circulation 2008;117(5):660-669.

29. Yang J, Riella LV, Chock S, Liu T, Zhao X, Yuan X et al. The novel costimulatory programmed death ligand 1/B7.1 pathway is functional in inhibiting alloimmune responses in vivo. J Immunol 2011;187(3):1113-1119.

30. Cuff CA, Kothapalli D, Azonobi I, Chun S, Zhang Y, Belkin R et al. The adhesion receptor CD44 promotes atherosclerosis by mediating inflammatory cell recruitment and vascular cell activation. The Journal of clinical investigation 2001;108(7):1031-1040.

31. Mann DL. The emerging role of innate immunity in the heart and vascular system: for whom the cell tolls. Circulation research 2011;108(9):1133-1145.

32. Kashima Y, Takahashi M, Shiba Y, Itano N, Izawa A, Koyama J et al. Crucial role of hyaluronan in neointimal formation after vascular injury. PloS one 2013;8(3):e58760.

33. Chang MY, Chan CK, Braun KR, Green PS, O'Brien KD, Chait A et al. Monocyteto-macrophage differentiation: synthesis and secretion of a complex extracellular matrix. The Journal of biological chemistry 2012;287(17):14122-14135.

34. Shirali AC, Goldstein DR. Activation of the innate immune system by the endogenous ligand hyaluronan. Current opinion in organ transplantation 2008;13(1):2025. 
35. Tesar BM, Jiang D, Liang J, Palmer SM, Noble PW, Goldstein DR. The role of hyaluronan degradation products as innate alloimmune agonists. Am J Transplant 2006;6(11):2622-2635.

Chapter III

1. Libby, P. and Pober, J.S., “Chronic Rejection”, Immunity, Vol.14, 2001, 387-397.

2. Wehner, J., Morrell, C. N., Reynolds T., Rodriguez E. R. and Baldwin III, W. M., “Antibody and complement in transplant vasculopathy”, Circulation Research, 100, 2007, 191-203.

3. Stewart S, Winters GL, Fishbein MC, Tazelaar HD, Kobashigawa J, Abrams J, Andersen CB, Angelini A, Berry GJ, Burke MM, Demetris AJ, Hammond E, Itescu S, Marboe CC, McManus B, Reed EF, Reinsmoen NL, Rodriguez ER, Rose AG, Rose M, Suciu-Focia N, Zeevi A, Billingham ME. Revision of the 1990 working formulation for the standardization of nomenclature in the diagnosis of heart rejection. J Heart Lung Transplant. 2005;24:1710- 1720.

4. Michaels PJ, Kobashigawa J, Laks H, Azarbal A, Espejo ML, Chen L, Fishbein MC. Differential expression of RANTES chemokine, TGF-beta, and leukocyte phenotype in acute cellular rejection and quilty B lesions. J Heart Lung Transplant. 2001;20:407-416. 5. van Loosdregt J, van Oosterhout MF, Bruggink AH, van Wichen DF, van Kuik J, de Koning E, Baan CC, de Jonge N, Gmelig-Meyling FH, de Weger RA. The chemokine and chemokine receptor profile of infiltrating cells in the wall of arteries with cardiac allograft vasculopathy is indicative of a memory T-helper 1 response. Circulation. 2006;114:1599-1607. 
6. Nadel JA, Murray JF, Mason RJ. Murray and Nadel's Textbook of Respiratory Medicine, $4^{\mathrm{TH}}$ Ed. Philadelphia, Pa. : Elsevier Saunders, c2005.

7. Raisky O, Morrison KJM, Obadia JF, McGregor J, Yacoub MH, Rose ML. Acute Rejection and Cardiac Graft Vasculopathy in the Absence of Donor-Derived ICAM-1 or P-Selectin. J Heart Lung Transplant 2001;20:340-349.

8. Scholzen T, Gerdes J. The Ki-67 protein: from the known and the unknown. J Cell Physiol. 2000; 182(3):311-22.

9. Arnon TI, Cyster JG. Blood, sphingosine-1-phosphate and lymphocyte migration dynamics in the spleen. Curr Top Microbiol Immunol. 2014;378:107-28.

10. Mosser DM, Edwards JP. Exploring the full spectrum of macrophage activation. Nature reviews 2008;8(12):958-969.

11. Mills CD, Ley C. M1 and M2 Macrophages: The Chicken and the Egg of Immunity. Journal of Innate Immunity.2014;6:716-726.

12. Mehra MR, Kobashigawa JA, Deng MC, Fang KC, Klingler TM, Lal PG, Rosenberg S, Uber PA, Starling RC, Murali S, Pauly DF, Dedrick R, Walker MG, Zeevi A, Eisen HJ. Transcriptional signals of T-cell and corticosteroid-sensitive genes are associated with future acute cellular rejection in cardiac allografts. J Heart Lung Transplant. 2007;26:1255-1263.

13. Mehra MR, Kobashigawa JA, Deng MC, Fang KC, Klingler TM, Lal PG, Rosenberg S, Uber PA, Starling RC, Murali S, Pauly DF, Dedrick R, Walker MG, Zeevi A, Eisen HJ. Clinical implications and longitudinal alteration of peripheral blood transcriptional signals indicative of future cardiac allograft rejection. J Heart Lung Transplant. 2008;27:297-301. 
14. McDaniel DO, Zhou X, Moore CK, Aru G. Cardiac allograft rejection correlates with increased expressions of Toll-like receptors 2 and 4 and allograft inflammatory fac. Transplantation proceedings. 2010;42(10):4235-7.

15. Blyszczuk P, Kania G, Dieterle T, Marty RR, Valaperti A, Berthonete C. Myeloid Differentiation Factor-88/Interleukin-1 Signaling Controls Cardiac Fibrosis and Heart Failure Progression in Inflammatory Dilated Cardiomyopathy. Circ Res. 2009;105:912920

16. Hill DR, Kessler SP, Rho HK, Cowman MK and De la Motte CA. Specific-sized Hyaluronan Fragments Promote Expression of Human b-Defensin 2 in Intestinal Epithelium. J. Biol. Chem. 2012, 287:30610-30624. 


\section{APPENDIX}

In continuation with chapter II, we have additional findings on transfer of different numbers of Marilyn CD4 T-cells to female B6 SCID recipient of male B6 heart grafts. These results show that the reconstitution of B6 SCID recipients of heart transplants with CD4+ cells from Marilyn mice is dose dependent in the spleen and blood. Additionally, the acute production of chemokines (MIG, RANTES, IP-10, MCP-1 and INFG) in the graft caused by transferring CD4+ Marilyn T Cells is both dose and time dependent.

\section{Hearts transplanted from male to immunodeficient female B6 reconstituted with Marliyn CD4 T cells is dose and time dependent in both blood and spleen}

Hearts were transplanted from wild type male B6 mice into female B6 Rag1 deficient recipients (B6.RAG-/-), which lack mature $\mathrm{T}$ and $\mathrm{B}$ cells. One week later we reconstituted the recipients with $5 \times 10^{4}, 2 \times 10^{4}, 2 \times 10^{3}, 1 \times 10^{3}$ CD4 T cells from transgenic female B6 mice that express T-cell receptors for $\mathrm{H}-\mathrm{Y}$ peptides in the context of $\mathrm{H} 2-\mathrm{IAb}$ (Marilyn mice). Female B6.RAG-/- recipients were sacrificed at days 6, 7-8, 15, 16 and 4 weeks after cell transfer. The flow-cytometry results showed that reconstitution with Marilyn CD4 T cells is dose and time dependent in blood and spleen (Figure 1). 

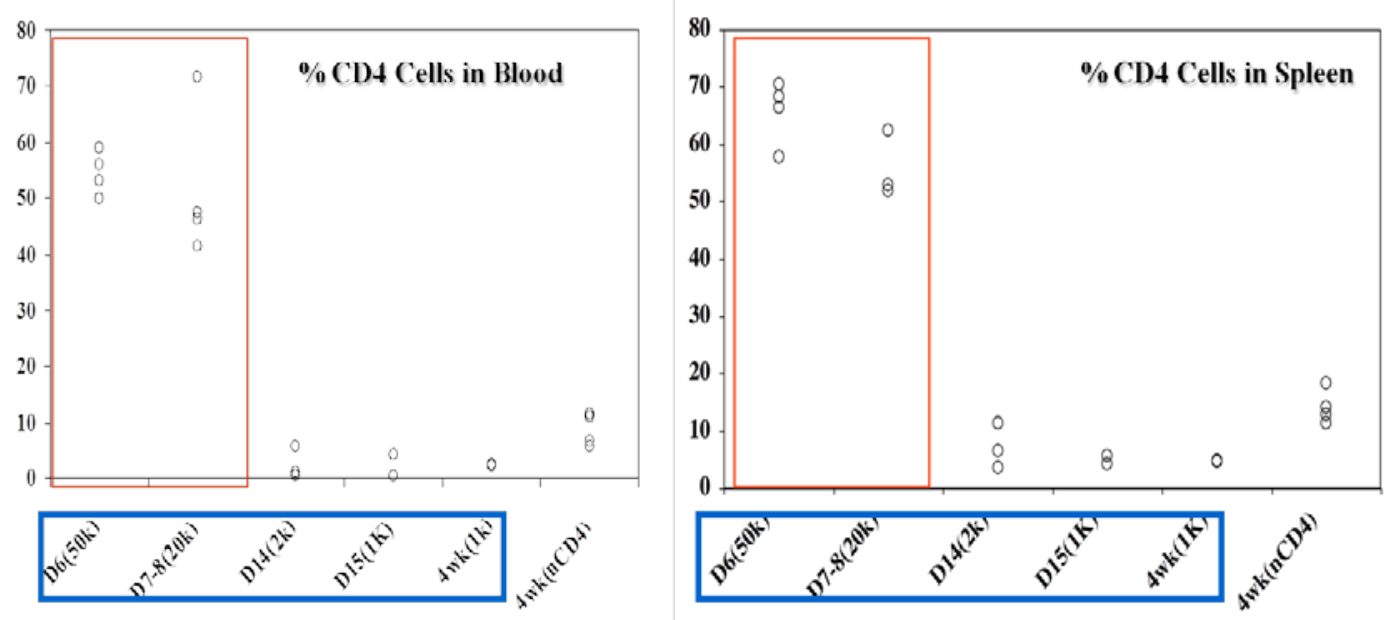

Figure 1. Flowcytometry analysis showing percentage of CD4 T-cells in blood and spleen of immunodeficient recipient at different time points.

Percentage of CD4 T cells in Blood and Spleen is definitively time dependent.

Male hearts which were transplanted into female B6 Rag1 recipient reconstituted with 2x10 4 Marilyn CD4 $\mathrm{T}$ cells and sacrificed at 1,4 and 6 weeks. The results from flowcytometry showed that percentage of CD4 T-cells decreasing with time for a constant dosage (Figure 2A-B). Even the splenic weight of these mice decreased with time. These results correlated with the histology data from cardiac allografts, (refer chapter-II), depicting intense infiltration of cells at early time point that further decreases with time. 

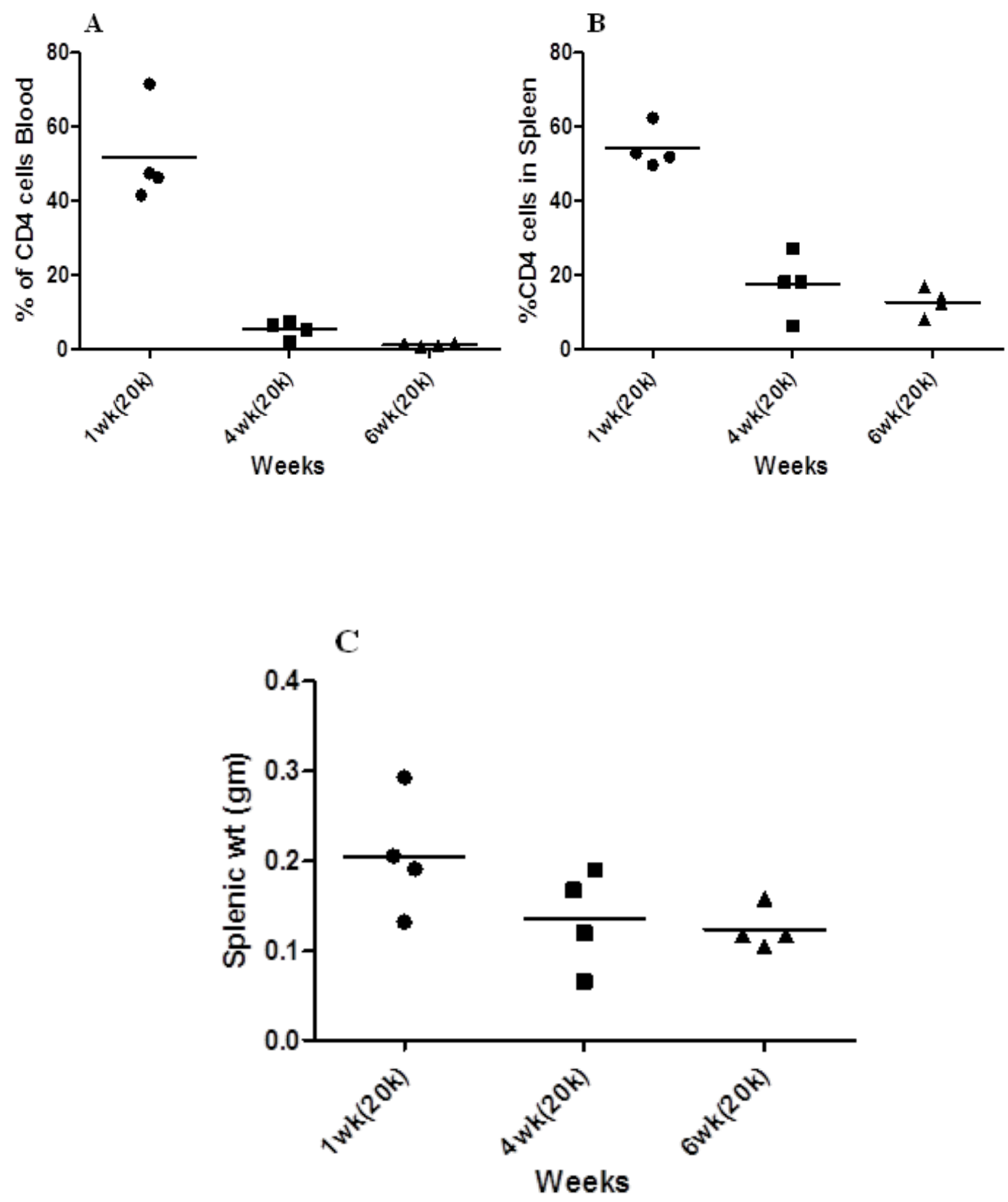

Figure 2. Flowcytometry analysis showing percentage of CD4 T cells in Blood (A) and Spleen (B). The splenic weight (C) shows the same trend with time. 
Acute production of chemokines in the graft caused by transferring CD4+ Marilyn T cells is time dependent.

Chemokine expression was quantitatively evaluated at protein level by ELISA on tissue homogenates of male hearts which were transplanted into female B6 Rag1 recipient reconstituted with $2 \times 10^{4}$ Marilyn CD4 T cells and sacrificed at 1, 4 and 6 weeks. MIG, RANTES, MCP-1, IP-10 and INFg decreased with time with constant dosage (Figure 2). These homogenates were prepared from the apex of the heart that contains myocardium but no large arteries, and therefore, sampled the interstitial compartment. However, isograft control at 1 and 6 week did not show any chemokine production.
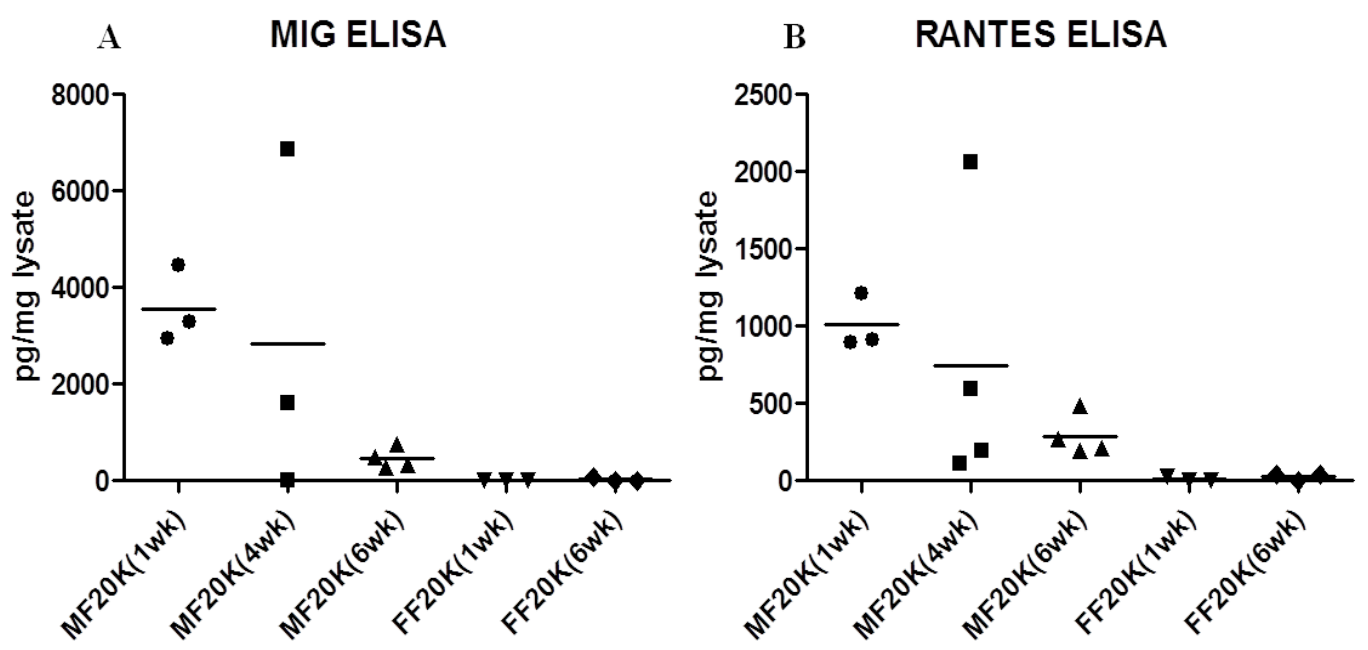

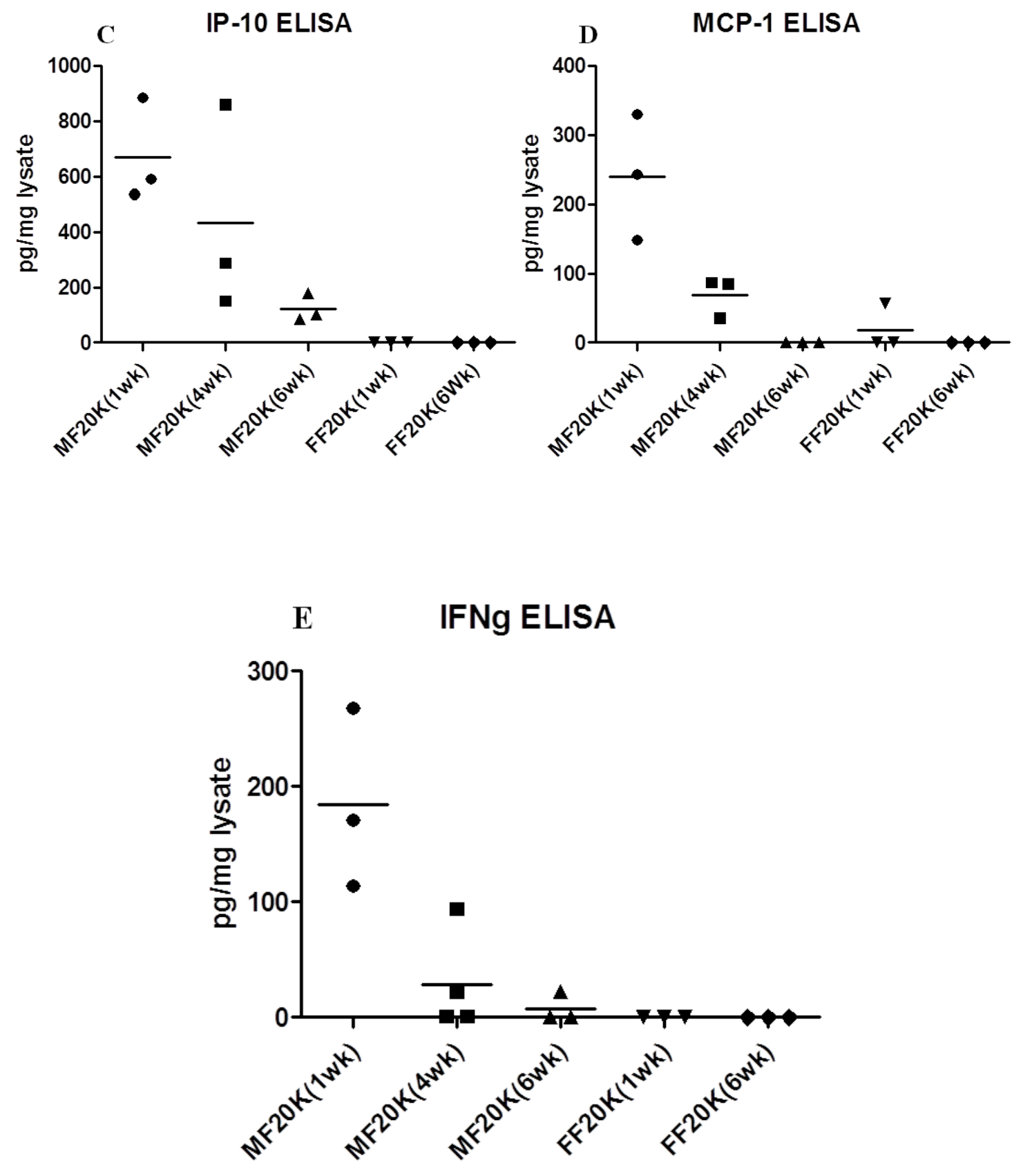

Figure 3. Chemokine MIG (A) RANTES (B) MCP-1 (C) IP-10 (D) \& IFNg (E) expression in cardiac allografts were quantified using ELISA on tissue homogenates of allografts and isografts graft at $1 \mathrm{wk}, 4 \mathrm{wk}$ and $6 \mathrm{wks}$ 